\title{
The role of acoustic and visual signals in species recognition in true lemurs (Eulemur: Primates)
}

\author{
Dissertation \\ for the award of the degree \\ "Doctor of Philosophy" (Ph.D.) \\ Division of Mathematics and Natural Sciences \\ of the Georg-August-Universität Göttingen \\ within the doctoral program Biology \\ of the Georg-August University School of Science (GAUSS) \\ submitted by \\ Miadana Hanitriniaina Markolf Rakotonirina \\ from Antsirabe, Madagascar
}

Göttingen, 2016 



\section{Thesis committee}

Prof. Dr. Peter M. Kappeler

Behavioral Ecology \& Sociobiology Unit, German Primate Center, Department of Sociobiology/Anthropology, University of Göttingen,

Prof. Dr. Eckhard W. Heymann

Behavioral Ecology \& Sociobiology Unit, German Primate Center, Göttingen

Dr. Claudia Fichtel

Behavioral Ecology \& Sociobiology Unit, German Primate Center, Göttingen

\section{Members of the Examination Board}

First Reviewer: Prof. Dr. Peter M. Kappeler

Behavioral Ecology \& Sociobiology Unit, German Primate Center,

Department of Sociobiology/Anthropology, University of Göttingen,

Second Reviewer: Prof. Dr. Eckhard W. Heymann

Behavioral Ecology \& Sociobiology Unit, German Primate Center, Göttingen

\section{Further members of the Examination Board:}

Prof. Dr. Erwin Bergmeier

Department Vegetation and Phytodiversity Analysis, University of Göttingen

PD. Dr. Matthias Waltert

Conservation Biology/Workgroup on Endangered Species, University of Göttingen

PD. Dr. Oliver Schuelke

Behavioral Ecology Johann-Friedrich-Blumenbach-Institute for Zoology \& Anthropology

Dr. Claudia Fichtel

Behavioral Ecology \& Sociobiology Unit, German Primate Center, Göttingen 



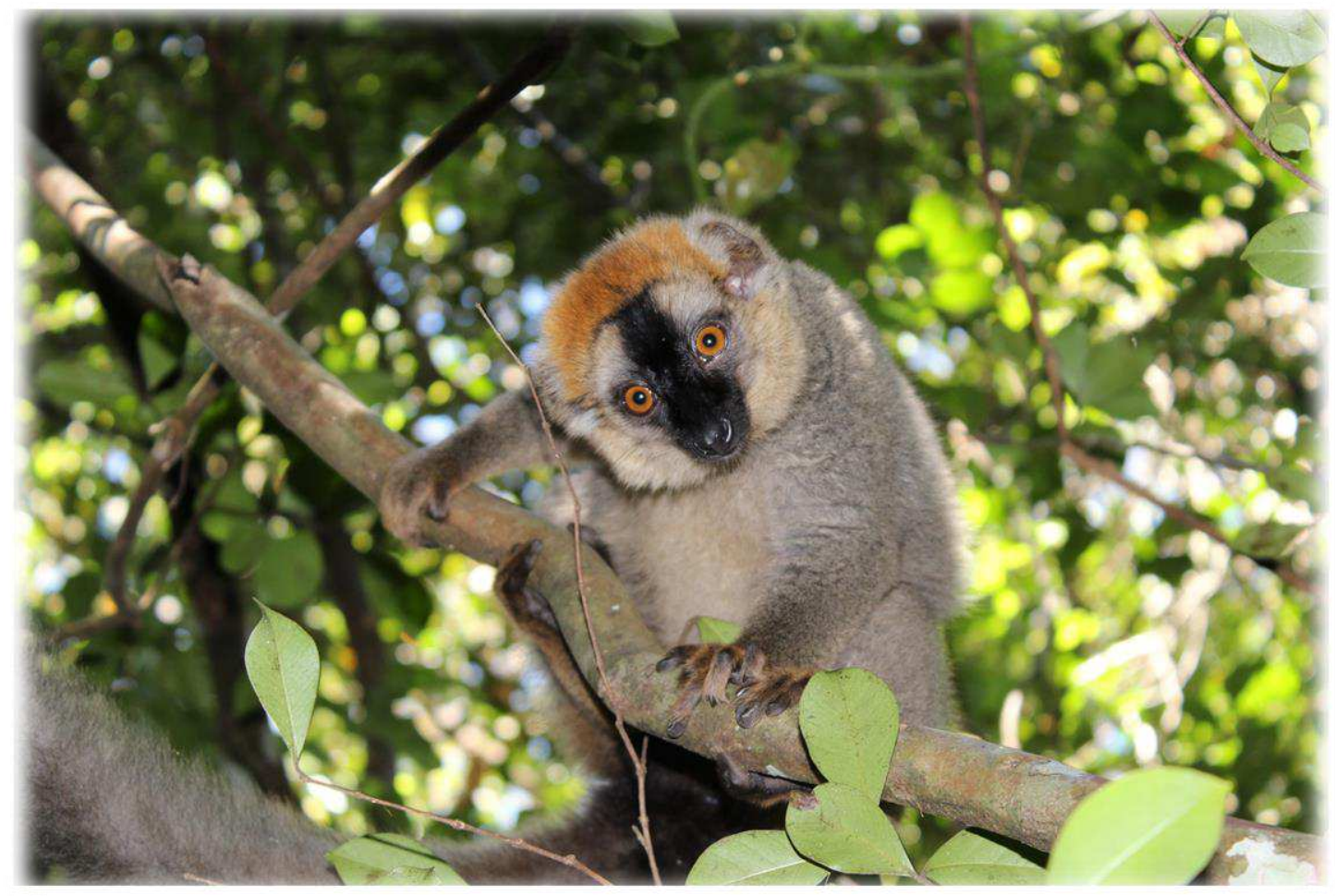

(C) Markolf Rakotonirina

\section{DEDICATION}

This thesis is dedicated to

Jean de Dieu Rakotonirina

Fleurette R. Razafimahazo

Haridera V. Rakotonirina

Matthias Markolf 



\section{CONTENTS}

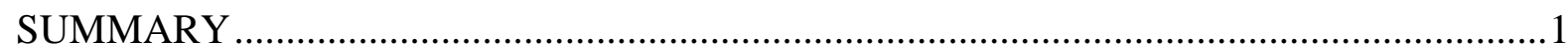

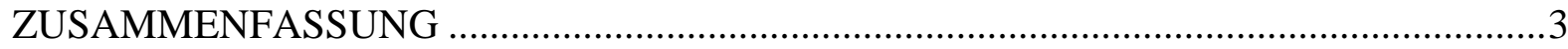

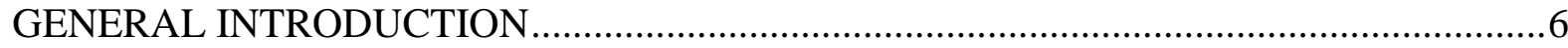

Chapter 1 - The role of acoustic signals for species recognition in redfronted lemurs (Eulemur rufifrons)

Chapter 2- The role of facial color variation for species recognition in redfronted lemurs (Eulemur rufifrons)

Chapter 3 - Evolution of facial color complexity in lemurs 65

GENERAL DISCUSSION 84

CONCLUSIONS. .96

REFERENCES 100

APPENDICES 123

ACKNOWLEDGEMENTS 138

CURRICULUM VITAE .139

DECLARATION 





\section{SUMMARY}

Signals represent important tools for animal social behavior. Numerous animal species use signals for communication as they serve as information transmitted from one individual to another. Signals also play essential roles in the evolution and the diversification of species as they can function for species recognition in several taxa. Additionally, they have evolved under several selective pressures such as natural selection through adaptation to natural habitats, sexual selection for species recognition or simply by random genetic drift. Several animal species including non-human primates use different species-specific signals to discriminate their own species from heterospecifics. Species recognition has been suggested to play an important role in order to avoid costly interbreeding, especially in female primates if they function as premating isolation mechanism. Primates can use different species-specific signals, such as olfactory, acoustic or visual signals, for species recognition. In lemurs, however, the use of speciesspecific signals for species recognition as well as the potentially selective factors influencing their evolution is largely unexplored.

The aim of this thesis was to investigate the importance of acoustic and visual signals for species recognition in true lemurs (Eulemur taxa). To this end, I focused on wild redfronted lemurs (Eulemur rufifrons), which have a disjunct distribution in Madagascar and partly occur in sympatry with congeners. Males of the genus Eulemur exhibit high facial color variation and previous studies found small but significant differences in the acoustic structure of loud calls among Eulemur species. I therefore conducted playback experiments in two very different habitats in Madagascar (Kirindy Forest in the West and Ranomafana National Park in the East) in order to identify the role of acoustic signals such as loud calls for species recognition in E. rufifrons. Additionally, experiments using photographs of faces of different Eulemur species were conducted in Kirindy forest to test the ability of E. rufifrons for visual species recognition. Eulemur species used as stimuli in both experiments were composed of Eulemur rufifrons, E. rufus, E. fulvus, E. albifrons and E. rubriventer. I also aimed to identify the relative contribution of social and ecological factors to the diversification of facial color patterns in a comparative framework for the lemurs of Madagascar. To do so, I collected and analyzed photographs of 65 lemur species and ran phylogenetic comparative analyses in order to 
investigate the influence of social or ecological factors on the evolution of facial color patterns in lemurs.

Results from playback experiments indicated that Eulemur rufifrons were not able to discriminate loud calls of their own species and closely related heterospecifics in both locations. However, animals were able to discriminate genetically distant E. rubriventer in Kirindy, but not in Ranomafana. Experiments using photographs of faces of different Eulemur species revealed that E. rufifrons were able to visually distinguish their own species from all heterospecifics. Additionally, their responses in terms of time looking towards the pictures were negatively correlated with genetic distance between the species used as stimuli. They also showed sniffing behavior that differed between each species stimulus. This again correlated negatively with genetic distance between the species stimuli. My phylogenetic comparative analyses indicated that social factors might have little or no influence on the evolution of facial color complexity in lemurs, whereas ecological factors might have marginally influenced the evolution of some facial regions. This part of my study also showed a strong effect of phylogeny on the evolution of color patterns in lemurs.

The results of my thesis indicate that acoustic signals such as loud calls might play a less important role for species recognition in eulemurs, whereas visual signals such as facial color variation might be important for species recognition in order to avoid heterospecific mating. Diversification in acoustic signals of Eulemur rufifrons might be the result of random genetic drift, whereas both sexual selection and genetic drift might have influenced the evolution of facial color patterns in lemur species.

This thesis has been the first comparative study investigating the evolution of facial color patterns in lemurs. It is also the first study conducting playback experiments and experiments using photographs in wild eulemurs to investigate their ability for species recognition using acoustic and visual signals. As there are many new questions that arose during the study concerning the evolution of signals in lemurs, my study opens several doors to explore the use and origin of signals in lemurs in more detail. 


\section{ZUSAMMENFASSUNG}

Signale gelten als wichtige Instrumente für das Sozialverhalten von Tieren und tragen dazu bei Informationen von einem Individuum auf ein anderes zu übertragen. Sie dienen daher als Kommunikationsmittel. Da Signale auch für die Arterkennung in vielen Taxa eine Rolle spielen, haben Signale ebenfalls eine herausragende Bedeutung für die Evolution und Diversifizierung von Arten. Die Evolution von Signalen kann unterschiedlichen Selektionsdrücken unterliegen. Zum Beispiel der natürlichen Selektion in Form von Anpassungen an das natürliche Habitat. Oder der geschlechtlichen Selektion im Zusammenhang mit der Arterkennung und der Fortpflanzung. Letztlich kann die Evolution von Signalen aber auch einfach nur zufällig durch genetische Drift beeinflusst worden sein. Viele Tierarten, darunter auch viele nichtmenschliche Primaten, benutzen artspezifische Signale um Artgenossen von Individuen einer anderen Spezies zu unterscheiden. Arterkennung wird daher als wichtiger präkopulatorischer Isolationsmechanismus angesehen, um die Kosten heterospezifischer Fortpflanzung für weibliche Primaten zu vermeiden. Primaten nutzen verschiedene artspezifische Signale für diesen Arterkennungsprozess, darunter olfaktorische, akustische oder auch visuelle Signale. Die Bedeutung, die die artspezifischen Signale für die Arterkennung bei Lemuren spielen, ist bisher wenig erforscht - genauso wie die Selektionsfaktoren, die zur Evolution solcher Signale beigetragen haben.

Das Ziel dieser Arbeit war es die Bedeutung akustischer und visueller Signale für die Arterkennung in der Gattung Eulemur zu untersuchen. Zu diesem Zweck wählte ich als Studienobjekt freilebende Rotstirnmakis (Eulemur rufifrons). Rotstirnmakis haben zwei separate Verbreitungsgebiete und leben daher teilweise sympatrisch mit einer Art der gleichen Gattung. Die Männchen der Gattung Eulemur zeigen große Variation in der Gesichtsfärbung und frühere Studien fanden ebenfalls signifikante Unterschiede in der Struktur von Lauten (loud calls) zwischen Arten dieser Gattung. Aufgrund dieser Informationen führte ich Playback-Experimente in zwei unterschiedlichen Habitaten (Kirindy-Wald im Westen und Ranamafana im Osten) durch, um die Bedeutung von akustischen Signalen (loud calls) für die Arterkennung bei Rotstirnmakis zu untersuchen. Zusätzlich führte ich Experimente mit Fotografien von Gesichtern verschiedener Eulemurarten im Kirindy-Wald durch, um die potentielle Fähigkeit für visuelle 
Arterkennung in Rotstirnmakis zu testen. Die Stimuli in beiden Experimenten waren die Arten Eulemur rufifrons, E. rufus, E. fulvus, E. albifrons und E. rubriventer. Ein weiteres Ziel meiner Arbeit war es herauszufinden, welche sozialen und ökologischen Variablen zur Diversität der Gesichtsfarbenmuster bei Lemuren beigetragen haben könnten. Für diese vergleichende Studie analysierte ich Fotografien von 65 Lemurenarten und untersuchte mit Hilfe von phylogenetisch kontrollierten Modellen, die relative Bedeutung sozialer und ökologischer Faktoren für die Evolution von Gesichtsfarbenmustern in Lemuren.

Die Resultate der Playback-Experimente zeigten, dass Rotstirnmakis, weder im Westen noch im Osten zwischen arteigenen Lauten und Lauten nahverwandter Arten diskriminieren können. In Kirindy konnten die Rotstirnmakis die Laute des etwas entfernter verwandten Rotbauchmakis (E. rubriventer) von ihren eigenen unterscheiden, jedoch nicht in Ranomafana, wo sie sympatrisch mit diesen vorkommen. Die Experimente mit Fotografien von Gesichtern verschiedener Eulemurarten zeigten, dass Rotstirnmakis ihre eigene Art visuell von anderen Arten der Gattung unterscheiden können. Darüber hinaus korrelierte die Betrachtungszeit der Bilder negativ mit der genetischen Distanz zwischen Rotstirnmakis und den Stimuli. Ebenfalls schnüffelten die Tiere unterschiedlich lang in Richtung verschiedener arteigener und artfremder Stimuli und die Intensität des Schnüffelverhaltens war wiederum negativ korreliert mit der genetischen Distanz zischen Rotstirnmaki und den Stimuli. Die vergleichenden phylogenetischen Analysen zeigten, dass soziale Faktoren wenig oder keinen Einfluss auf die Evolution von Gesichtsfarbenmustern genommen haben, und dass ökologische Faktoren nur manche Gesichtsregionen marginal beeinflusst haben. Die Ergebnisse sprechen für einen starken Einfluss der Phylogenie auf die Evolution der Gesichtsfarbenmuster bei Lemuren.

Die Ergebnisse meiner Doktorarbeit deuten darauf hin, dass akustische Laute, wie die hier verwendeten „loud calls“, keine große Rolle für die Arterkennung spielen. Visuelle Signale in Form von Farbvariationen in Gesichtern könnten dagegen eine wichtige Rolle für die Arterkennung spielen und potentiell auch für die Vermeidung heterospezifischer Fortpflanzung in der Gattung Eulemur wichtig sein. Die Unterschiede zwischen den akustischen Signalen in Eulemuren scheint das Resultat genetischer Drift $\mathrm{zu}$ sein, wohingegen die Evolution von Gesichtsfarbenmustern in Lemuren, 
wahrscheinlich sowohl durch sexuelle Selektion als auch durch genetische Drift beeinflusst worden ist. 


\section{GENERAL INTRODUCTION}

\section{Signals and the evolution of signals}

\section{Signals}

Signals represent important tools for social behavior (Endler 1993). In order to communicate, numerous animal species use signals as they serve as information transmitted from one individual to another (Bradbury \& Vehrencamp 1998). Signals are defined as trait or behavior produced by one individual (signaler), used as message or information, which can be transmitted from one individual (signaler) to another (receiver) (Endler 1993, Hauser 1996, Laidre \& Johnstone 2013). Such information is perceived in different ways (seen, heard, smelled ...) by the individual receiver and can alter its behavior as well (Rendall et al. 2009). Types of signals for communication are manifold ranging from the emittance of sounds, the production and placement of olfactory cues or the display of specific fur or skin colorations, which are often associated with specific behaviors, such as mating displays, warning or camouflage (Laidre \& Johnstone 2013). Alarm calls, for example, can function as signals for detected predators in several birds and mammals (Sherman 1977, Seyfarth et al. 1980, Evans et al. 1993, Manser et al. 2001, Fichtel \& Kappeler 2002). Feather colors and songs of birds can be used as sexual signals for mate choice (Moller \& Pomiankowski 1993, Cardoso et al. 2012) and scents can also signal the presence of other conspecifics and heterospecifics in many species of primates (Ueno 1994, Harrington 1979). Hence, these examples show that different types of signals, such as calls, scents, or the coloration of fur, skin or feathers provide different functions for intra- and/or interspecific communication.

Signals are not only important for communication, but they also play important roles in the evolution and diversification of species (Ryan \& Rand 1993, Grant \& Grant 2006, Robillard et al. 2006, Boul et al. 2007) as species-specific signals can also function for species recognition in several taxa. Several studies have shown the use of 
species-specific signals for species recognition. For example in bats, the use of olfactory signals has been demonstrated by Caspers et al. (2009), where females of Saccopteryx bilineata were shown to be able to recognize and even prefer wing sac scents of male conspecifics over those of male from a sister species (S. leptura). Olfactory and visual signals have also been shown to be used by fish for species recognition (McLennan \& Ryan 1997, Seehausen et al. 2008). McLennan and Ryan (1997) found in their study that female swordtails (Xiphophorus cortezi) differentiated olfactory cues of males of their own species from those of heterospecifics (X. nigrensis and X. montezumae) and showed a stronger response to conspecific males. Seehausen et al. (2008) demonstrated that two species of cichlid fish (Pundamilia pundamilia and $P$. nyererei) use coloration to differentiate male conspecifics from male heterospecifics. Similarly in birds, Alatalo et al. (1994) demonstrated that male coloration plays an important role for species recognition in sympatric flycatchers (Ficedula hypoleuca and F. albicollis). Numerous studies have also shown that acoustic signals are used for species recognition in frogs, birds and mammals. For instance, green tree frogs (Hyla cinerea) were shown to be able to discriminate between conspecific and heterospecific calls (H. gratiosa), and their preference for conspecifics was even greater when both species occur in sympatry (Höbel \& Gerhardt 2003). Moreover, Brenowitz (1983) demonstrated in playback experiments that songs of red-winged blackbirds (Agelaius phoeniceus) are used for species recognition as these birds show stronger response to their own songs than to songs of heterospecific mockingbirds (Mimus polyglottos). Similarly, in species of migrating shearwaters sharing the same breeding area (Puffinus mauretanicus, $P$. yelkouan, Calonectris $d$. diomedea), same-time breeders can acoustically discriminate conspecifics from heterospecifics (Curé et al. 2012). Finally, playback experiments conducted in Lar gibbons (Hylobates lar) showed as well that these animals were able to distinguish their own loud calls, which are mainly used for territoriality, from those of capped gibbons (H. pileatus) (Raemaekers \& Raemaekers 1985). Hence, speciesspecific signals are essential for numerous animal species to differentiate conspecifics from heterospecifics, and animals can rely on several traits such as acoustic, olfactory or visual signals for species recognition.

\section{The evolution of signals}

Given the significance and variable utilization of signals in the animal kingdom as 
described above it seems interesting to ask which evolutionary selective pressures are responsible for the properties of species-specific signals and their evolution. In general, three hypotheses have been postulated to explain species differences in salient signals.

\section{Natural selection}

Species-specific signals can be the result of natural selection through adaptations to local habitat conditions ('acoustic adaptation hypothesis': Morton 1975; Forrest 1994; Brown et al. 1995; Padgham 2004). These can be expressed by background acoustic or visual noise masks (Brumm et al. 2004; Francis et al. 2011; Potvin et al. 2011) and displays (Ord et al. 2007). For example, frogs living close to noisy streams produce calls in ultra-sound range above the frequency range of running water (Feng et al. 2006). According to the acoustic habitat hypothesis, longer calls with lower frequencies and short, rapidly repeated elements are favored in more open habitats, and shorter calls with higher frequencies and slower modulated elements in denser vegetation structure (Wiley \& Richards 1978; Brown et al. 1995). In lizards, obstructions in the environment can have an impact on the evolution of visual signals where the complexity of signals is influenced by ecological forces such as home range size (via pressure of degradation), arboreality (for a better vision) and diet of mobile prey (via defense of resource), whereas signal diversity is correlated with closed habitats (Ord et al. 2002). Finally, Caro (2005) suggested that white face markings in ungulates might have been the result of living in open habitats. Thus, environmental conditions can influence the evolution of signals and their diversity.

\section{Genetic drift}

Signal diversification may also occur "passively" by cultural or genetic drift (e.g. birds: Irwin et al. 2008; Benedict \& Bowei 2009; mammals: Campbell et al. 2010; Wich et al. 2012), whereby stochastic processes generate species-specific signals in the absence of selection (Grant \& Grant 2009). For example, song divergence in greenish warblers (Phylloscopus trochiloides) or Neotropical singing mice (Scotynomis teguina, S. xerampelinus) is correlated with both geographic and genetic distance, suggesting that divergence was most likely due to genetic drift (Irwin et al. 2008; Campbell et al. 
2010). Moreover, song diversity of crested gibbons (Nomascus nasutus, N. concolor, $N$. leucogenys, N. siki, N. annamensis and N. gabriellae) is correlated also with geographic distance and genetic relatedness (Thinh et al. 2011). Finally, in langurs (genus Presbytis), it was as well shown that the structure of loud calls is correlated with genetic distance and also with geographic distance (Meyer et al. 2012). Thus, if signal evolution is due to stochastic processes, signal variability will tend to track phylogeny, with closely related species exhibiting more similar signals than those of distantly related species (Irwin et al. 2008).

\section{Sexual selection}

Heterospecific mating (or copulation between members of two different species) among closely related species can produce viable, but rarely fertile offspring (e.g. toads: Pfennig 2007). Although heterospecific mating does sometimes occur and can even produce new, independently evolving lineages (Arnold \& Meyer 2006, Zinner et al. 2009, Mallet 2007, Salazar et al. 2010), interbreeding often leads to developmental disorders or abortion (Keller \& Waller 2002, Coyne \& Orr 2004). As females typically invest more in reproduction and offspring than males (Williams 1966; Trivers 1972; Clutton-Brock \& Parker 1992), the costs of interspecific breeding are necessarily bigger for females, and mechanisms to prevent hybridization should be more pronounced in females (Pfennig 2007; Kappeler 2012). These mechanisms can be grouped into postand pre-zygotic isolation mechanisms. Post-zygotic isolation mechanisms resulting in a lack of hybrid viability and/or hybrid sterility act on the cellular or molecular level (Coyne \& Orr 2004). However, pre-zygotic isolation mechanisms should be more prevalent because they avoid the waste of gametes and reduce the costs of mating and early reproductive investment (Martin \& Hosken 2003). Its mechanisms include physical compatibility of the reproductive organs (Anderson 2000, Torrentera \& Belk 2002) and, more importantly, active mate choice (Reynolds \& Gross 1990, Jennions \& Petrie 1997). For sympatric species there might be strong selection for pre-zygotic isolation because reinforcement can enhance natural selection against unfit hybrids and costly interspecific mating in divergent populations (Bultin 1995, Lukhtanov et al. 2005). Therefore, female mate choice, as one of the main drivers of pre-zygotic isolation, can be considered as an important evolutionary selective mechanism to avoid 
hybridization (Byers \& Waits 2006).

Pre-copulatory mate choice, however, requires that individuals are able to recognize, distinguish and prefer members of their own species from heterospecifics (Ryan \& Rand 1993). Species recognition should therefore be one of the most relevant mechanisms used by numerous animal species to avoid costly interbreeding. Thus, species-specific signals may represent the result of sexual selection (Gray \& Cade 2000) if they function as a premating isolation mechanism, requiring the ability for species recognition (Mayr 1996, Nevo et al. 1987, Kraaijeveld et al. 2011, Höbel \& Gerhardt 2003, Coyne 1992). In this context it is important to demonstrate that females of a species do not only discriminate between conspecific and heterospecific signals, but also to demonstrate a preference for conspecific (or avoidance of heterospecific) signals in the actual context of reproduction or mating (Snowdon 2004). For example, in some species of sticklebacks (Gasterosteus spp.) and fish (Pseudotropheus emmiltos), females were shown to prefer scents of males of their own species over those from heterospecific males, suggesting that olfactory signals function as a premating isolation barrier (Plenderleith et al. 2005, Rafferty \& Boughman 2006). Similarly, females of some butterfly species (Pieris occidentalis, P. protodice) and cichlid fish (Pundamilia pundamilia, $P$. nyereeri) were shown to prefer male conspecific coloration over heterospecific males with different coloration (Wiernasz \& Kingsolver 1992; Maan et al. 2004; Seehausen et al. 2008). Female frogs (Hyla ebracatta) also showed preference for their conspecific male advertisement calls over heterospecific male ones $(H$. microcephala and H. phlebodes) (Backwell \& Jennions 1993). Thus, in species in which olfactory, visual and acoustic signals play an important role in the context of reproduction, signal divergence is most likely driven by sexual selection.

\section{Signals and species recognition in animals and primates}

Based on the ability to distinguish signals from its own and another species, species recognition has been shown to be essential in numerous animal species. As mentioned above, many studies have investigated species recognition in different animal taxa. For instance, birds are able to recognize acoustically their conspecifics from heterospecifics (Brenowitz 1983, Curé et al. 2012). The same applies to frogs 
using acoustic signals as well (Ryan \& Rand 1993, Boul et al. 2007). Fish and butterflies can use visual signals to differentiate conspecifics from heterospecifics (Wiernasz \& Kingsolver 1992; Maan et al. 2004), and bats can use olfactory signals for species recognition (Caspers et al. 2009). Because the ability to discriminate heterospecifics to avoid costly interbreeding appears to be widespread among animals (Seehausen et al. 2008, Caspers et al. 2009, Braune et al. 2008), experimental studies in which the animals themselves are "asked" which taxa they can discriminate and recognize as conspecifics should therefore provide constructive contributions to this topic.

In primates, the mechanisms underlying signal divergence and the use of signals to recognize species remains largely unexplored. Diversification in olfactory signals in primates due to sexual selection has been suggested in some lemurs (Lemur catta: Kappeler 1998; Charpentier et al. 2008; 2010; Eulemur spp.: delBarco-Trillo et al. 2012); and species recognition based on olfactory cues has been demonstrated in true lemurs (Eulemur fulvus, Harrington 1979), bushbabies (Otolemur spp.: Clark 1988) and capuchin monkeys (Cebus apella: Ueno 1994). Diversification in visual signals, such as pelage color or facial color patterns, has also been suggested to function in species recognition among primates. In New World and Old World monkeys, which exhibit great diversity in facial color patterns, species living in sympatry with a higher number of congener species evolved more complex facial color patterns, suggesting that facial color variation has been selected for species recognition (Santana et al. 2012, 2013). The evolution of facial pigmentation and hair length, however, is linked to ecological factors (Santana et al. 2012, 2013) and influenced by natural selection. The importance of facial cues in species recognition has been shown in macaques (Macaca ssp.); they were shown to be able to recognize and even exhibit a preference for pictures of their own species when given the opportunity to press a lever to watch pictures of different species (Fujita 1987; Fujita et al. 1997). Similar studies with macaques and chimpanzees raised under different captive conditions revealed the importance of early social experience in forming such preferences, i.e. they are unlikely to be innate (Tanaka 2007). In contrast, predominantly innate acoustic signals such as loud calls have been suggested to serve as species-specific signals in several species such as in lion tamarins (Leontopithecus ssp.: Snowdon et al. 1986), gibbons (Nomascus: Konrad 
\& Geissmann 2006) and lemurs (Macedonia \& Stanger 1994). Call divergence in three species of mouse lemurs has been suggested to be due to habitat adaptations (Braune et al. 2008), whereas call divergence in gibbons might be due to stochastic processes because they closely track phylogeny (Thinh et al. 2011). Thus, the mechanisms underlying call divergence in primates remain rarely explored. In addition, the necessary playback experiments demonstrating that primates actually discriminate heterospecific calls have only rarely been conducted (tarsiers, Tarsius spp.: Nietsch \& Kopp 1998; macaques: Muroyama \& Thierry 1998; gibbons, Hylobates spp.: Raemaekers \& Raemaekers 1985; Mitani 1987, mouse lemurs, Microcebus ssp.: Braune et al. 2008). Thus, primates evolved species-specific signals in at least three modalities, and some studies demonstrated that these signals play an important role in species recognition. 


\section{The suitability of lemurs and redfronted lemurs (Eulemur rufifrons) to study signal diversification and the role of acoustic and visual signals for species recognition}

Madagascar, as one of the hottest global biodiversity hotspots (Myers et al. 2000) is famous for its endemic primate infraorder, the Lemuriformes, which represent one of the best-known examples of Malagasy endemism and biodiversity. Lemurs today represent more than $20 \%$ of all living primate species and more than $25 \%$ of primate families (Mittermeier et al. 2010).

The diversity of lemur species has nearly tripled since 1982 (36 from Tattersall (1982) to 101 in Mittermeier et al. (2010)). Such recent changes in taxonomy were criticized repeatedly as "taxonomic inflation" by several authors (Tattersall 2007, Markolf et al. 2013), because of a change in the application of species concepts and the use of solely few genetic data. It is known that the units of fundamental interest in all biological disciplines are species (de Queiroz 2005, Sites \& Marshall 2004, Wiens \& Penkrot 2002, Wiens \& Servedio 2000) and that they also serve as currency for biodiversity classification of geographic regions and are therefore used to define regions of conservation priority, so-called biological hotspots (Agapow et al. 2004, Balakrishan 2005). Apart from genetic and morphological data taxonomists also use animal signals frequently to delimit the fundamental biological category, the species. Examples are numerous and range from the use of acoustic data to the molecular composition of scents or the external morphology such as differences in skin or coat coloration of taxonomic groups (e.g. see Thinh et al. 2011, Markolf et al. 2013, delBarco-Trillo et al. 2012). However, the significance of divergent signals for the animals themselves in relation to reproductive isolation and species recognition has rarely been tested (but see Braune et al. 2008, Marechal et al. 2010, Cooper \& Hosey 2003). If differences in acoustic or visual signals between putative species have any significance for the animals themselves in the process of species recognition is analyzed in Chapter $\mathbf{1}$ and $\mathbf{2}$ of this dissertation. By asking the lemurs themselves to differentiate between species, this study provides empirical evidence for the biological significance of currently recognized Eulemur species. 
The genus Eulemur is particularly suited for such studies because it consists of 12 species (Eulemur albifrons, E. cinereiceps, E. collaris, E. coronatus, E. flavifrons, E. fulvus, E. macaco, E. mongoz, E. rubriventer, E. rufifrons, E. rufus and E. sanfordi; Figure 1, Groves 2001), which occupy very different habitats, including rainy, dry and spiny forests, across Madagascar (Mittermeier et al. 2010). Seven of these species ( $E$. albifrons, E. cinereiceps, E. collaris, E. fulvus, E. rufifrons, E. rufus and E. sanfordi) were formerly subspecies of E. fulvus (“E. fulvus group” (Figure 1, Johnson 2007)), then elevated to full species by Groves in 2001 and are now classified as distinct species based also on the analyses of signals such as loud calls and color variation (Markolf et al. 2013). In addition, some, but not all species occur in sympatry with a congener and occupy different habitats at the same time, such as redfronted lemurs (Eulemur rufifrons, Mittermeier et al. 2010). Eulemurs are cat-sized, live in groups of up to 15 individuals except E. mongoz and E. rubriventer, which are pair-living (Kappeler 1997, 1998, Kappeler \& Fichtel 2015). Eulemurs are characterized by sexual dichromatism, present a large variation in facial color patterns across species and this variation is specifically pronounced in the faces of males (Mittermeier et al. 2010). However, it is unclear whether the evolution of this facial variation in eulemurs is used as signal for species recognition and which evolutionary selective pressures triggered signal divergence. Previous studies suggested that some Eulemur species kept in captivity are able to differentiate familiar and unfamiliar individuals visually using facial coloration and might have the ability for species recognition (Marechal et al. 2010). It has also been shown that females of Eulemur species showed clear preference for colorful males when they were presented to photographs of males of their own species that were digitally modified to be more or less colorful (Cooper \& Hosey 2003). Hence, as these previous studies already showed the ability of eulemurs for visual recognition, more investigation is needed in order to investigate whether eulemurs also have the ability for species recognition based on visual signals in their natural habitats.

In addition, all Eulemur species regularly produce loud calls for intra- and intergroup communication (Pereira \& Kappeler 1997). Acoustic variation in loud calls of seven Eulemur species (Eulemur albifrons, E. cinereiceps, E. collaris, E. fulvus, E. rufifrons, E. rufus and E. sanfordi) was already investigated in previous studies (Markolf et al. 2013). Since these species are closely related, acoustic signals might 
have been important for species recognition to avoid costly hybridization. Previous acoustic analyses revealed that the calls of some species were more similar in their acoustic structure than others (Markolf et al. 2013). However, it is completely unclear whether these differences are significant for the animals themselves in terms of species recognition and which evolutionary selective pressures drove acoustic signal divergence.

Lemur diversity is also reflected by an immense variation in pelage coloration (Mittermeier et al. 2010). Variation in fur coloration may account for numerous functions such as individual, mate or species signaling and thermoregulation (Caro 2005). Facial areas in lemurs are especially highly diverse in color and form across species and genera (Mittermeier et al. 2010). Despite this diversity in facial color patterns, so far no study has been investigating evolutionary drivers and functions of facial color pattern in the lemurs of Madagascar. Investigating the main drivers of this remarkably high facial diversity in lemurs is in particular interesting as lemurs occupy different habitats and ecological niches and show all forms of social organizations (solitary, pair-living and group living) and activity patterns (nocturnal, cathemeral and diurnal) (Kappeler 1997, Kappeler 2012, Mittermeier et al. 2010, Kappeler \& Fichtel 2015). Moreover, lemurs can occur in sympatry or allopatry on the generic or family level (Mittermeier et al. 2010). Several selective pressures can therefore be at the origin of the high variation of facial color patterns in lemurs. Chapter 3 of this dissertation is investigating potential factors that might have influenced the evolution of facial color complexity in this radiation of primates. 
Against this background, the following specific questions will be addressed in this dissertation:

\section{Chapter 1}

Are redfronted lemurs (Eulemur rufifrons) able to recognize their own species from different Eulemur species using acoustic signals?

\section{Chapter 2}

Can redfronted lemurs (Eulemur rufifrons) visually recognize their conspecifics from heterospecifics?

\section{Chapter 3}

Which factors have driven the evolution of facial color patterns in lemurs? 


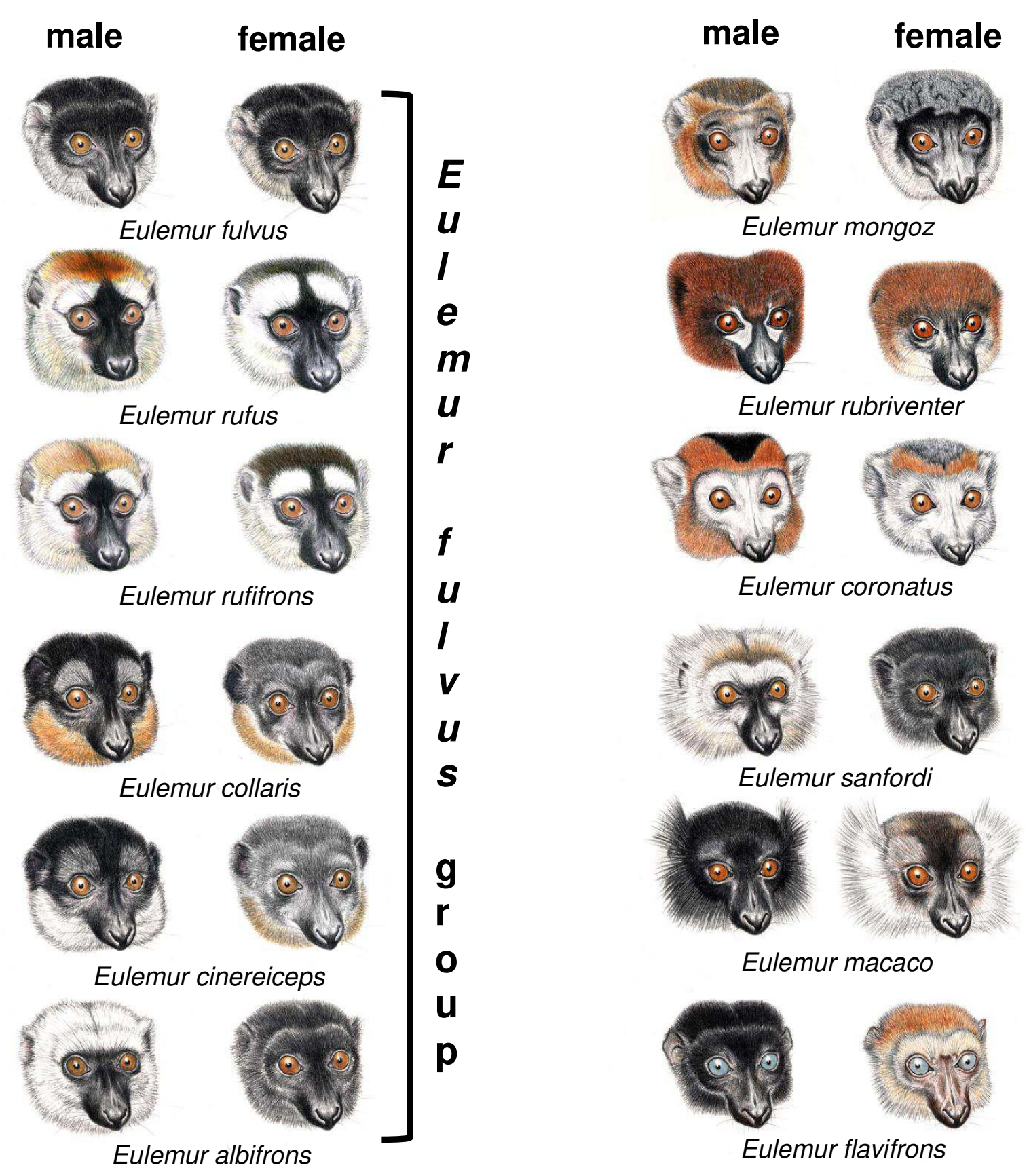

Figure 1. Photographs all Eulemur species showing sexual dichromatism (illustrations: S. Nash). 


\section{CHAPTER 1}

\section{The role of acoustic signals for species recognition in redfronted lemurs (Eulemur rufifrons)}

with Peter M Kappeler and Claudia Fichtel

BMC Evolutionary Biology, 2016, 16:100 


\section{Abstract}

Background: Signals are essential for communication and play a fundamental role in the evolution and diversification of species. Olfactory, visual and acoustic species-specific signals have been shown to function for species recognition in non-human primates, but the relative contributions of selection for species recognition driven by sexual selection, natural selection, or genetic drift for the diversification of these signals remain largely unexplored. This study investigates the importance of acoustic signals for species recognition in redfronted lemurs (Eulemur rufifrons). We conducted playback experiments in both major populations of this species separated by several hundred kilometers: Kirindy Forest in the west and Ranomafana National Park in the east of Madagascar. The playback stimuli were composed of species-specific loud calls of $E$. rufifrons, three closely related species (E. albifrons, E. fulvus and E. rufus) and one genetically more distant species (E. rubriventer) that occurs in sympatry with eastern redfronted lemurs. We tested the ability of redfronted lemurs to discriminate conspecific from heterospecific loud calls by measuring the time spent looking towards the speaker after presentation of each loud call. We also tested the difference between female and male responses because loud calls may play a role in mate choice and the avoidance of heterospecific mating.

Results: Redfronted lemurs in Kirindy Forest did not discriminate their own loud calls from those of E. albifrons, E. fulvus and E. rufus, but they discriminated loud calls of $E$. rubriventer from their own. The Ranomafana population was tested only with three playback stimuli (E. rufifrons, E. albifrons, E. rubriventer) and did not discriminate between their own loud calls and those of E. albifrons and E. rubriventer. The response of females and males to playbacks did not differ in both populations. However, subjects in Ranomafana National Park responded more strongly to playback stimuli from $E$. rubriventer than subjects in Kirindy Forest.

Conclusions: We conclude that in both populations individuals were not able to discriminate between loud calls of closely related species living in allopatry and that responses to more distantly related congeners are likely to be modulated by experience. Subjects in Ranomafana paid more attention to loud calls of syntopic E. rubriventer in 
comparison to the Kirindy subjects, suggesting that experience is important in facilitating discrimination. Because acoustic and genetic distances among eulemurs are correlated, diversification in their acoustic signals might be the result of genetic drift.

Keywords: Eulemur rufifrons, species recognition, acoustic signals, mate choice, genetic drift. 


\section{Background}

Signals are not only essential for conspecific communication, but also play an important role in the evolution and diversification of species (Ryan \& Rand 1993, Grant \& Grant 2006, Robillard et al. 2006). Species-specific signals may evolve in response to different evolutionary pressures. First, such signals may represent the result of sexual selection if they function as a premating isolation mechanism (Gray \& Cade 2000), requiring the ability for species recognition in heterospecific receivers (Coyne 1992, Höbel \& Gerhardt 2003, Kraaijeveld et al. 2011, Mayr 1996, Nevo et al. 1987). Based on the ability of an individual to discriminate between signals from its own and other species, species recognition is used in many different taxa to avoid costly interbreeding. This ability has been demonstrated in several taxa, such as bats using olfactory signals (Caspers et al. 2009), fish using olfactory or visual signals (McLennan \& Ryan 1997, Seehausen et al. 2008) and frogs, birds and mammals using acoustic signals (Höbel \& Gerhardt 2003, Boul et al. 2007, Curé et al. 2012, Raemaekers \& Raemaekers 1985).

Second, species-specific signals can also be the result of natural selection through adaptations to local habitat conditions. For example, frogs (Amolops tormotus) living close to noisy streams shifted the frequency of their calls in the ultra-sound range to avoid masking of background noise of the stream (Feng et al. 2006). In little greenbul (Andropadus virens) occurring in two different forest types (rainforest or ecotone forest), habitat-dependent selection has also been suggested to cause divergence of acoustic traits because songs of rainforest populations differ in spectral and temporal characteristics compared to those in the ecotone forest (Slabbekoorn \& Smith 2002). Finally, signal diversification may also be driven by cultural or genetic drift, where stochastic processes generate species-specific signals in the absence of selection (Grant \& Grant 2009). For example, in greenish warblers (Phylloscopus trochiloides) and Neotropical singing mice (Scotinomys teguina, S. xerampelinus), diversification in songs was shown to be correlated with both geographic distance and genetic divergence, suggesting that differentiation in this signal were largely shaped by genetic drift (Campbell et al. 2010, Irwin et al. 2008). Although the ability to use signals for species recognition is widespread, the relative contributions of selection for species recognition driven by 
sexual selection, natural selection, or genetic drift for the diversification of species signals remain poorly understood.

Primates are an interesting taxon for studies of species recognition because they often occur in sympatry with other species, they inhabit a range of tropical habitats, and they exhibit social communication, relying on olfactory, visual and acoustic signals. Sexual selection has been suggested to have driven diversification of primate olfactory signals (Kappeler 1998, delBarco-Trillo et al. 2012), and species recognition based on olfactory cues has been demonstrated in true lemurs (Eulemur sp. Harrington 1979), bushbabies (Galago sp.: Clark 1988) and capuchin monkeys (Cebus sp.: Ueno 1994). Interspecific variation in visual signals has also been suggested to function in species recognition among primates (Fujita 1987, Fujita et al. 1997, Marechal et al. 2010). For example, in both New World monkeys (platyrrhines) and Old World monkeys (catarrhines), facial color complexity is positively related to the number of sympatric congeners (Santana et al. 2012, 2013). However, the evolution of facial pigmentation and hair length in platyrrhines was linked to ecological factors since these traits are strongly related to the geographical distribution of species (Santana et al. 2012).

Acoustic signals have also been suggested to represent a useful tool for species delimitation in several primate species, including lion tamarins (Leontopithecus rosalia, L. chrysopygus and L. chrysomelas: Snowdon et al. 1986), crested gibbons (Nomascus gabriellae and N. leucogenys siki (Konrad \& Geissmann 2006) and lemurs (Lemuridae: Macedonia \& Stanger 1994). Even in closely related species, such as gibbons (Nomascus nasutus, $N$. concolor, $N$. leucogenys, $N$. siki, $N$. annamensis and $N$. gabriellae: Thinh et al. 2011), langurs (Presbytis thomasi, P. potenziani siberu, P. comata comata and all four subspecies of P. melalophos (P. m. melalophos, P. m. mitrata, P. m. bicolor and P. m. sumatrana), Meyer et al. 2012), Decken's and crowned sifakas (Propithecus deckenii and P. coronatus, Fichtel 2014), or in black lemurs (Eulemur macaco and E. flavifrons, Gamba \& Giacoma 2008), calls are characterized by species-specific acoustic structure. However, whether these differences between acoustic signals evolved in the context of species recognition and are used to discriminate between conspecifics and heterospecifics by the animals remains unknown. Moreover, whether call divergence has been driven by habitat adaptations, as in catarrhines (Brown et al. 1995), or is the result of stochastic 
processes, as in gibbons (Thinh et al. 2011), or of sexual selection, as in orangutans (Pongo sp.: Mitani 1985), is often also unknown.

Specific tests involving playback experiments to demonstrate that primates are able to discriminate heterospecific from conspecific calls have only rarely been conducted (e.g. in tarsiers, Tarsius spp. (Nietsch \& Kopp 1998); macaques, Macaca tonkeana, M. maurus, M. hecki and M. nigrescens (Muroyama \& Thierry 1998); gibbons, Hylobates spp. (Raemaekers \& Raemaekers 1985, Mitani 1987) and mouse lemurs, Microcebus ssp.: (Braune et al. 2008)) and yielded variable results. For example, Nietsch and Kopp (1998) found that Tarsius spectrum discriminated vocalizations of conspecifics and heterospecifics (Diane's and Tongian tarsiers). Mitani (1987) showed that agile gibbons (Hylobates agilis) responded similarly to conspecific songs from the local and allopatric populations but differentiated between those and allopatric heterospecific songs $(H$. muelleri). Finally, gray mouse lemurs (Microcebus murinus), which occur in sympatry with golden-brown mouse lemurs (M. ravelobensis) but in allopatry with Goodman's mouse lemurs (M. lehilahytsara) responded stronger to conspecific than to heterospecific advertisement calls (essential in the context of reproduction) and, interestingly, stronger to calls of the allopatric than the sympatric species (Braune et al. 2008). This result suggests that the spatial cohesiveness of species in sympatry led to species-specific divergence of acoustic signals to avoid costly hybridization (Braune et al. 2008). Thus, primates are able to discriminate between conspecific and heterospecific calls, irrespective of whether they occur in sympatry or allopatry (indicating different diversification mechanisms of acoustic signals in different genera).

In this study, we investigated the ability of redfronted lemurs (Eulemur rufifrons) to discriminate between loud calls of allopatric and sympatric congeners. The endemic Malagasy genus Eulemur consists of 12 species occupying all major primary habitats in Madagascar. Seven species of the genus, formerly classified as the "Eulemur fulvus group" (E. albifrons, E. cinereiceps, E. collaris, E. fulvus, E. rufifrons, E. rufus, and E. sanfordi) are closely related and probably diverged only in the last million years (Markolf et al. 2013). Geographically, they are distributed in allopatric populations and the other species of the genus Eulemur (E. coronatus, E. flavifrons, E. macaco, E. mongoz, and E. rubriventer) are distributed in sympatry with one of the "Eulemur fulvus group" taxa 
(Mittermeier et al. 2010). Loud calls or "croaks" in eulemurs are long and noisy vocalizations that are used during intergroup encounters and as alarm or group cohesion calls (Pereira \& Kappeler 1997, Fichtel \& Kappeler 2002). The acoustic structure of Eulemur loud calls shows considerable variation, with subtle differences between loud calls of species belonging to the "Eulemur fulvus group", but pronounced acoustic differences between loud calls of members of the "Eulemur fulvus group" and the other five members of the genus (Markolf et al. 2013). Thus, diversification of acoustic signals of Eulemur species occurring in allopatry is not pronounced, whereas sympatric species differ, suggesting that the need for reliable species recognition may have favored acoustic diversification.

Accordingly, we predicted that in response to playback experiments, eulemurs do not discriminate (operationalized as time spent looking towards the speaker) between their own loud calls and those of allopatric species, but between their own and loud calls of sympatric congeners. If, however, diversification of acoustic signals is the result of genetic drift, we predicted that eulemurs do not discriminate between loud calls of genetically closely related congeners, but between loud calls of more distantly related congeners. Finally, as heterospecific mating is more costly for females because they invest more in reproduction than males (Trivers 1972, Clutton-Brock \& Parker 1992), females should respond stronger to these loud calls than males.

Redfronted lemurs are an interesting model species to evaluate the relative importance of different evolutionary pressures in shaping species-specific acoustic signals because this species has a disjunct distribution, with sub-populations occurring in western dry deciduous forests and eastern mountain rain forests (Figure 1). Whereas E. rufifrons populations in the east are sympatric with a congeneric species (E. rubriventer), western populations have no sympatric congener. In addition, E. rufifrons and E. rubriventer produce loud calls during interspecific group encounters (Rakotonirina pers. obs). The acoustic differences between E. rubriventer and E. rufifrons are much more pronounced than between more closely related species (Markolf et al. 2013). A previous study indicated no acoustic difference between eastern and western populations, suggesting that there might be no habitat effect on acoustic signals of the two populations of $E$. rufifrons (Markolf et al. 2013). Since western E. rufifrons do not occur in sympatry with $E$. 
rubriventer but eastern populations do, we predicted different responses to the respective loud calls in each population. Accordingly, western E. rufifrons should not discriminate between their own calls and those of E. rubriventer, whereas eastern redfronted lemurs should do so.

\section{Methods}

\section{Study sites}

Playback experiments were conducted at two sites in Madagascar: Kirindy Forest (KF) and Ranomafana National Park (RNP) (Figure 1). At KF, Eulemur rufifrons have been individually marked as part of a long-term study (Kappeler \& Fichtel 2012a, 2012b), and we studied 16 individuals ( 8 females and 8 males) from 4 groups. At RNP, we studied 21 individuals (11 females and 10 males) from 7 groups that were distinguished by their size, sex ratio and home range location. We recognized individuals through earmarks, scratches or distinctive fur coloration. 


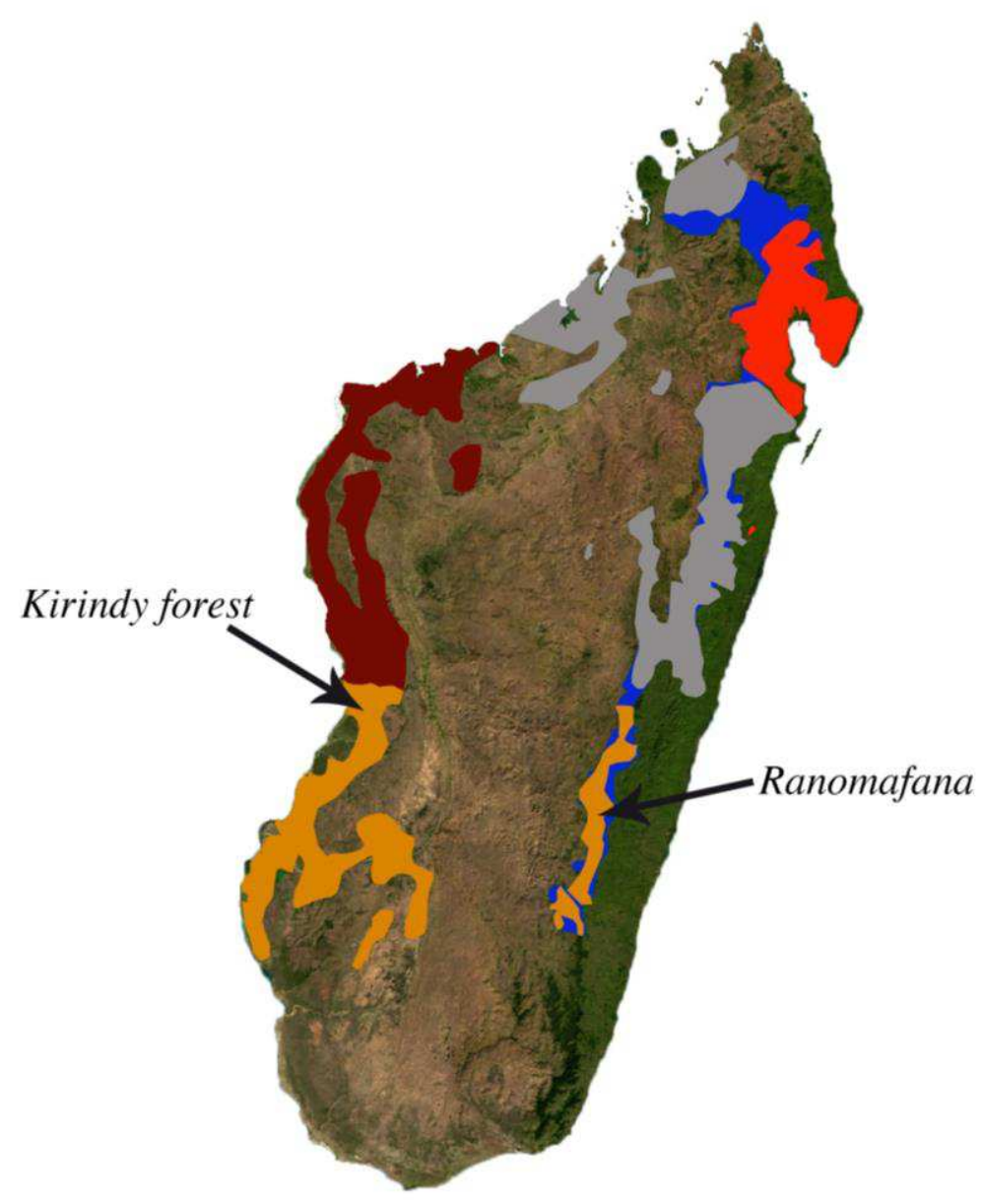

Eulemur albifrons

Eulemur fulvus

Eulemur rubriventer

Eulemur rufifrons

Eulemur rufus

Figure 1. Map of Madagascar with distribution of Eulemur species used as stimuli for playback experiments and locations of field sites.

\section{Playback stimuli and design}

Loud calls (croaks) used as playback stimuli were recorded as responses to playback experiments with conspecific loud calls in wild populations of E. albifrons, E. fulvus, E. rubriventer, E. rufifrons and E. rufus as part of an earlier study (Markolf et al. 2013, Figure 2). Recordings were made with a Marantz solid-state recorder PMD 660 (frequency response 40-20.000 Hz) and a Sennheiser directional microphone K6 power module and ME66 recording head (frequency response 40-20.000 Hz) with a MZ W66 pro windscreen. Because E. rufifrons usually produces bouts of loud calls in territorial contexts, each playback stimulus was repeated twice with intervals of $5 \mathrm{~s}$ silence in 
between, using Cool Edit 2000 (Syntrillium Phoenix, AZ). The sound pressure level of all playback stimuli was adjusted to $34 \pm 3 \mathrm{~dB}$ using Cool Edit and broadcast with the same volume settings at the loud speaker. Playback stimuli were presented with a Marantz solid-state recorder PMD 660 connected to a loud speaker (Davidactve, Visonik) hidden in the vegetation at a distance of $10 \mathrm{~m}$ behind a focal animal, so that the individual looking towards the speaker had to look in the opposite direction of the researcher, who was positioned at a distance of about $7 \mathrm{~m}$ in front of the focal subject to video-tape its response.

We used the following 5 stimuli for playback experiments in the (KF) population: loud calls of E. albifrons, E. fulvus, E. rubriventer, E. rufifrons and E. rufus (Figure 2, Table 1). In the RNP population, the number of playback stimuli was reduced from 5 to 3 because some of the groups at RNP could not be located on a regular basis. We therefore presented E. rufifrons at RNP only loud calls of their own species as well as calls of $E$. albifrons and E. rubriventer (Table 1). In both populations, we used as heterospecific playback stimuli the same calls, however, as conspecific playback stimulus we used calls that were recorded in the respective population (Kirindy or Ranomafana). Since in earlier playback studies with subjects from the population in Kirindy Forest focal subjects did not respond to controls (loud calls from chacma baboons or the song from a local parrot (Fichtel \& Kappeler 2002, Fichtel 2004)), we refrained from using such a control in the current study because of the low response and the logistical efforts for every single playback are enormous - especially in the rain forest. 


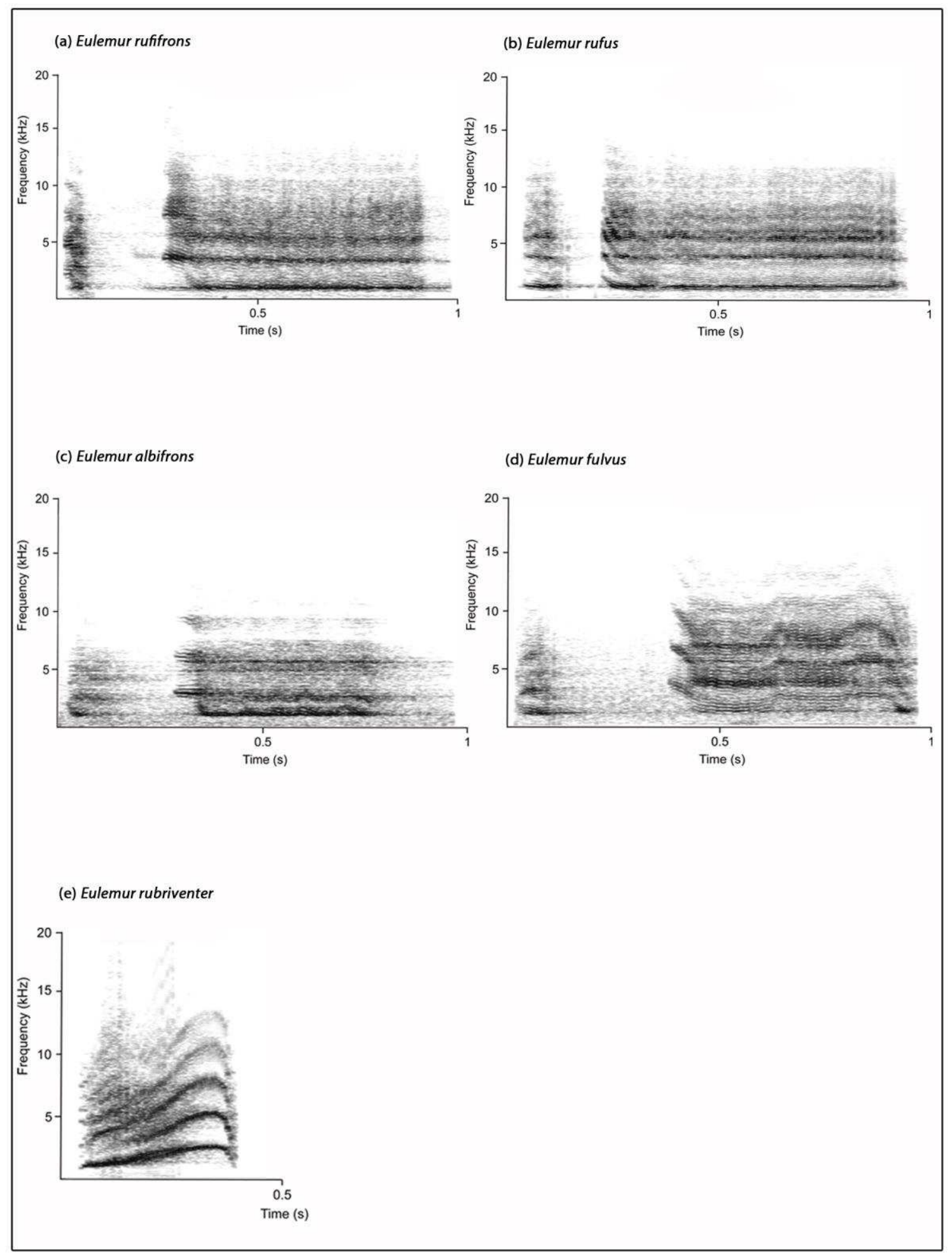

Figure 2. Spectorgrams of loud calls of Eulemur rufifrons, E. rubriventer, E. albifrons. E. fulvus, and E. rufus. 
Table 1: Number of individuals tested for each playback stimulus in both populations.

\begin{tabular}{lcc}
\hline & \multicolumn{2}{c}{ Population } \\
\hline Species of playback stimulus & Kirindy Forest & Ranomafana National Park \\
Eulemur rufifrons & $\mathrm{N}=16$ & $\mathrm{~N}=16$ \\
Eulemur albifrons & $\mathrm{N}=16$ & $\mathrm{~N}=17$ \\
Eulemur rubriventer & $\mathrm{N}=16$ & $\mathrm{~N}=17$ \\
Eulemur fulvus & $\mathrm{N}=16$ & \\
Eulemur rufus & $\mathrm{N}=16$ & \\
\hline
\end{tabular}

Playbacks were conducted only with animals that were engaged in relatively quiet activities, such as resting or grooming. To avoid pseudo-replication, we used loud calls from a different individual for each playback experiment, and subjects were tested with each stimulus in a randomized but counter-balanced order. Each playback stimulus was tested only once every $2^{\text {nd }}$ day per group. Subjects' responses to the playback stimuli were recorded with a SONY digital video camera briefly before and $1 \mathrm{~min}$ after the onset of each playback experiment. Based on these video-recordings we measured the time the animal spent looking towards the speaker (looking direction within $45^{\circ}$ angle to the direct line of sight towards the loud speaker, see appendix 1) and time spent looking around in other directions after the onset of the playback stimulus, and we calculated the percentage of time spent looking towards the speaker from the total time spent looking around. Video analyses were conducted with a frame-by-frame analysis with a resolution of 30 frames/s using Adobe Premiere Elements (12.0). 10\% of all experiments were scored by a second observer, naive to the research question. The Intraclass Correlation Coefficient was very good with ICC $=0.97$.

\section{Statistic analyses}

Linear mixed models (LMM) were used to test for differences in the percentage of time spent looking towards the speaker of redfronted lemurs in response to different playback stimuli in both populations respectively using lmerTest package in $\mathrm{R}$ (Kuznetsova et al. 2013). Percentage of time spent looking towards the speaker was 
arcsine-squareroot transformed and fitted as response. Playback stimulus and sex were fitted as fixed factors and individual identity as random factor. LMMs were also used to examine whether genetic distances between species influenced the percentage of time spent looking towards the speaker, with the latter variable fitted as response, genetic distance and sex as fixed factors and individual identity as random factor. To test for differences in responses of E. rufifrons to loud calls of E. albifrons, E. rubriventer and $E$. rufifrons between the two populations (KF and RNP), we conducted a Mann-Whitney U test.

To examine the relationship between genetic distance and acoustic signal divergence, we calculated the Euclidian distance between each pair of species on the basis of the group centroids revealed by a discriminant function analysis calculated in SPSS (Markolf et al. 2013). The function cophenetic.phylo of the R package APE 3.0-11 was used to calculate pairwise genetic distances between pairs of tips from a phylogenetic tree using its branch length, using the Eulemur species tree published by Markolf et al. (Markolf et al. 2013). Since both populations of E. rufifrons do not differ genetically (Markolf et al. 2013), they were combined for this analysis. Acoustic and genetic distances were then subjected to a Spearman's rank correlation. All analyses were conducted in $\mathrm{R}$ version 3.1.2.

\section{Results}

\section{Responses of redfronted lemurs at Kirindy Forest (KF)}

The percentage of time spent looking towards the speaker during the first minute following the onset of a playback differed significantly among stimuli (Table 2, LMM, $\left.\mathrm{X}^{2}=16.64, \mathrm{p}=0.005\right)$. Specifically, E. rufifrons spent less time looking towards the speaker after the presentation of loud calls of the genetically more distantly related $E$. rubriventer (Figure 3a). There was no sex difference in the percentage of time spent looking towards the speaker after presentation of the different playback stimuli (Table 2). However, the percentage of time spent looking towards the speaker was significantly influenced by the genetic distance between the species (Table 2, LMM, $\mathrm{X}^{2}=16.15, \mathrm{p}<0.001$ ). 
Table 2. Parameter estimates for the Linear Mixed Models (LMM) on the influence of the different playback stimuli and the genetic distance between species on the percentage

\begin{tabular}{|c|c|c|c|c|c|c|c|}
\hline & Model & Response variable & $\begin{array}{l}\text { Random } \\
\text { factors }\end{array}$ & Fixed factors & Estimate & $\mathbf{S E}$ & P-value \\
\hline \multirow[t]{6}{*}{$\mathrm{a}$} & LMM & Percentage of time & individual & intercept & 0.56 & 0.08 & $<0.001$ \\
\hline & & spent looking towards & identity & E. rufus & 0.02 & 0.11 & 0.81 \\
\hline & & the speaker & & E. albifrons & -0.02 & 0.11 & 0.85 \\
\hline & & & & E. fulvus & 0.01 & 0.11 & 0.91 \\
\hline & & & & E. rubriventer & -0.33 & 0.11 & 0.003 \\
\hline & & & & $\operatorname{sex}$ & -0.07 & 0.68 & 0.28 \\
\hline \multirow[t]{3}{*}{$\mathrm{b}$} & LMM & Percentage of time & individual & intercept & 0.60 & 0.05 & $<0.001$ \\
\hline & & spent looking towards & identity & genetic distance & -0.08 & 0.02 & $<0.001$ \\
\hline & & the speaker & & $\operatorname{sex}$ & -0.07 & 0.07 & 0.29 \\
\hline \multirow[t]{4}{*}{$\mathrm{c}$} & LMM & Percentage of time & individual & intercept & 0.28 & 0.1 & $<0.001$ \\
\hline & & spent looking towards & identity & E. rubriventer & 0.12 & 0.11 & 0.09 \\
\hline & & the speaker & & E. albifrons & 0.19 & 0.11 & 0.49 \\
\hline & & & & sex & 0.09 & 0.11 & 0.42 \\
\hline \multirow[t]{3}{*}{$\mathrm{d}$} & LMM & Percentage of time & individual & intercept & 0.39 & 0.09 & $<0.001$ \\
\hline & & spent looking towards & identity & genetic distance & -0.001 & 0.02 & 0.97 \\
\hline & & the speaker & & sex & 0.07 & 0.11 & 0.52 \\
\hline
\end{tabular}

of time spent looking towards the speaker for redfronted lemurs tested at Kirindy (a, b) and at Ranomafana (c, d). 


\section{Responses of redfronted lemurs in Ranomafana National Park (RNP)}

Eulemur rufifrons at RNP did not differ in the average percentage of time spent looking towards the speaker during the first minute following the onset of a playback between the three different playback stimuli of E. albifrons, E. rubriventer and $E$. rufifrons (Figure 3b, Table 2, LMM, $\mathrm{X}=3.49, \mathrm{p}=0.321$ ). There was also no sex difference in time spent looking towards the speaker after presentation of the different playback stimuli (Table 2). The percentage of time spent looking towards the speaker was not influenced by the genetic distance of the two species (Table 2, LMM, $\mathrm{X}^{2}=0.46, \mathrm{p}=0.79$ ).
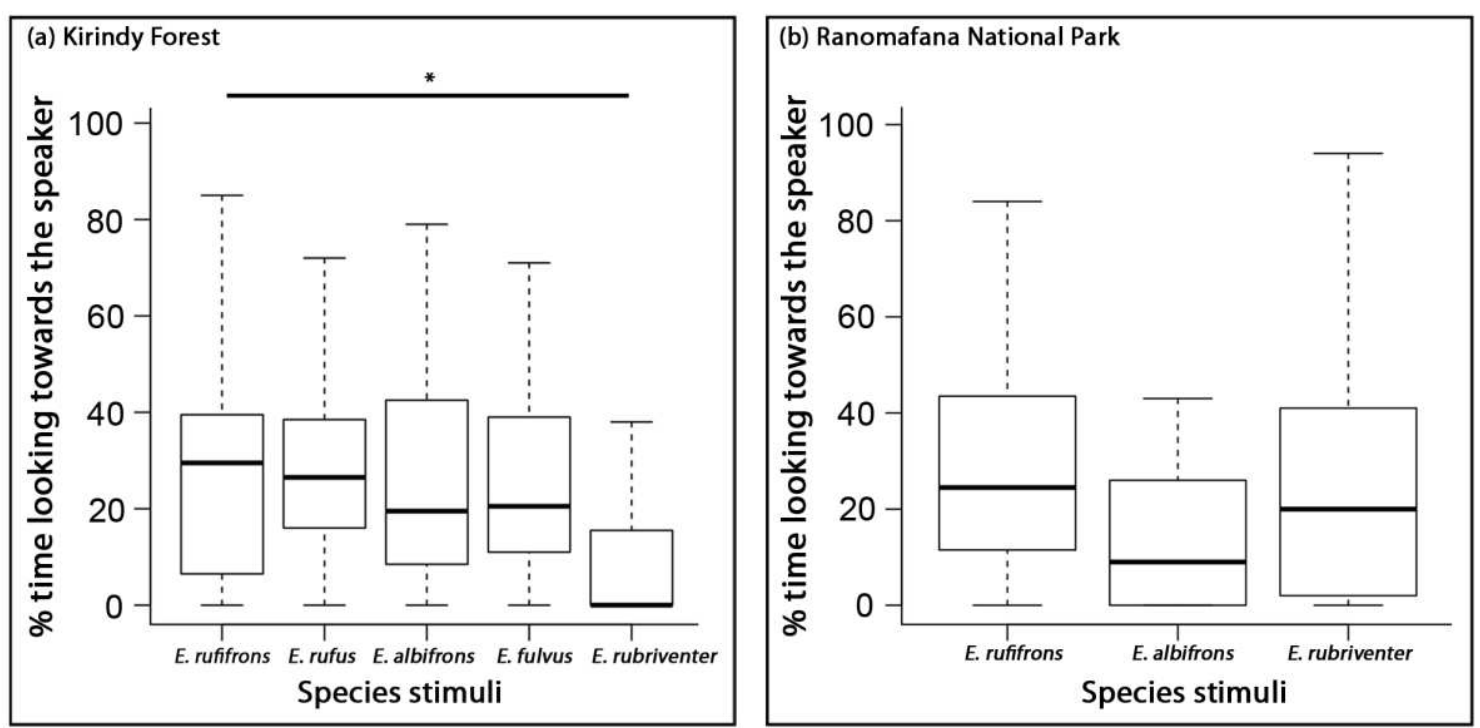

Figure 3 a, b. Boxplot of the percentage of time spent looking towards the speaker of Eulemur rufifrons in a) Kirindy Forest and b) in Ranomafana National Park in response to playbacks of loud calls from different congeneric species. Depicted are the median (black bars), interquartile range (boxes) and ranges (whiskers). 


\section{Comparison between redfronted lemurs at KF and RNP}

The comparison of looking responses between redfronted lemurs from both populations revealed no significant differences in time spent looking towards the speaker after the presentation of their own species loud calls (Mann Whitney U test, $\mathrm{p}=0.993$ ) and loud calls of E. albifrons (Mann Whitney $U$ test, $\mathrm{p}=0.132$ ). However, redfronted lemurs at RNP spent significantly more time looking towards the speaker after presentation of the sympatrically occurring $E$. rubriventer than redfronted lemurs at $\mathrm{KF}$, which do not occur sympatrically with E. rubriventer (Mann Whitney U test, $\mathrm{p}=0.026$, Figure $4 \mathrm{a}, \mathrm{b}$ and c).
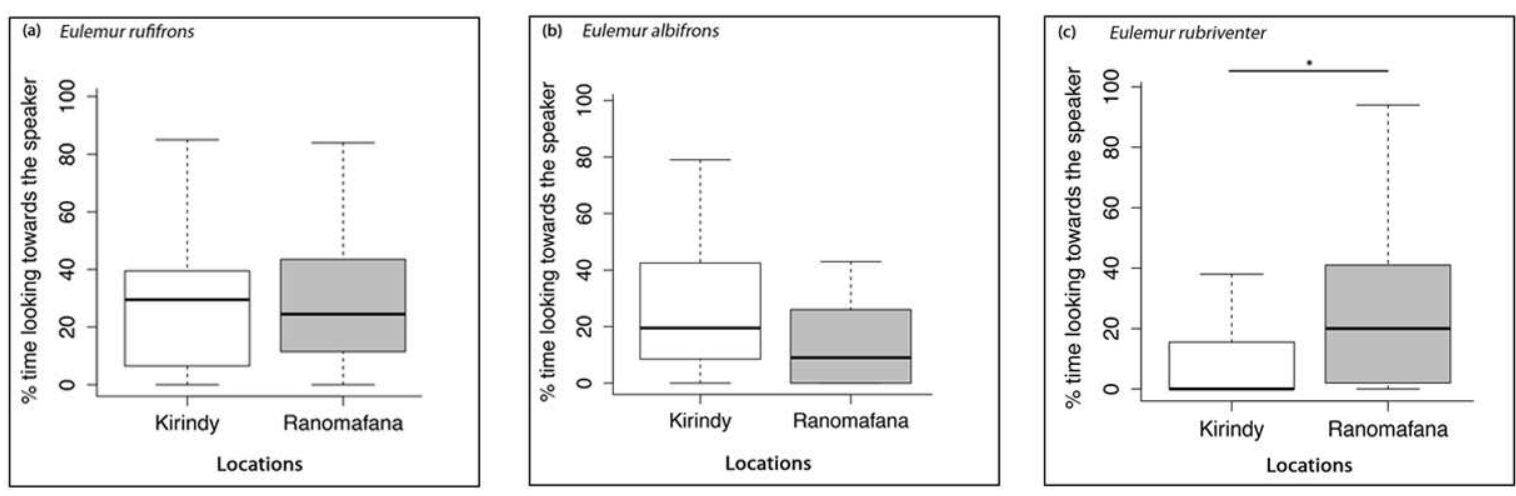

Figure 4 a, b, c. Boxplot of time spent looking towards the speaker after presentation of playbacks of (a) E. albifrons, (b) E. rufifrons and (c) E. rubriventer in KF (white) and RNP (grey). Represented are the median (black bars), interquartile range (boxes) and range (whiskers). 


\section{Genetic and acoustic distances}

The genetic distance of the 5 species correlated positively with their acoustic distance (Spearman rank: rho $=0.98, \mathrm{p}=0.005$; Figure 5).

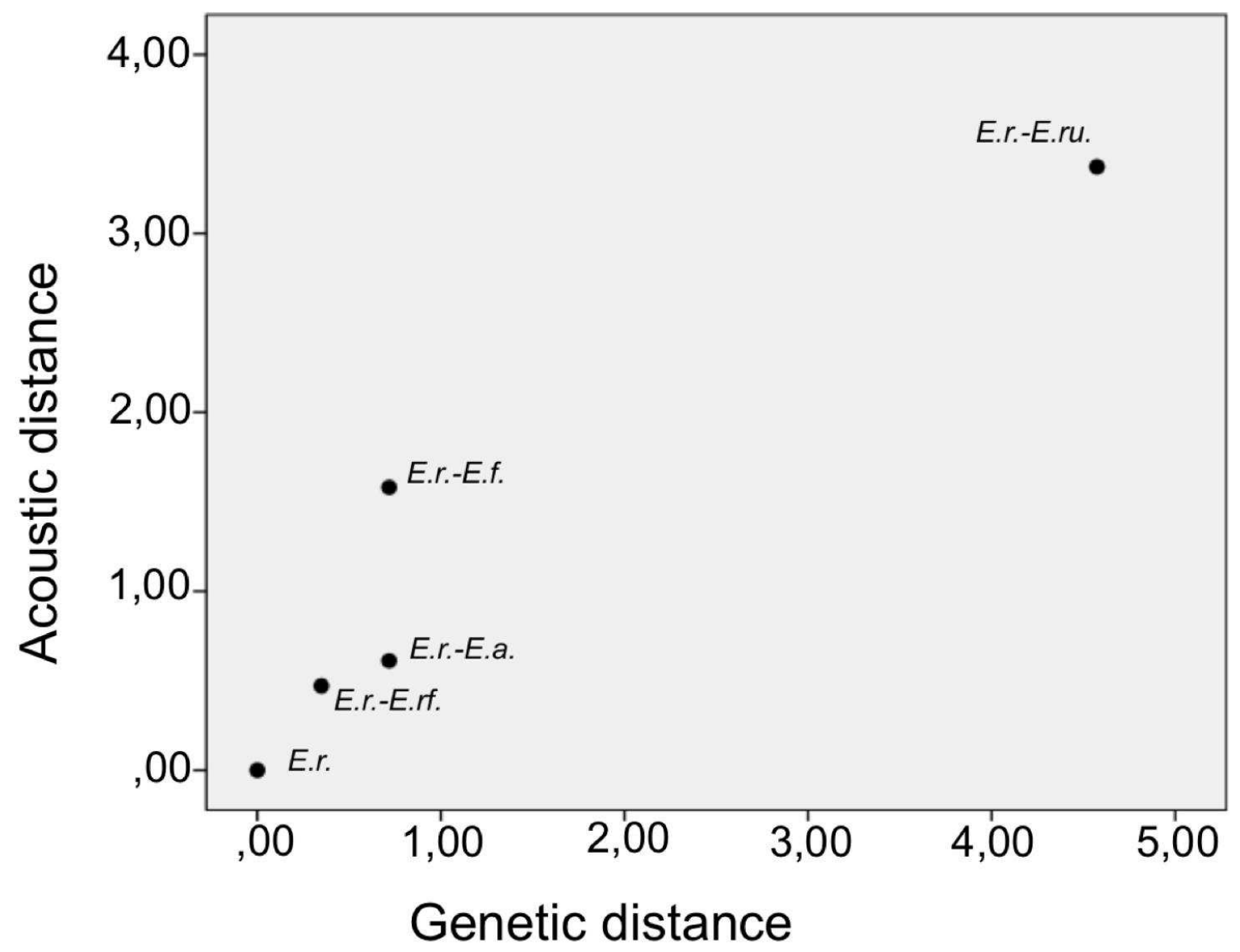

Figure 5. Acoustic distance vs. genetic distance between E. rufifrons and the Eulemur species used as stimuli. Each dot represents acoustic distance vs. genetic distance of one species pair. E.r.: E. rufifrons, E.r.-E.rf.: E. rufifrons - E. rufus, E.r.-E.a.: E. rufifrons - E. albifrons, E.r.-E.f.: E. rufifrons - E. fulvus, E.r.-E.ru.: E. rufifrons - E. rubriventer. 


\section{Discussion}

This study investigated the ability of Eulemur rufifrons to discriminate between conspecific and heterospecific loud calls. In KF, E. rufifrons did not discriminate between loud calls of closely related E. albifrons, E. fulvus and E. rufus. However, they discriminated between their own loud calls and those of E. rubriventer, as demonstrated by the shorter time spent looking towards the speaker. In RNP, E. rufifrons also did not discriminate between their own loud calls and those of the closely related E. albifrons but also not between their own calls and those of the more distantly related E. rubriventer. However, redfronted lemurs at RNP spent on average more time looking towards the speaker after presentations of E. rubriventer loud calls than did E. rufifrons in KF.

\section{Species recognition and sexual selection}

Vocalizations in numerous species of animals, including frogs, insects, birds and primates, are considered to be reliable source for the taxonomic delineation of subspecies or species (Gray \& Cade 2000, Irwin et al. 2008, Konrad \& Geissmann 2006, Funk et al. 2011). However, taxonomic decisions based on difference in vocalizations rarely consider the behavioral reactions of animals to acoustic cues and whether differences measured in vocalizations between subspecies and species are meaningful in terms of reproductive isolation for the taxa in question. Our study showed that differences among loud calls measured in previous studies between closely related eulemur species (Markolf et al. 2013) are apparently meaningless for the animals in terms of a potential reproductive barrier. We therefore suggest that taxonomic studies should investigate several traits and consider also the behavioral responses of the animals under study to traits supposedly involved in reproductive isolation.

The responses of females and males during all playback experiments did not differ from each other in time spent looking towards the speaker. Because females are known to invest more into reproduction than males, and heterospecific mating might be more costly for them (Trivers 1972, Kappeler 2012), we predicted that they should pay more attention to the loud calls and show stronger responses than males. In species where loud calls are also used in the mating context, such as in gibbons (Thinh et al. 2011 or langurs (Meyer 
et al. 2012), sexual selection might have driven the diversification of calls. However, differences seen between loud calls of E. rufifrons and closely related species are obviously not strong enough to contribute to reproductive isolation at least in the "Eulemur fulvus group". In fact, several Eulemur species also form viable hybrid populations in some areas in Madagascar (Johnson 2007, Pastorini et al. 2009), even among species exhibiting strong acoustic differences in their loud calls. Acoustic signals seem therefore not be used for avoidance of heterospecific mating in eulemurs, and it seems rather unlikely that call diversification evolved via sexual selection.

\section{Species recognition and natural selection}

Differences between loud calls of the "Eulemur fulvus group" seem not to be strong enough that $E$. rufifrons showed differentiated responses after presentation of their own loud calls and those of closely related species. Natural selection and habitat differences therefore seem unlikely to be responsible for the divergence of acoustic signals in eulemurs. There are several Eulemur species occurring in similar habitats along the east coast as well as along the west coast (see Mittermeier et al. 2010). Acoustic differences are not stronger between eastern and western species than between species occurring only in the east or only in the west (Markolf et al. 2013). And, there is also no difference between loud calls of the eastern and the western E. rufifrons populations (Markolf et al. 2013) although the same species occurs in different habitats with different ecologies (Muldoon \& Goodman). Moreover, Eulemur species occurring in sympatry show the strongest acoustic differences in loud calls despite inhabiting the same habitat and being exposed to similar natural selection pressures (Markolf et al. 2013). This effect is also evident in our study species because E. rufifrons and E. rubriventer in RNP show strong acoustic differences. Therefore, natural selection and habitat differences seem unlikely to have played a role in the diversification of acoustic signals in E. rufifrons. 


\section{Species recognition and genetic drift}

Finally, it is likely that the observed call divergence is mostly influenced by genetic drift. The fact that differences between loud calls of closely related eulemurs are rather small and calls get more distinctive as genetic distance between taxa increases (Markolf et al. 2013), suggests an influence of genetic drift. Although our sample size is rather small, the acoustic and genetic distances correlated positively among the Eulemur species investigated in this study. Eulemur rufifrons in both populations did not distinguish between calls of closely related species. Since closely related Eulemur taxa diverged more recently, genetic drift might not have yet produced strong differences between loud calls to be recognized. In contrast, a recent playback study on two subspecies of saddle-back tamarins (Saguinus fuscicollis nigrifrons and S. f. lagonotus) revealed that Saguinus fuscicollis nigrifrons differentiated between long calls of these two subspecies (Bradley \& McClung 2015). However, divergence estimates for these taxa are about 2.9 million years (Matauschek et al. 2011), whereas taxa from the "Eulemur fulvus group" diverged only during the last 1 million years (Markolf et al. 2013). Interestingly, in the KF populations, the time spent looking towards the speaker correlated negatively with the genetic distance to the stimulus species, indicating potential effects of genetic drift. Therefore, it seems most parsimonious to conclude at this point that genetic drift played a major role in the diversification of acoustic signals in eulemurs.

\section{Potential mechanisms involved in species recognition}

Acoustic recognition of heterospecific calls has also been documented in other species of mammals occurring in sympatry, for example between redfronted lemurs and Verreaux's sifakas (Propithecus verreauxi: Fichtel 2004), between ring-tailed lemurs (Lemur catta) and P. verreauxi (Oda \& Masataka 1996) and between bonnet macaques (Macaca radiata) and two species of langurs (Trachypithecus johnii and Semnopithecus entellus) and Sambar deer (Ramakrishnan \& Coss 2000). Those studies underline the importance of experience and learning for the ability to recognize heterospecific calls for sympatric species and might explain why E. rufifrons in this study responded more strongly to loud calls of sympatric E. rubriventer in RNP than in KF. Therefore, our results suggest that in E. rufifrons in RNP learning may play a role in recognizing 
heterospecific calls. As E. rufifrons and E. rubriventer occur sympatrically at RNP, E. rufifrons might have paid more attention to loud calls of E. rubriventer because they indicate the presence of a food competitor (Overdorff 1993, Overdoff \& Tecot 2007). In fact, experiments were conducted mostly during guava fruiting season and animals of both species were observed feeding from the same resources (personal obs., see also Overdorff \& Tecot 2007). It is also known that in some species of primates territorial confrontations may occur with neighboring groups of different species and that vocal signals such as loud calls may be used in such contexts in order to defend mates or resources (e.g. between saddle-back tamarins (Saguinus fuscicollis avilapiresi) and redcapped moustached tamarins (Saguinus mystax pileatus), Peres 1992).

\section{Other signals for species recognition in eulemurs}

Primates and other animals use different signals for communication, and the use of species-specific signals for species recognition has already been demonstrated by several authors (Höbel \& Gerhardt 2003,Caspers et al. 2009, McLennan \& Ryan 1997, Curé et al. 2012, Harrington 1979, Clark 1988, Ueno 1994). However, only few studies have investigated the role of species-specific signals in lemurs (delBarco-Trillo 2012, Braune et al. 2008), even though they represent endpoints of recent adaptive radiations. Whereas species recognition based on olfactory cues has been demonstrated in true lemurs (Eulemur sp.: Harrington 1979) only one study analyzed the role of visual speciesspecific signals (facial features) in eulemurs (Marechal et al. 2010). Our study tested the ability of redfronted lemurs to recognize conspecifics from heterospecifics via acoustic signals, suggesting that acoustic signals apparently play a less important role for eulemurs in species recognition. However, Eulemur species exhibit a wide variety in terms of facial color patterns and especially males, with the exception of E. rufifrons and E. rufus (see Mittermeier et al. 2010, Clough et al. 2009), show colorful and pronounced facial hair patterns that could serve as species-specific visual signals. We therefore suggest that future studies on species recognition using visual signals may provide important insights into the relative importance of either olfactory, acoustic or visual signals in species recognition of eulemurs. 


\section{Conclusions}

We conclude that E. rufifrons are not able to discriminate between loud calls of closely related species living in allopatry and that responses to more distantly related congeners are likely to be modulated by experience. Eulemur rufifrons at $\mathrm{KF}$ discriminated between loud calls of them and their own calls, whereas E. rufifrons at RNP did not. Because members of the two study populations responded differently to these calls, we suggest that experience, presumably based on learning, may have modulated the response of the RNP population to calls of E. rubriventer, which acts as a food competitor there. In addition, species differences in loud calls are likely partly the result of genetic drift. Since closely related Eulemur taxa diverged only recently, genetic drift might not have yet produced strong differences between loud calls to be recognized, suggesting that these calls are less important for species recognition in these cathemeral primates. Thus, playback experiments are important to understand whether differences between acoustic signals used for species delimitation are also used by the animals themselves to discriminate between conspecific and heterospecific calls.

\section{Acknowledgements}

We thank the Malagasy Ministère de l'Environnement et des Eaux et Forêts, the Departement de Biologie Ecologie et Conservation Animale de l'Université d'Antananarivo, the Centre National de Formation, d'Etudes et de Recherche en Environnement et Foresterie de Morondava, Madagascar National Parks and the Centre ValBio Ranomafana for allowing and supporting research in Kirindy Forest and Ranomafana National Park. We are grateful to our field assistants Tiana, Jipa, Mamy and Victor without whom playback experiments would not have been possible. The clarity of a previous version of this manuscript was greatly improved by comments from two anonymous referees, whom we also wish to thank. 


\section{Chapter 2}

\section{The role of facial color variation for species recognition in redfronted lemurs (Eulemur rufifrons)}

with Peter M Kappeler and Claudia Fichtel

To be submitted to BMC Evolutionary Biology 


\section{Abstract}

Background: Species recognition, the ability of species to distinguish conspecifics from heterospecifics, plays an essential role in the context of reproduction. In non-human primates, facial cues are considered to be a particularly relevant species-specific signal for species recognition and have been investigated in a variety of species. However, the role of visual cues for species recognition has not been investigated in the primates of Madagascar (Lemuriformes) so far. In this study, we therefore investigate the role of facial color variation for species recognition in wild redfronted lemurs (Eulemur rufifrons) at Kirindy Forest, western Madagascar. Pictures of male faces of E. rufifrons, three closely related species (E. albifrons, E. fulvus and E. rufus) and genetically more distant E. rubriventer were used in an experimental setting to investigate the ability of individual males and females of E. rufifrons to distinguish between male facial color variation.

Results: Eulemur rufifrons looked significantly longer at pictures of their own species than at those of heterospecifics. Moreover, the time spent looking towards the pictures was correlated with genetic distance between E. rufifrons and the species stimuli. Females spent less time looking at heterospecific pictures than males, who looked significantly longer at pictures of heterospecific pictures of E. albifrons, E. fulvus and E. rubriventer. However, there was no overall significant sex difference between the tested individuals. Tested individuals showed additional sniffing behavior while looking at each visual stimulus, and the time spent sniffing pictures was significantly longer towards conspecifics compared to heterospecifics. The duration of sniffing behavior was also correlated with genetic distance to the species providing the stimuli.

Conclusions: We conclude that Eulemur rufifrons have the ability for visual species recognition using facial color variation, which may afford them the ability to avoid costly interbreeding. If so, sexual selection might have influenced the evolution of facial color patterns in eulemurs. However, as responses were correlated with genetic distance, genetic drift might have also played a role in the evolution of facial cues in eulemurs. Finally, our study suggests that eulemurs might have the ability for multi-modal species 
recognition using visual and olfactory sensory modalities, but further experiments are required.

Keywords: Eulemur rufifrons, species recognition, visual signals, sexual selection, genetic drift 


\section{Background}

The ability to differentiate conspecifics from heterospecifics plays an important role in the context of reproduction for many animals (Ratcliffe \& Grant 1983, Fujita 1987, Ryan \& Rand 1993, Boake et al. 1997, Baugh et al. 2008, Caspers et al. 2009). It has long been proposed that heterospecific mating can be especially costly for females (Trivers 1972, Clutton-Brock \& Parker 1992, Kappeler 2012). Females should therefore be selected to recognize and discriminate against heterospecific males to avoid costly interbreeding (Kappeler 2012). Indeed, many non-human primates were proposed to use species recognition as premating isolation mechanism in order to avoid interbreeding (Fujita 1987, Fujita et al. 1997, Braune et al. 2008). For instance, playback experiments have shown that grey mouse lemurs (Microcebus murinus) were able to discriminate their own species advertisement calls from those of sympatric and allopatric heterospecifics $(M$. ravelobensis and $M$. lehilahytsara), and showed a preference for conspecific calls (Braune et al. 2008). Additionally, their response (orientation to the calls) to allopatric heterospecific were stronger than to sympatric ones, suggesting that species recognition functions as premating isolation in sympatric species (Braune et al. 2008). Moreover, females and males of some species of Sulawesi macaques (Macaca nigra, M. nigrescens, M. hecki, M. tonkeana, M. maurus, M. ochreata and M. brunnescens) visually preferred their own species while looking at full-body pictures of con- and heterospecifics (Fujita et al. 1997). Similarly, five other macaque species (Macaca fuscata fuscata, M. mulatta, M. radiata, $M$. nemestrina, and $M$. arctoides) were also shown to visually differentiate their own species from heterospecific photographs (Fujita 1987). The longer duration individuals watched the pictures of conspecifics indicated the ability of these macaques for visual species recognition, which was suggested to potentially function as reproductive isolation mechanism in these species (Fujita 1987, Fujita et al. 1997).

As in many other animal species, facial cues are among the phenotypic traits that play a communicative role in social interactions of primates (Nahm et al. 1997, Parr et al. 1998, Pascalis \& Bachevalier 1998, Parr et al. 2000, Setchell et al. 2006). Facial cues can contain visual information such as shape and colors that differ across individuals or species (Dufour et al. 2006, Burrows 2008, Santana et al. 2012, 2013), and which can 
provide information about social status, condition and identity of an individual (Parr et al. 2000; Setchell 2005; Setchell et al. 2006; Marty et al. 2009). These visual differences can be perceived by other individuals (conspecifics and heterospecifics) and may function in individual, kin or species recognition (Parr \& de Waal 1999, Paar et al. 2000, Dufour et al. 2006)), but also in intra- or interspecific interactions (Ueno 1994, Bradley \& Mundy 2008).

Several studies have suggested that non-human primates are able to differentiate individuals of their own kin/group from strangers or conspecifics and heterospecifics based on facial cues (Gauthier \& Logothetis 2000, Bruce 1982, Fujita 1987, Dittrich 1994, Fujita et al. 1997, Pascalis \& Bachevalier 1998, Allen \& Higham 2015). Individual recognition has been demonstrated for example in chimpanzees (Pan troglodytes) and rhesus macaques (Macaca mulatta), which can use facial cues in black-and-white photographs presented on a computer screen to visually discriminate different individuals (Parr et al. 2000). Other experiments demonstrated the ability of chimpanzees for visual kin recognition as well. When black-and-white photographs of mothers and their offspring were shown to chimpanzees, individuals were shown to be able to identify mother-son dyads but not mother-daughter ones (Parr \& de Waal 1999).

Species recognition based on visual cues has been demonstrated in several species of macaques (Fujita 1987, Fujita et al. 1997, Dufour et al. 2006) and has been suggested for some other non-human primates as well. For instance, a study conducted by Dufour et al. (2006) found that, when pictures of faces of conspecifics and heterospecifics were presented to Tonkean macaques (Macaca tonkeana) and brown capuchin monkeys (Cebus apella), individuals of both species were able to visually recognize their own species from different ones as shown by longer time they looked at pictures of their own species. The overall facial pattern of guenons might also provide information about individual identity and therefore may be used for species recognition as well (Allen \& Higham 2015). In New World and Old World primates, the number of sympatric species and group size were shown to have influenced the evolution of facial color patterns, also suggesting that the latter can be used for individual or species recognition (Santana et al. 2012, 2013). 
Among non-human primates, the lemurs of Madagascar also exhibit highly diverse facial color patterns (Mittermeier et al. 2010), which may have a communicative function in species recognition and social interactions as well. Up to now, only a few studies have investigated the potential use of species-specific signals for species recognition in lemurs. For instance, olfactory signals have been suggested to function in some species to differentiate conspecifics from heterospecifics (Harrington 1979, Kappeler 1998, delBarco-Trillo et al. 2012). Additionally, acoustic signals have been shown to be used by mouse lemurs to distinguish conspecifics from heterospecifics (Braune et al. 2008), whereas they do not play an important role for species recognition in redfronted lemurs (Rakotonirina et al. 2016).

The use of visual signals for species recognition in lemurs has not been studied so far. However, Marechal et al. (2010) demonstrated that some true lemurs (E. fulvus and E. macaco) are able to differentiate familiar and unfamiliar individuals visually, suggesting a potential ability for visual species recognition as well (Marechal et al. 2010). Additionally, females of some true lemurs (E. mayottensis, E. albifrons, E. rufus, E. collaris, E. sanfordi and E. cinereiceps) have been shown to have the ability to differentiate colorful and non-colorful male photographs, showing a preference for more colorful ones (Cooper \& Hosey 2003).

Investigating whether visual signals can provide cues to discriminate con- from heterospecifics is particularly important for species that share a common habitat with several closely related species. Lemur communities can be large and consist of up to 13 different lemur species in the wild (e.g. in Andasibe, Ranomafana, Tsingy de Bemaraha (Mittermeier et al. 2010)). Within the genera Eulemur and Microcebus, at least two species of the same genera occur in sympatry in several sites in Madagascar (Mittermeier et al. 2010). Additionally, eulemurs are known to form viable and sometimes fertile hybrids in their natural habitats (Rumpler 1975, Hamilton \& Buettner- Janusch 1977, Pastorini et al. 2001, Johnson 2002, 2007, Delmore et al. 2011). Thus, it is biologically relevant to investigate whether lemurs have the visual capability to distinguish con- from heterospecifics, which can serve as reproductive isolation mechanism to avoid costly interbreeding. 
The genus Eulemur comprises 12 species (Markolf et al. 2013). Seven of them (E. albifrons, E. cinereiceps, E. collaris, E. fulvus, E. rufifrons, E. rufus, and E. sanfordi) were long considered as subspecies of E. fulvus, as they are closely related and distributed in allopatry throughout Madagascar (Johnson 2007, Mittermeier et al. 2010, Markolf et al. 2013). Eulemurs are the only lemurs with sexual dichromatism, and males are particularly colorful and show considerably more variation especially in facial color patterns than females (Bradley \& Mundy 2008). As most lemur species, eulemurs have dichromatic color vision, except from females that are either dichromatic or show polymorphic trichromacy in color vision (Jacobs \& Deegan 1993, 2008, Tan \& Li 1999), suggesting that variation in facial coloration can be perceived (see also Clough et al. 2009).

Given the limited information available about the use of visual signals for species recognition in lemurs despite their high diversity in pelage coloration and especially facial color patterns, our study aimed to investigate the role of facial cues as visual signals for species recognition in this radiation of primates. We were therefore interested in whether facial color variation of different Eulemur species functions in species recognition, using wild redfronted lemurs (Eulemur rufifrons) as subjects. Eulemur rufifrons has a disjunct distribution with one population occurring in the west of Madagascar without sympatric congener and the other population occurring in the east of the island in sympatry with E. rubriventer (Markolf \& Kappeler 2013).

If variation in facial color patterns functioned in species recognition in eulemurs, we predicted that individuals of E. rufifrons would respond stronger to pictures of faces of their own species than to pictures of faces of heterospecifics. Additionally, if sexual selection has played a role in the evolution of facial color variation, we predicted that females should show stronger responses than males. Finally, as the species used as stimuli differ in relatedness to the test species, we predicted that if genetic drift has played a role in the evolution of facial color patterns in eulemurs, the response of E. rufifrons should correlate negatively with their respective genetic distance. 


\section{Methods}

\section{Study site}

Experiments were conducted with Eulemur rufifrons in Kirindy Forest, western Madagascar (Figure 1). Study subjects are individually marked as part of a long-term study and are well habituated to human observers (Kappeler \& Fichtel 2012a, 2012b). We studied 8 females and 7 males in four different groups.

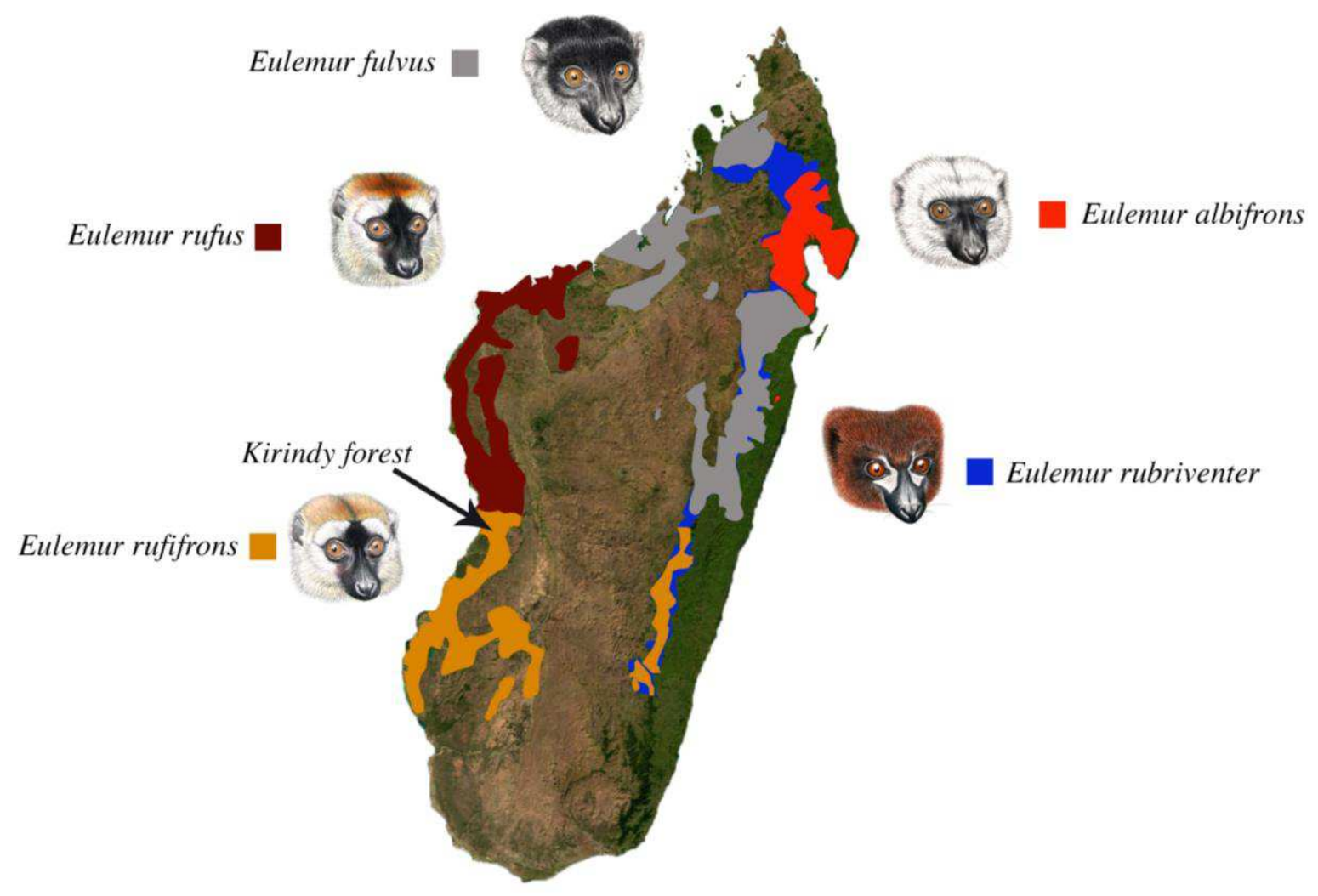

Figure 1. Map of Madagascar showing the distribution of Eulemur species used as stimuli during the experiments. The pictures depict drawings of the male faces of the different species used as stimuli (Illustrations: S. Nash). 


\section{Experimental design}

During the experiments, we presented each experimental subject of Eulemur rufifrons a color photo of either a conspecific or heterospecific male, i.e., photographs of an E. rufifrons, the closely related E. rufus, E. fulvus and E. albifrons or of the genetically more distant E. rubriventer. Each photograph contained only the head of the animal on a gray background (Figure 2) and was adjusted to have approximately the same size as the head of Eulemur individuals. Each picture was placed in a picture frame made of wood to facilitate the presentation of the picture to the focal animal as well as to stabilize the picture itself (Figure 2). In the following we briefly describe variation in facial color patterns of the species used as stimuli during the experiments (Figure 1) based on descriptions in Mittermeier et al. (2010):

- Eulemur rufifrons: dark red crown, black muzzle, golden-red cheek beard, creamy-white patches above the eyes.

- Eulemur rufus: allopatric heterospecific and very similar to E. rufifrons in facial color patterns: brick-red crown, golden-red cheek beard, black muzzle and black midfacial stripe extending from crown to nose.

- Eulemur albifrons: occurs in allopatry with E. rufifrons and facial color variation differs strongly from E. rufifrons. Black muzzle, white beard, cheeks and crown.

- Eulemur fulvus: occurs in allopatry with E. rufifrons and is slightly different in facial color patterns. Dark-brown to almost black muzzle and crown, light grey beard and variable patches of light fur above the eyes.

- Eulemur rubriventer: occurs in sympatry with E. rufifrons in the eastern parts of Madagascar but not at the study site in the West and is very different in facial color patterns. Black muzzle, face shading to black; patches of white skin form characteristic "tear-drops" beneath the eyes, no bushy beard. 


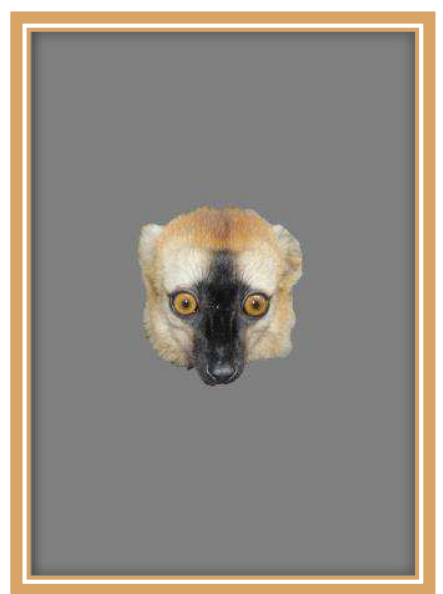

Eulemur rufifrons

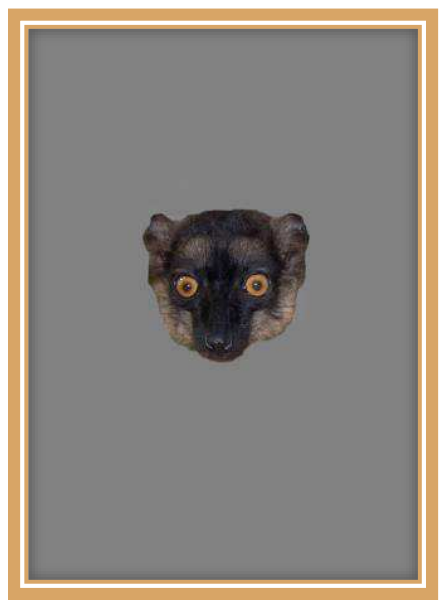

Eulemur fulvus

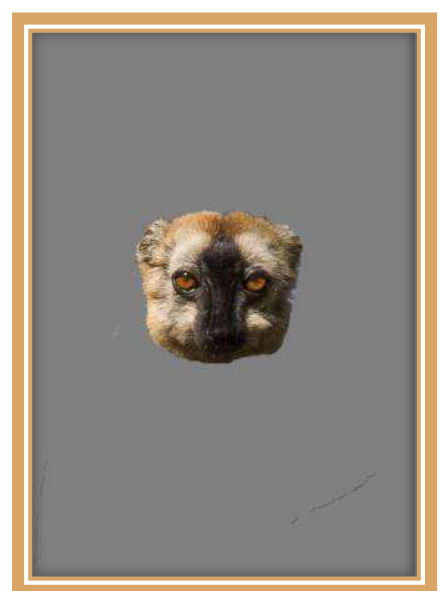

Eulemur rufus

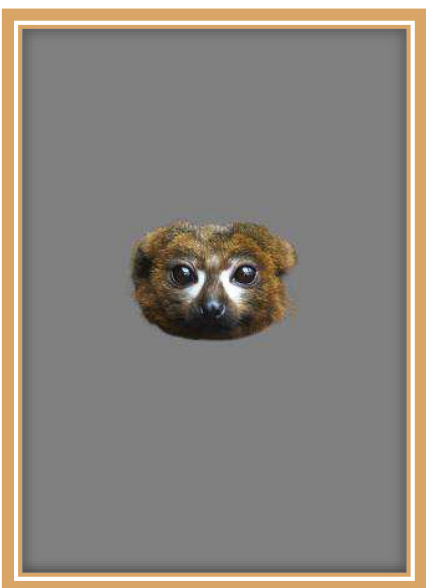

Eulemur rubriventer

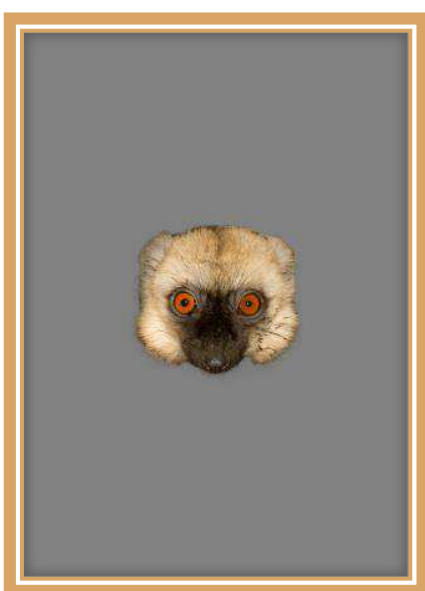

Eulemur albifrons

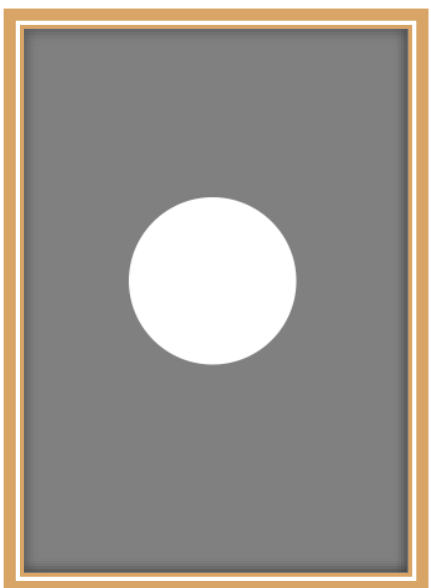

control

Figure 2. Examples of pictures of each species used as stimuli during the experiments and the control (white circle).

Before each test, individuals were called with a clicker to a location on the ground, where they were fed some raisins. Experiments were conducted with animals that were engaged in quiet activities, such as resting or grooming at the periphery of the group after a feeding session. Once the focal individual was isolated, the experimenter (HR) approached the focal individual carefully. The picture frame was hidden behind the back until the focal individual was stationary. We presented each picture at a distance of $1 \mathrm{~m}$ from the focal individual on the ground so that the picture frame was at the same height as the focal individual (see Appendix 2). In order to avoid pseudo-replication, every individual was tested with a different picture of the given species (one picture per 
individual). As a control, we presented a picture frame containing a white circle on a gray background having the same size as the faces on the other pictures (Figure 2). Each individual was tested only once every second day.

Responses of experimental subjects were recorded with a SONY digital video camera from briefly before until 60 seconds after the onset of each experiment. The camera was placed in front of the focal animal, aligned with the picture frame so that the responses were clearly recorded. Based on these video-recordings, we measured the time each subject spent looking towards the picture after the onset (looking direction within a $45^{\circ}$ angle of the direct line of sight towards the picture), and calculated the percentage of time spent looking towards the picture from the total time spent looking around. In addition, during the experiments, we observed sniffing behaviors of focal individuals while performing each test. We therefore measured the time individuals spent sniffing (inhaling a short and distinct breath through the nose) towards each picture after the onset and calculated the percentage of time spent sniffing. Videos were analyzed frame-byframe with a resolution of 30 frames/s, using Adobe Premiere Elements (12.0). All experiments were rated by HR, and $10 \%$ were rated by a second observer. The intraclass coefficient was very high $(\mathrm{ICC}=0.95)$.

\section{Statistic analyses}

We used linear mixed models (LMM) to test for differences in the percentage of time E. rufifrons spent looking towards the pictures as well as the percentage of time spent sniffing at the pictures in response to different stimuli using LmerTest package in $\mathrm{R}$ (Kuznetsova et al. 2013). Percentage of time looking towards the pictures and percentage of time sniffing the pictures were arcsine-squareroot transformed and fitted as responses. Species and sex were fitted as fixed factors and individual identity as a random factor. We also used a LMM in order to examine whether genetic distances between species correlated with the responses of the percentage of time E. rufifrons spent looking towards the pictures as well as sniffing the pictures of each stimulus. The latter variable was fitted as response, genetic distance and sex fitted as fixed factors and individual identity as random factor. All analyses were conducted in $\mathrm{R}$ version 3.1.3. 


\section{Results}

\section{Time spent looking towards the picture}

Eulemur rufifrons looked significantly longer towards pictures of their own species than towards pictures of heterospecifics (Table 1, Figure 3, LMM, $X^{2}=15.94$, $\mathrm{p}<0.01)$. There was no overall effect of sex in the percentage of time spent looking towards the pictures (Table 1), but males spent significantly longer looking at pictures of E. albifrons, E. fulvus and E. rubriventer (Figure 3). Additionally, the percentage of time spent looking towards the pictures was significantly correlated with the genetic distance between the stimuli and the test species. Eulemur rufifrons looked significantly longer at pictures of genetically more closely related species (Table $1, \mathrm{LMM}, \mathrm{X}^{2}=21.69, \mathrm{p}<0.001$ ). 
Table 1. Parameter estimated for the Linear Mixed Models (LMM) on the influence of the different pictures used as stimuli and the genetic distance between species on the percentage of time spent looking towards the pictures $(a, b)$ and the percentage of time spent sniffing the pictures $(\mathrm{c}, \mathrm{d})$ for redfronted lemurs.

\begin{tabular}{|c|c|c|c|c|c|c|c|}
\hline & Model & Response variable & $\begin{array}{l}\text { Random } \\
\text { factors }\end{array}$ & $\begin{array}{l}\text { Fixed } \\
\text { factors }\end{array}$ & Estimate & SE & $\begin{array}{l}P \text { - } \\
\text { value }\end{array}$ \\
\hline \multirow[t]{12}{*}{$\mathrm{a}$} & \multirow[t]{12}{*}{ LMM } & \multirow{12}{*}{$\begin{array}{l}\text { Percentage of time } \\
\text { spent looking } \\
\text { towards the pictures }\end{array}$} & \multirow{12}{*}{$\begin{array}{l}\text { Individual } \\
\text { identity }\end{array}$} & intercept & 0.64 & 0.04 & $<0.001$ \\
\hline & & & & E. rufus & -0.16 & 0.05 & 0.002 \\
\hline & & & & E. fulvus & -0.30 & 0.05 & $<0.001$ \\
\hline & & & & E. albifrons & -0.30 & 0.05 & $<0.001$ \\
\hline & & & & E. rubriventer & -0.35 & 0.05 & $<0.001$ \\
\hline & & & & control & -0.35 & 0.05 & $<0.001$ \\
\hline & & & & $\operatorname{sex}$ & -0.05 & 0.06 & 0.47 \\
\hline & & & & $\begin{array}{ll}\text { E. } & \text { rufus-sex } \\
\text { male } & \end{array}$ & 0.10 & 0.07 & 0.18 \\
\hline & & & & $\begin{array}{l}\text { E.fulvus-sex } \\
\text { male }\end{array}$ & 0.15 & 0.07 & 0.03 \\
\hline & & & & $\begin{array}{l}\text { E. albifrons-sex } \\
\text { male }\end{array}$ & 0.26 & 0.07 & $<0.001$ \\
\hline & & & & $\begin{array}{l}\text { E. rubriventer- } \\
\text { sex male }\end{array}$ & 0.18 & 0.07 & 0.01 \\
\hline & & & & Control-sex male & 0.09 & 0.07 & 0.21 \\
\hline \multirow[t]{3}{*}{$\mathrm{b}$} & \multirow[t]{3}{*}{ LMM } & \multirow{3}{*}{$\begin{array}{l}\text { Percentage of time } \\
\text { spent looking } \\
\text { towards the pictures }\end{array}$} & \multirow{3}{*}{$\begin{array}{l}\text { Individual } \\
\text { identity }\end{array}$} & intercept & 0.47 & 0.03 & $<0.001$ \\
\hline & & & & genetic distance & -0.04 & 0.009 & $<0.001$ \\
\hline & & & & sex & 0.09 & 0.04 & 0.06 \\
\hline \multirow[t]{7}{*}{$\mathrm{c}$} & \multirow[t]{7}{*}{ LMM } & \multirow{7}{*}{$\begin{array}{l}\text { Percentage of time } \\
\text { spent of sniffing } \\
\text { events }\end{array}$} & \multirow{7}{*}{$\begin{array}{l}\text { Individual } \\
\text { identity }\end{array}$} & intercept & 0.34 & 0.04 & $<0.001$ \\
\hline & & & & E. rufus & -0.10 & 0.05 & $<0.05$ \\
\hline & & & & E. fulvus & -0.22 & 0.05 & $<0.001$ \\
\hline & & & & E. albifrons & -0.13 & 0.05 & $<0.05$ \\
\hline & & & & E. rubriventer & -0.23 & 0.05 & $<0.001$ \\
\hline & & & & control & -0.25 & 0.05 & $<0.001$ \\
\hline & & & & sex & 0.06 & 0.04 & 0.19 \\
\hline \multirow[t]{3}{*}{$\mathrm{d}$} & \multirow[t]{3}{*}{ LMM } & \multirow{3}{*}{$\begin{array}{l}\text { Percentage of time of } \\
\text { sniffing events }\end{array}$} & \multirow{3}{*}{$\begin{array}{l}\text { Individual } \\
\text { identity }\end{array}$} & intercept & 0.25 & 0.04 & $<0.001$ \\
\hline & & & & genetic dis & -0.03 & 0.01 & $<0.01$ \\
\hline & & & & sex & 0.06 & 0.05 & 0.27 \\
\hline
\end{tabular}




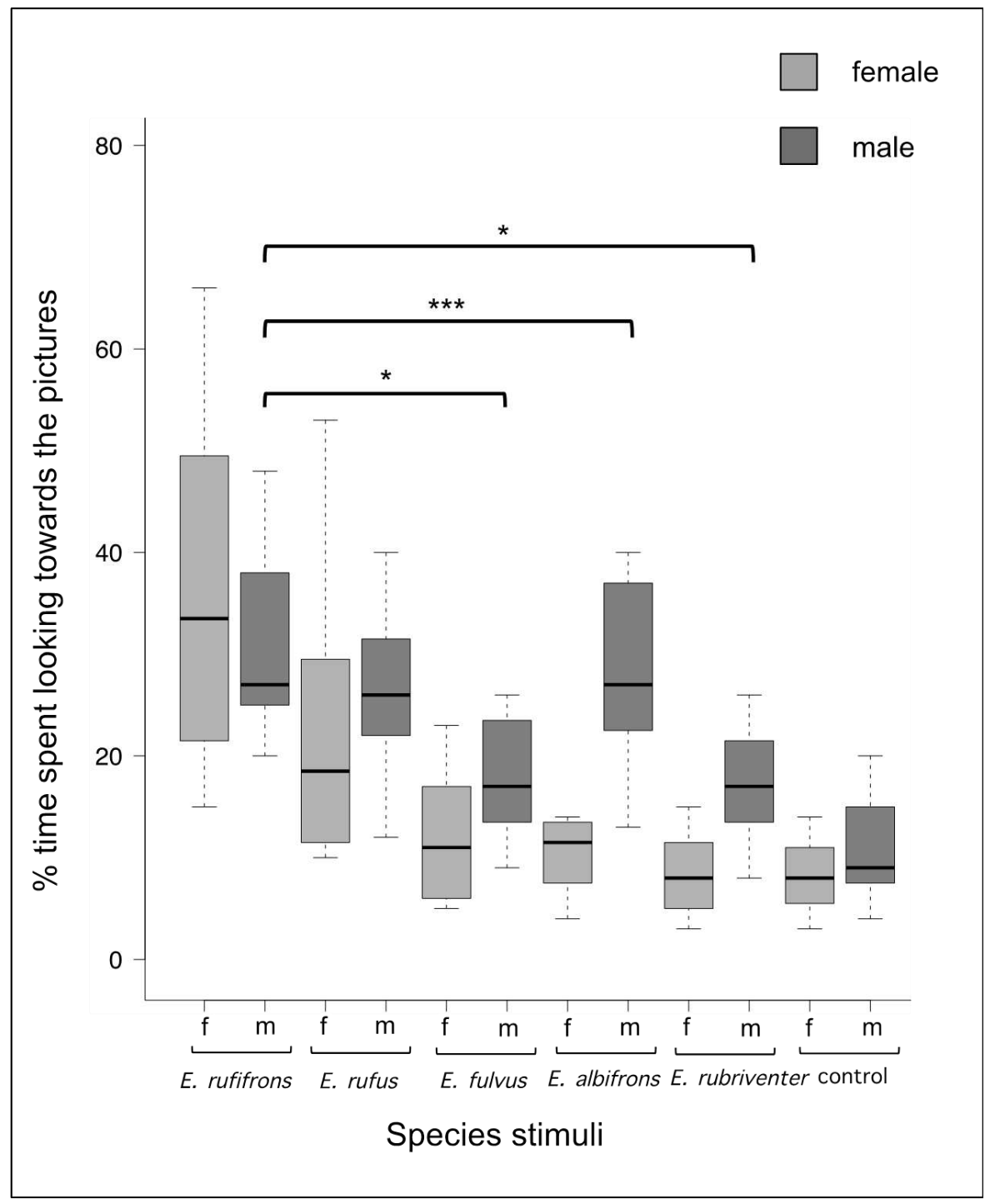

Figure 3. Boxplot of the percentage of time Eulemur rufifrons spent looking towards the different stimuli showing the responses separated by sex. Depicted are the median (black bars), interquartile range (boxes) and ranges (whiskers). $* \mathrm{p}<0.05, * * * \mathrm{p}<0.001$. 


\section{Percentage of time of sniffing events}

Eulemur rufifrons also spent significantly more time sniffing pictures of their own species compared to those of heterospecifics (Table1, Figure 4, LMM, $X^{2}=32.92$, $\mathrm{p}<0.001)$. The percentage of time sniffing was also significantly correlated with genetic distance, with E. rufifrons sniffing significantly longer during presentation of photos of closely related congeners (Table1, Figure 4, LMM, $\mathrm{X}^{2}=11.41, \mathrm{p}<0.01$ ). However, we found no effect of sex on the percentage of time spent sniffing (Table 1).

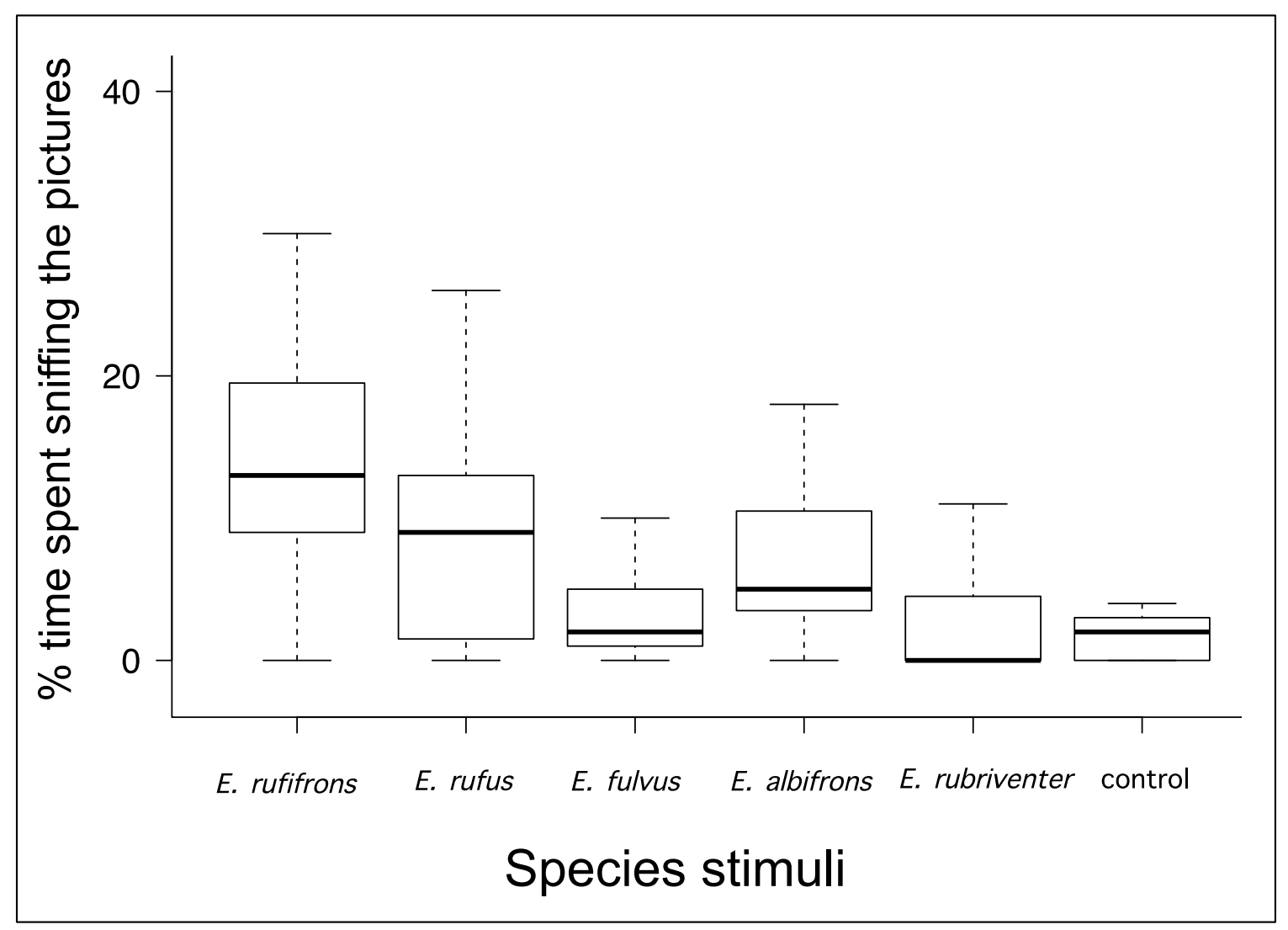

Figure 4. Boxplot of the percentage of time Eulemur rufifrons spent sniffing the pictures. Depicted are the median (black bars), interquartile range (boxes) and ranges (whiskers). 


\section{Discussion}

This study provides the first investigation of wild lemurs' abilities to discriminate between photographs of their own and closely related species. Our results indicate that $E$. rufifrons can differentiate visual cues of facial color patterns from different species. Interestingly, test subjects also spent more time sniffing during presentation of conspecific pictures, indicating that they also try to use olfactory cues in this context. Hence, multi-modal communication might play an important role in species recognition in these animals. Although there was no overall sex effect, we observed differences in the responses of males and females in time spent looking towards the pictures of visually different heterospecifics, which may suggest a potential role of sexual selection in the evolution of facial color variation in this species. However, there was no sex difference in time spent sniffing the pictures. The time spent looking as well as sniffing were negatively correlated with genetic distance between stimuli species and E. rufifrons, suggesting that genetic drift may have also influenced the evolution of facial color patterns in this species. These results therefore indicate that E. rufifrons has the ability to use facial color variation for species recognition and that there might be a potential simultaneous processing of olfactory and visual signals to differentiate conspecifics from heterospecifics in this species. We discuss the key results in more detail below.

Our study showed not only the ability of E. rufifrons for visual species recognition, but also that experimental designs such as the use of photographs can represent a feasible approach to test the ability of non-human primates for species recognition. Several studies already conducted experiments testing non-human primates' ability for visual recognition using photographs and were able to successfully demonstrate that their study species have the ability for such recognition. For instance, in Japanese macaques, Fujita (1987) showed pictures of conspecifics and heterospecifics in computer slide shows where the animals pressed a lever in order to change the slide and look at the next picture. Another experiment conducted on different species of macaques presented pictures of conspecifics and heterospecifics using different slides on a computer, where the slides were changed by the experimenter (Fujita et al. 1997). Similarly, Parr et al. (1999, 2000) also showed black-and-white portraits of chimpanzees on a computer screen to investigate the ability 
of these animals for kin and individual recognition. Experiments conducted in lemurs also used photographs containing faces of different individuals, which were presented in a square polystyrene panel to animals in cages (Marechal et al. 2010).

Our study also used photographs of different Eulemur species in order to investigate the ability of E. rufifrons for visual species recognition. Our experiments and those of other studies collected data on the duration the animals looked at the picture stimuli as response. Based on these durations, each study successfully determined the difference in attention that subjects payed for each presented stimulus, and therefore demonstrated their ability to discriminate different individuals (Fujita 1987, Fujita et al. 1997, Parr et al. 1999, 2000). Our experiment differed from others as the experimenter (HR) presented each picture stimulus directly to the focal individual because the study was conducted in the wild. Although we can not completely rule out animal distractions caused by the presence of a presenter during the experiments, we did not see any signs of such distractions during our experiments. Furthermore, the potential for distractions by the presenter was kept at minimum as all experiments were conducted by the same presenter wearing a white lab coat (see Appendix 2). The use of photographs is therefore a reliable tool for experimental studies investigating the ability for visual recognition in primates and minor difference in data collection protocols lead to similar results.

Individuals of E. rufifrons looked relatively longer at pictures of the genetically closer stimuli. Eulemur rufus looks very similar in facial appearance to E. rufifrons (Figure 1), which might explain the particular high attention E. rufifrons payed towards pictures of E. rufus. In contrast, individuals of E. rufifrons paid the least attention towards E. rubriventer pictures. More generally, the degree of visual differences between $E$. rufifrons and Eulemur species used as stimuli in this study corresponded to the genetic distance between the species and therefore suggests that random genetic drift might have played a role in the evolution of facial color pattern in eulemurs as well. Other studies such as those of Fujita (1987) also found that the responses of macaques were correlated with the genetic distance between the species. It was also suggested that responses of the subjects might be the result of morphological similarity in facial patterns between closely related species (Fujita 1987, Fujita et al. 1997). Similarly, the degree of visual differences 
between E. rufifrons and Eulemur species used as stimuli in this study corresponded to the genetic distance between the species as well as to the time E. rufifrons looked at each stimulus. We therefore suggest that random genetic drift might have played a role in the evolution of facial color pattern in eulemurs as well.

As interbreeding can occur in non-human primates (e.g. in macaques: Watanabe \& Mutsurama 1991; eulemurs: Rumpler 1975, Hamilton \& Buettner- Janusch 1977, Pastorini et al. 2001, Johnson 2002, 2007, Delmore et al. 2011), sexual selective pressure acting on the species level should occur to avoid potentially costly heterospecific mating. Species used as stimuli in this study are allopatric to E. rufifrons except from $E$. rubriventer, which occurs in sympatry with E. rufifrons in the east of Madagascar (Markolf \& Kappeler 2013). Eulemur albifrons and E. fulvus also occur in sympatry with E. rubriventer in the east of Madagascar. All three species (E. rufifrons, E. fulvus and E. albifrons) are visually very different from its sympatric congener, which suggests that visual signals such as facial color variation might play a role as a reproductive barrier in these species. When Eulemur species diverged, sexual selective pressures might have played a role in the evolution of visual signals in order to prevent interbreeding especially for sympatric congeners. Today all members of the former "E. fulvus group" are distributed in allopatry and we do not know their distribution during times of speciation (Markolf \& Kappeler 2013). Pronounced sexual dichromatism, striking differences in male coloration and the fact that females looked significantly shorter to pictures of visually different heterospecifics during our experiments than males suggest that there might be a potential ability to avoid interspecific mating in females of E. rufifrons and that sexual selection might have as well played a role in the evolution of facial color patterns in this species and in the genus Eulemur. It remains unclear why eulemurs frequently hybridize in their natural habitats. Thus, future experiments in hybrid zones or on (semi-) captive populations including hybrids could investigate whether individuals potentially avoid interbreeding using facial color variation.

The differences in responses between males and females found in our study might potentially also reflect mate preferences of females of E. rufifrons due to differences in color vision between sexes. Females can have polymorphic trichomacy or be dichromatic 
in color vision, whereas males are all dichromatic (Jacobs 2008). It has been suggested that Eulemur females having genetic polymorphic trichromacy in color vision can have the ability to perceive red and orange color (Sumner \& Mollon 2003). Studies have also shown that females of some species of Eulemur can distinguish and even show a preference for more colorful males (Cooper \& Hosey 2003). This variation in color vision may explain as well why the females tested in this study payed more attention to conspecific pictures. It might also explain the fact that female subjects tested in this study payed more attention, especially to E. rufifrons and E. rufus, as males of both species have this type of color in their crown (Figure 1). However, genetic analyses have to confirm whether the focal females have indeed polymorphic trichromatic color vision.

Interestingly, males paid more attention to males of E. albifrons, E. fulvus and E. rubriventer than females. Indeed, facial colors of these three species are dominated by dark face with light (white or light gray) patches (Figure 1). It has been suggested that contrasting colors such as black and white face masks might function for conspecific signaling in non-human primates (Caro 2009). As males of E. rufifrons show dichromatic color vision (Bradley \& Mundy 2008, Surridge et al. 2003), contrasting dark and light areas might be more important for dichromatic males than to polymorphic females. This may explain the stronger response of males of E. rufifrons towards the three species stimuli compared to females. Genetic polymorphism in color vision of females might have influenced the difference in responses between females and males during our experiments and might as well have played a role in the evolution of Eulemur facial color patterns.

Finally, studies have shown that animal species can process and use signals of different modalities for species recognition (Ettlinger \& Wilson 1990, Matyjasiak 2004, Proops \& McComb 2012). For example, male blackcaps (Sylvia atricapilla) were shown to be able to associate acoustic and visual sensory modalities matching species-specific songs and species-specific plumage to distinguish their own species from sympatric heterospecifics (Sylvia borin) during playback experiments presented with stuffed models of conspecifics and heterospecifics (Matyjasiak 2004). Moreover, domestic horses (Equus caballus) were also shown to be able to match visual-auditory sensory modalities to distinguish familiar from unfamiliar humans when they were presented to humans in 
playback experiments (Proops \& McComb 2012). The use of different sensory modalities for species recognition has also been shown in non-human primates (Evans et al. 2005, Sliwa et al. 2011, Adachi et al. 2006). For instance, it has been shown that tufted capuchin monkeys (Cebus apella) can use two different sensory modalities (auditoryvisual matching) for species recognition. Sliwa et al. (2011) also demonstrated that rhesus macaques (Macaca mulatta) are able to use visual and acoustic sensory modalities (voiceface matching) to distinguish familiar conspecifics and humans presented during playback experiments combined with different images on a screen. Similarly, infant Japanese macaques (Macaca fuscata) have the ability to use auditory and visual sensory modalities by matching voice and face during playback experiments presented simultaneously with photographs of their conspecifics and humans (Adachi et al. 2006).

Up to now, no such study was conducted in lemurs for species recognition, but a study by Kulahci et al. (2014) showed that Lemur catta is capable of multi-modal (olfactory-auditory matching) individual recognition. The use of olfactory signals for species recognition in some eulemurs has been already shown (Harrington 1979, delBarco-Trillo et al. 2012). Whether E. rufifrons is capable of multi-modal species recognition was not explicitly tested in this study as we only investigated one sensory modality at a time. However, our results showed that while E. rufifrons processed visual cues during the experiment they also sniffing the stimuli. Thus, E. rufifrons might be able to use two different sensory modalities (olfactory-visual matching) at the same time to discriminate their own species from different ones. This suggests potential multi-modal species recognition in this species. However, future experiments presenting signals of two different modalities are required to confirm if they have multi-modal species recognition ability. 


\section{Conclusion}

This study revealed the importance of facial color variation as visual signals for species recognition in E. rufifrons. Females of E. rufifrons may also be more careful in differentiating conspecifics from heterospecifics due to costs of heterospecific mating. Our findings suggest a potential role of sexual selection as well as genetic drift influencing the evolution of facial color variation in eulemurs. Moreover, this study showed clear evidence of visual species recognition abilities in wild redfronted lemurs; whatever factors might have influenced the evolution of facial variation in eulemurs. However, it remains unclear which specific components of the facial cues represent an importance for E. rufifrons for species recognition, and this requires further investigations in order to determine the essential cue(s), such as colors, patterns or a combination of both, used by eulemurs to recognize their own from different species.

\section{Acknowledgements}

We thank the Malagasy Ministère de l'Environnement et des Eaux et Forêts, the Departement de Biologie Ecologie et Conservation Animale de l'Université d'Antananarivo, the Centre National de Formation, d'Etudes et de Recherche en Environnement et Foresterie de Morondava, Madagascar National Parks and the Centre ValBio Ranomafana for allowing and supporting research in Kirindy Forest and Ranomafana National Park. We are grateful to Daniela Fuchs for helping with the video analyses, as well as Stephen Nash for the illustraions of Eulemur faces. We thank the German Academic Exchange Service (DAAD) for supporting and funding this study. 


\section{Chapter 3}

\section{Evolution of facial color complexity in lemurs}

with Peter M Kappeler and Claudia Fichtel

To be submitted to Proceedings of the Royal Society B: Biological Sciences 


\section{Abstract}

Primates' remarkable variation in skin and pelage coloration has been linked to several social and ecological factors. As primates also exhibit great variation in facial color patterns, recent studies have examined the role of sociality and ecology in the evolution of facial color patterns in New and Old World primates as well, but these studies also identified differences between these two main groups of anthropoids, for example in the effect of group size. The factors influencing facial color patterns in the third large primate radiation, the lemurs of Madagascar, may therefore shed additional light on convergences and divergences in this context. To this end, we analyzed photographs of the complete face of 65 lemur species. Photographs were divided into 11 areas and 6 regions in order to categorize hair length, hair and skin coloration and color brightness. Social variables investigated were group size, social organization and the number of sympatric species. The influence of ecological factors was taken into account by incorporating climatic factors, such as minimum rainfall, maximum temperature and upper elevation of a species' range. Phylogenetically controlled analyses revealed that group size and the number of sympatric species did not influence the evolution of facial color complexity in lemur species. Climatic factors, however, influenced pigmentation and hair length in a few regions of the face. Phylogenetic signals were moderate to high for each model tested. Thus, social variables might have had relatively little influence on the evolution of facial color patterns in lemurs, whereas climatic factors might have marginally influenced their evolution. The strong influence of phylogeny suggests that facial color patterns of lemurs might be mainly the result of random genetic drift. Thus, the evolution of facial color patterns in the three great primate radiations exhibits only few convergent patterns.

Key words: lemurs, primates, facial color variation, sociality, climate, species recognition 


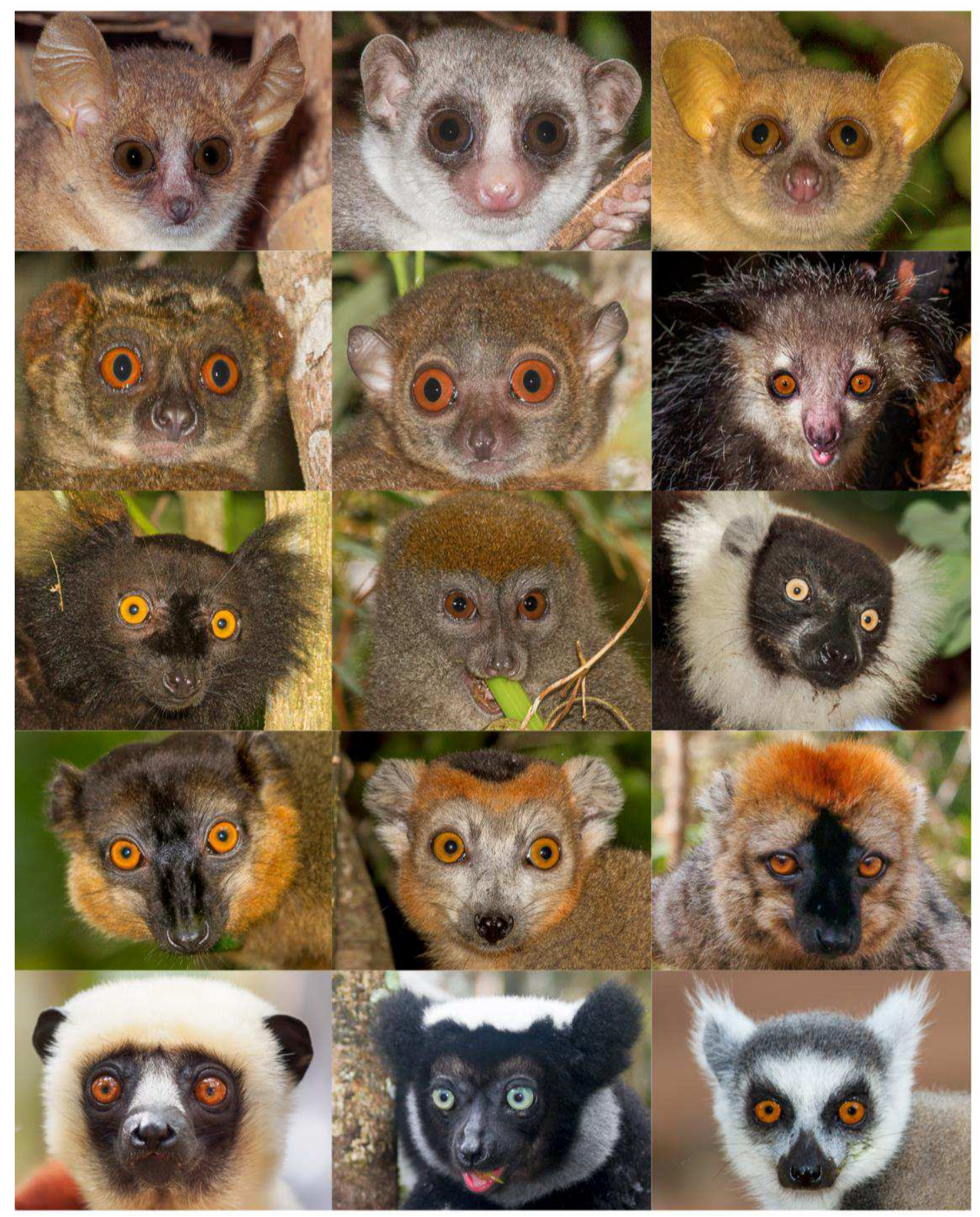

Figure 1. Examples of facial color patterns diversity in lemurs. Presented are (left to right): nocturnal species composed by: Microcebus murinus, Cheirogaleus medius, Mirza coquereli, Avahi laniger, Lepilemur dorsalis, Daubentonia madagascariensis, cathemeral species: Eulemur macaco, Hapalemur griseus, Varecia variegata, Eulemur collaris, Eulemur coronatus, Eulemur rufifrons; diurnal species: Propithecus coquereli, Indri indri, Lemur catta. (All photographs taken by M. Markolf). 


\section{Background}

Fur, skin and plumage coloration are highly diverse in animals and can take on many functions, such as communication, thermoregulation or predation avoidance (Endler 1978, 1990; Ortolani 1999; Stoner et al. 2003a; Burtt \& Ichida 2004; Prum \& Torres 2004; Caro 2005; Stevens 2007; Stevens \& Merilaita 2009; Stoddard \& Prum 2011; Santana et al. 2012, 2013). For example, plumage coloration in birds can provide camouflage (ruffed grouse, Bonasa umbellus, Furtman 2004, Thayer 1896) or information used in mate choice (cattle egrets, Bubulcus ibis ibis, Krebs et al. 2004). Chameleons use their coloration for background matching to avoid predators (e.g. in dwarf chameleons, Bradypodion taeniabronchum, Stuart-Fox et al. 2008, 2009). In mammals, variation in pelage coloration can also reduce detection by predators (e.g. in oldfield mice, Peromyscus polionotus, Belk \& Smith 1996), improve thermoregulation (e.g. dark pelage of tropical bovids, Stoner et al. 2003b) or serve as a signal in visual communication (e.g. facial color pattern in New World monkeys, Santana et al. 2012). Accordingly, a combination of social and ecological selective pressures has driven the enormous variation in animal coloration (Stoner et al. 2003b, Hoekstra et al. 2005, Caro 2005, Caro et al. 2012).

Among mammals, primates exhibit remarkable variation in skin and pelage coloration (Bradley \& Mundy 2008, Sumner \& Mollon 2003), perhaps because they exhibit more variation in ecology, activity period and social systems than most other mammalian orders. Primates are therefore an excellent group for elucidating factors influencing variation in coloration within and among species (Caro 2005, Bradley \& Mundy 2008, Higham 2009). Previous studies revealed that intra- or interspecific variation in facial hair or skin color as well as hair length in primates may have evolved in response to social and ecological pressures (Santana et al. 2012, 2013; Allen \& Higham 2015). Whereas intraspecific variation in facial coloration has been suggested to play a role in social interactions because it contains information about an individual's identity, status and condition (Burt \& Perrett 1995, Parr et al. 1998, Parr \& Taubert 2011, Gerald 2001; Dufour et al. 2006, Tibbets \& Dale 2007, Yovel \& Freiwald 2013; Santana et al. 2012, 2013; Allen \& Higham 2015), interspecific variation has been suggested to reflect social and ecological adaptations. For example, in Neotropical primates, more 
variation in facial color pattern was found in species living in smaller groups and explained by the possibility of greater reliance on facial expression in species living in larger groups (Santana et al. 2012). However, in Old World primates, the opposite patterns were found because species in larger groups exhibit more variation in their facial color patterns (Santana et al. (2013). Interspecific variation in facial color pattern as found in New and Old World monkeys has also been linked to the need for reliable species recognition. Comparative studies revealed that species living with more sympatric congeners evolved indeed more complex facial color patterns than species living without or with fewer close relatives (Santana et al. 2012, 2013).

Variation in facial hair length and color has also been linked to ecological factors. For example, both New and Old World primates with longer facial hair occur more often in colder areas, and those exhibiting darker facial areas occur in denser forests rather than in more open habitats (Santana et al. 2012, 2013). Moreover, species occurring closer towards the equator sport darker coloration in some regions of the face (crown and eye mask), lighter coloration in others (nose and mouth), and shorter facial hair (Santana et al. 2012). Hence, facial color pattern complexity and variation in Old World and New World primates exhibits some convergent patterns, but they also diverge from each other in response to some social selective factors.

The adaptive radiation of primates endemic to Madagascar (Lemuriformes) provides an opportunity for an independent test of these relationships because they evolved in isolation from other primates for more than 50 million years (Yoder et al. 1996). With currently more than 100 recognized species, lemurs are taxonomically diverse, they occupy a range of different forest habitats from dry to humid forests (Muldoon \& Goodman 2010, Mittermeier et al. 2010), and they exhibit all major forms of social organizations found among anthropoid primates (Kappeler 1997, 2012). They also exhibit variation in activity patterns, including nocturnal, cathemeral and diurnal species (Santini et al. 2015). Although, only two lemur genera occur in sympatry with congeners (one sympatric congener per species per location) as for example in Eulemur and in some mouse lemurs (Microcebus spp.), most of the other species live at least in sympatry with one or more species belonging to the same family (Mittermeier et al. 2010). Most importantly, lemurs exhibit spectacular diversity in pelage coloration, particularly, in 
facial color patterns across families and species (Figure 1). Diurnal or cathemeral species have dichromatic vision, but some females exhibit polymorphic trichromacy, allowing them to perceive red and orange colors (Jacobs 1994, 2008, Surridge et al. 2003, Bradley \& Mundy 2008). Although some nocturnal species lack dichromatic color vision (Veilleux et al. 2013), differences in the brightness or contrasts of face patches might be conspicuous for them. Thus, from the perception side, variation in color patterns should be meaningful for lemurs, although this assumption remains to be experimentally demonstrated.

The aim of this study was therefore to investigate factors shaping facial color and hair patterns in lemurs. Based on the results of previous studies of New and Old World monkeys (Santana et al. 2012, 2013), we predicted that facial hair should be longer in lemurs inhabiting colder areas, and hair and skin coloration in different facial regions should be darker in species occurring in dense forest habitats. Furthermore, we predicted that variation in facial color patterns in lemurs should be related to group size, and that variation in facial coloration should increase with the number of sympatric species.

\section{Methods}

\section{Variation in facial patterns}

To investigate facial pattern complexity in lemurs, photographs from private collections, photographers and the Internet (All the World's Primates (http://www.alltheworldsprimates.org) and Arkive (http://www.arkive.org)) were chosen in order to quantify and categorize hair and skin color variation as well as hair length. Two to ten photographs with high resolution per species were chosen and categorized using Adobe Photoshop CS3 with the highest brightness of the screen. Each picture contained the photograph of one individual looking towards the camera where all areas of the face were well visible. Only photographs of adults were taken and categorized (Figure 1). We only used photographs of adult males from Eulemur species because they exhibit sexual dichromatism, with males being the more colorful sex. We collected data from a total number of 65 lemur species and analyzed 522 photographs. 


\section{Categorization of hair and skin color variation}

Our categorization followed the procedures described by Santana et al. (2012, 2013), who used facial hair color, skin color and hair length to investigate facial pattern complexity. In order to categorize facial coloration in lemurs, each photograph was first divided into 11 areas (Figure 2). For each area, we determined hair length (classified as either depilated (or no hair), short, medium to long, Appendix 3), hair coloration (either white, agouti, brown, grey or yellow) and skin coloration (classified as depigmented (no hair), pigmented (pink skin, mottled, or gold skin) to hyper-pigmented (black or brown), Appendix 4). For hair coloration, each color was additionally classified as light, medium or dark, depending on the intensity of pigmentation (Appendix 5). Furthermore, in order to determine the intensity of brightness (from light to dark) in facial hair, we divided the face into 6 regions (crown, forehead, eyes, ears, mouth and face margins, (Figure 2)), and we determined the most predominant color ( $~ 90 \%$ of all color) in each region of the face. Additionally, we categorized hair length per region (Figure 2). 

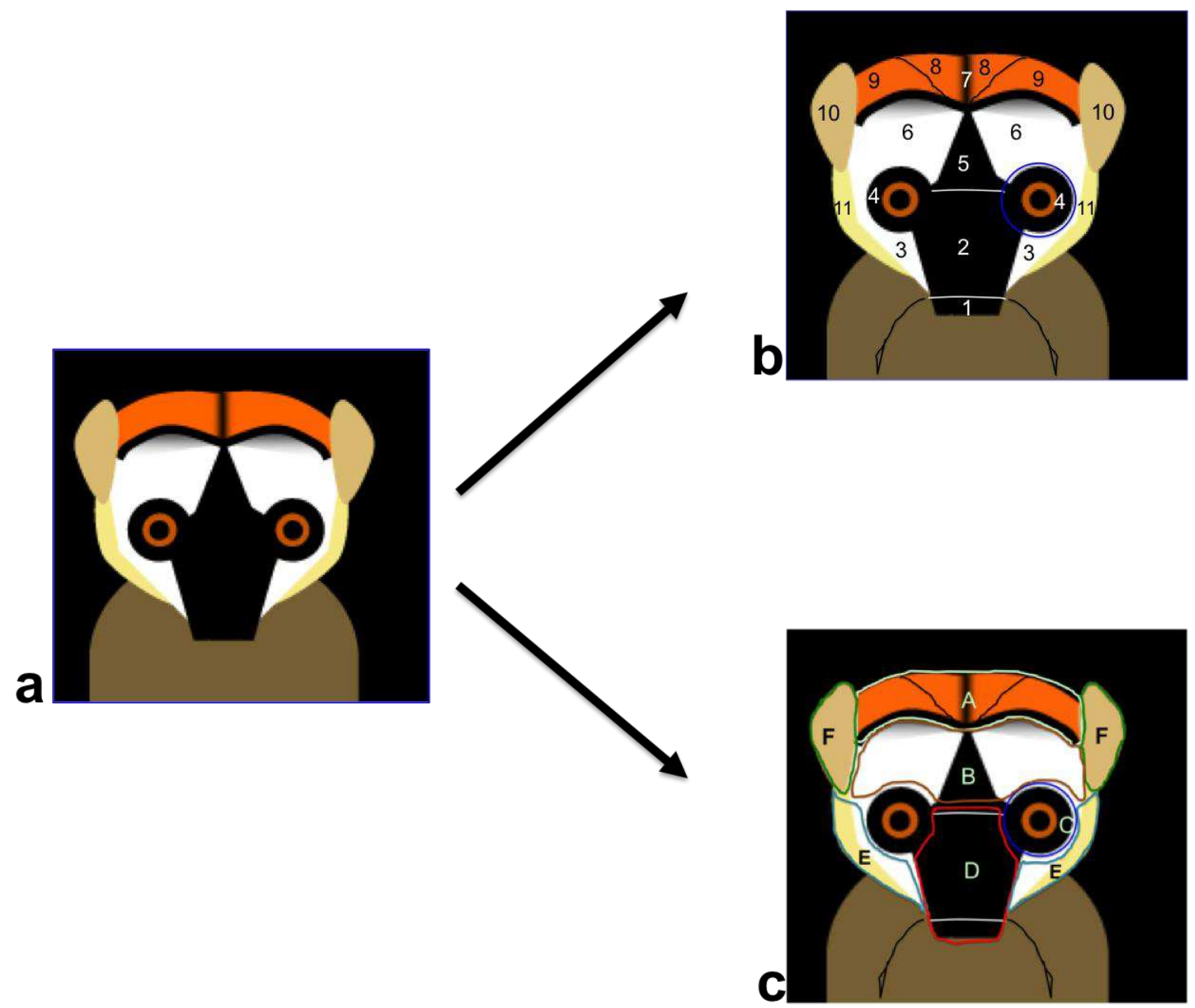

Figure 2. Schematic face (a) used to divide lemur faces into different areas (b) and regions (c) used to assess hair and skin color as well as hair length variation.

(a) Schematic face of a lemur.

(b) Face of a lemur divided in 11 areas: $1=$ nose; $2=$ area above the nose; $3=$ area below the eyes; $4=$ eye contour (in blue); $5=$ center area above the eyes; $6=$ forehead; $7=$ center of the crown; $8=$ first area of the crown; $9=$ second area around the crown; $10=$ ears; $11=$ face margins.

(c) Face of the lemur divided in 6 regions: $\mathrm{A}=$ crown $($ areas $7+8+9)$; $\mathrm{B}=$ forehead (areas 5+6); $\mathrm{C}=$ eyes (area 4); $\mathrm{D}=$ nose and mouth (areas 1+2); $\mathrm{E}=$ face margins $(\operatorname{areas} 3+11) ; \mathrm{F}=$ ears (area 10). All the areas are here combined into regions. 


\section{Ecological and social variables}

We collected data on Malagasy ecoregions and habitats based on their distributions and a classification made by Muldoon and Goodman (2010). Ecoregions were classified as follows: spiny thicket, succulent woodland, dry deciduous forest, subhumid forest and humid forest (Muldoon \& Goodman 2010). We also determined the upper elevation range, the minimum rainfall and the maximum temperature for each ecoregion where a species occurs (Muldoon \& Simons 2007) and calculated an average value if a given species occurred in different ecoregions. As social factors, we collected data on social organizations (solitary, pair living or group living), on average group size and activity patterns (nocturnal, cathemeral or diurnal activities) for each species (Appendix 7). Additionally, we determined the number of sympatric species for each species in each ecoregion and determined the total number of sympatric species at the family level (and genus level, Appendix 8) based on the species compilation in Muldoon \& Goodman (2010).

\section{Statistical analyses}

\section{Phylogenetic tree}

For a comparative phylogenetic analysis of variation in facial patterns, we obtained a phylogenetic tree of the species included in this study from genetic data (Figure 3). For tree construction, we assembled published sequence data of 65 lemur using Genbank (NCBI) for five mitochondrial (12S, 16S, COX2, ND3-4) and six nuclear loci (IRPB, MCR1, ABCA1, ADORA3, FGA, NRAMP). Not all species had sequence data available for all loci. Missing nucleotide data were coded as missing data (“?”) and aligned using the ClustalW algorithm in Mesquite. Alignments were checked by eye. We used MrBayes to calculate a consensus tree using a partitioned model. Substitution models were calculated using JModelTest. The MCMC algorithm was run for 10,000,000 generations with a sampling frequency of 1000 and burn-in of $25 \%$, resulting in 7500 trees to calculate the consensus tree. Due to the lack of genetic data for some species (Phaner, Hapalemur, Prolemur and Propithecus candidus) the consensus tree was subjected to 
three manual changes conducted in MESQUITE 3.04 in order to create a robust and "up to date" final phylogeny for further comparative analyses. First, both Phaner species were placed as sister clade to all other Cheirogaleidae. Prolemur and Hapalemur were made monophyletic (excluding Lemur catta from this clade) and Propithecus candidus was manually added to the tree as no sequence data were available for this taxon. All manual changes were made in accordance with the most recent and complete phylogeny by Hererra and Dávalos (2016). 

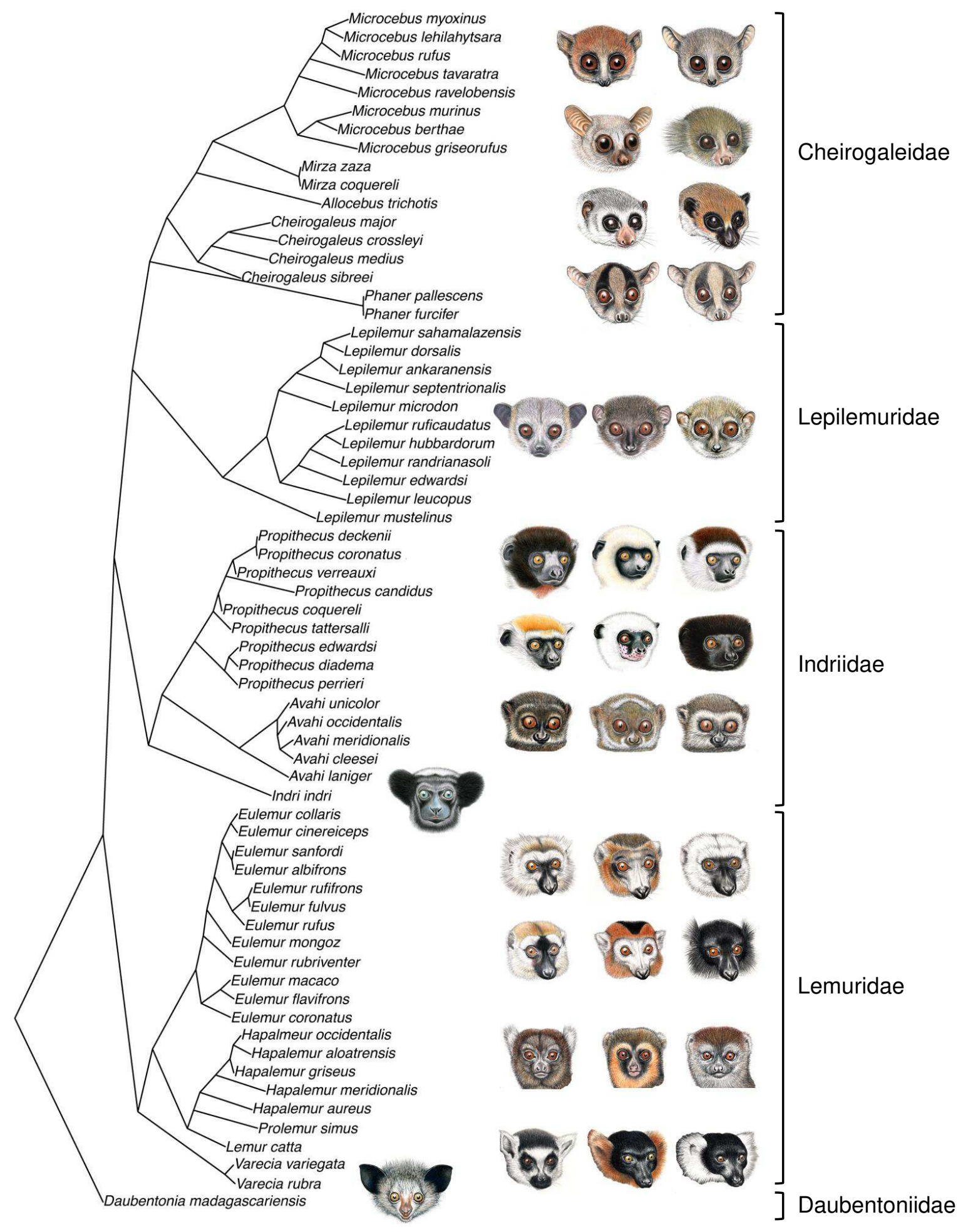

Figure 3. Phylogenetic tree of all lemur species used for Phylogenetic comparative analyses in this study. 


\section{Statistical analyses}

Because the upper elevation range, the minimum rainfall and the maximum temperature for each ecoregion are highly correlated (Pearson's correlation: minimum rainfall - maximum temperature: $\mathrm{rho}=-0.86, \mathrm{p}<0.001$; minimum rainfall - upper elevation: $r h o=-0.81, \mathrm{p}<0.001$; maximum temperature - upper elevation: rho $=-0.89$, $\mathrm{p}<0.001$; maximum temperature - upper elevation: $\mathrm{rho}=-0.89, \mathrm{p}<0.001 ; \mathrm{N}=65$ ), we run a Principal Component Analyses, yielding one factor capturing climatic variation (Bartlett's test of sphericity: $\chi^{2}=181.54, \mathrm{df}=3 ; \mathrm{p}<0.001$; Kaiser-Meyer-Olkin=0.64). Because variation in this climatic factor also correlated with habitat (rainy or dry forest; PGLS: $\lambda=$ 0.32 ; estimate $\pm \mathrm{SE}:-2.68 \pm 0.18, \mathrm{p}<0.001$ ), we included only the climate factor in the models below.

For each facial color trait, facial color pattern complexity (total number of different hair colors in all areas), skin pigmentation as well as hair length in each region, we determined the median from all scored pictures for each species. We then fitted phylogenetic generalized least-squares (PGLS) regressions, using a Brownian motion model to test for evolutionary relationships between facial, social and ecological variables, while controlling for phylogenetic effects (Chatterjee et al. 2009). Facial color traits were used as response variables. As fixed factors we included "climate", average group size and the number of sympatric species at the family level (as a crude measure of the risk of heterospecific mating). We could not use the number of sympatric congeneric species to operationalize this risk because only some Eulemur ssp. and Microcebus ssp. occur in sympatry with a congener. Because activity pattern correlated with ecological factors, with nocturnal species occurring in hotter and dryer habitats (Appendix 9; PGLS: $\lambda=0$, cathemeral vs diurnal species: $p=0.074$, cathemeral vs nocturnal species: $p=0.014$ ), we did not include activity pattern in the models. Facial color complexity, average group size and number of sympatric species were square-root transformed. Phylogenetic analyses were conducted using functions in the APE, GEIGER and NMLE packages in R 3.2.2 (R Core Development Team). 


\section{Results}

\section{Facial pattern complexity, sociality and species recognition}

Facial color complexity was independent of the number of sympatric species at the family level (Table 1, PGLS: $\lambda=0.671, \mathrm{p}=0.673, \mathrm{~N}=65$ ). Group size had no effect on facial color complexity (Table 1, PGLS: $\lambda=0.671, \mathrm{p}=0.095, \mathrm{~N}=65$ ).

Table 1. Results of the PGLS investigating social and ecological factors influencing facial

\begin{tabular}{lllrrr}
\hline Model & Response variables & Predictor variables & Estimate & SE & p-value \\
\hline PGLS & Facial color & Intercept & 2.28 & 0.18 & $<0.001$ \\
& complexity & Climate & 0.04 & 0.02 & 0.05 \\
& & Number of sympatric species at & 0.01 & 0.04 & 0.67 \\
& & family level & -0.13 & 0.08 & 0.09 \\
\hline
\end{tabular}

color pattern complexity.

\section{Facial regions: pigmentation, hair length and ecology}

Climate did neither influence hair color and hair length on the crown or the forehead, nor hair length in the face margins and hair color of the ears (Table 2, 3). However, climate was significantly related to pigmentation of the area around the eyes and hair color of the face margins. Specifically, species occurring in colder regions had darker color in the area around the eyes (Table 2, PGLS: $\lambda=0.504, \mathrm{p}<0.01, \mathrm{~N}=65$ ) and darker hair in the face margins (Table 2, PGLS: $\lambda=0, \mathrm{p}<0.05, \mathrm{~N}=65$ ). Additionally, species occurring in colder areas had longer hair on the ears (Table 3, PGLS: $\lambda=0.753$, $\mathrm{p}<0.01, \mathrm{~N}=65)$. Overall, ecological variables influenced some color variation in facial regions in lemurs, and all models showed considerable phylogenetic signal. 
Table 2. Results of the PGLS investigating social and ecological factors influencing

\begin{tabular}{|c|c|c|c|c|c|c|}
\hline Model & \multicolumn{2}{|c|}{$\begin{array}{l}\text { Response } \\
\text { variable }\end{array}$} & Predictor variables & Estimate & $\overline{\mathrm{SE}}$ & p-value \\
\hline \multirow[t]{4}{*}{ PGLS } & \multirow{4}{*}{\multicolumn{2}{|c|}{ Crown }} & Intercept & 3.10 & 0.30 & $<0.001$ \\
\hline & & & Climate & -0.07 & 0.06 & 0.24 \\
\hline & & & $\begin{array}{l}\text { Number of sympatric species at family } \\
\text { level }\end{array}$ & -0.05 & 0.09 & 0.60 \\
\hline & & & Group size & -0.03 & 0.15 & 0.87 \\
\hline \multirow[t]{4}{*}{ PGLS } & \multirow{4}{*}{\multicolumn{2}{|c|}{ Forehead }} & Intercept & 3.12 & 0.34 & $<0.001$ \\
\hline & & & Climate & -0.13 & 0.07 & 0.06 \\
\hline & & & $\begin{array}{l}\text { Number of sympatric species at } \\
\text { family level }\end{array}$ & -0.04 & 0.10 & 0.72 \\
\hline & & & Group size & -0.20 & 0.17 & 0.24 \\
\hline \multirow[t]{4}{*}{ PGLS } & \multirow{4}{*}{\multicolumn{2}{|c|}{ Eyes }} & Intercept & 2.97 & 0.27 & $<0.001$ \\
\hline & & & Climate & -0.10 & 0.35 & 0.004 \\
\hline & & & $\begin{array}{l}\text { Number of sympatric species at } \\
\text { family level }\end{array}$ & 0.10 & 0.06 & 0.09 \\
\hline & & & Group size & 0.08 & 0.12 & 0.53 \\
\hline \multirow[t]{4}{*}{ PGLS } & \multirow{4}{*}{\multicolumn{2}{|c|}{ Face margins }} & Intercept & 2.61 & 0.31 & $<0.001$ \\
\hline & & & Climate & -0.13 & 0.06 & 0.04 \\
\hline & & & $\begin{array}{l}\text { Number of sympatric species at } \\
\text { family level }\end{array}$ & -0.10 & 0.09 & 0.27 \\
\hline & & & Group size & -0.10 & 0.15 & 0.51 \\
\hline \multirow[t]{8}{*}{ PGLS } & \multirow{8}{*}{ Ears } & Hair & Intercept & 3.61 & 0.61 & $<0.001$ \\
\hline & & color & Climate & -0.17 & 0.11 & 0.15 \\
\hline & & & $\begin{array}{l}\text { Number of sympatric species at } \\
\text { family level }\end{array}$ & -0.03 & 0.17 & 0.88 \\
\hline & & & Group size & -0.47 & 0.24 & 0.06 \\
\hline & & Skin & Intercept & 1.83 & 0.19 & $<0.001$ \\
\hline & & color & Climate & -0.009 & 0.03 & 0.78 \\
\hline & & & $\begin{array}{l}\text { Number of sympatric species at } \\
\text { family level }\end{array}$ & -0.08 & 0.04 & 0.07 \\
\hline & & & Group size & 0.33 & 0.12 & 0.009 \\
\hline
\end{tabular}

pigmentation in the facial regions. 
Table 3. Results of the PGLS investigating social and ecological factors influencing hair

\begin{tabular}{|c|c|c|c|c|c|}
\hline Model & $\begin{array}{l}\text { Response } \\
\text { variables }\end{array}$ & Predictor variables & Estimate & SE & p-value \\
\hline \multirow[t]{4}{*}{ PGLS } & Crown & Intercept & 1.64 & 0.11 & $<0.001$ \\
\hline & & Climate & 0.007 & 0.01 & 0.47 \\
\hline & & $\begin{array}{l}\text { Number of sympatric species at } \\
\text { family level }\end{array}$ & 0.02 & 0.02 & 0.31 \\
\hline & & Group size & 0.01 & 0.04 & 0.71 \\
\hline \multirow[t]{4}{*}{ PGLS } & Forehead & Intercept & 1.32 & 0.12 & $<0.001$ \\
\hline & & Climate & -0.02 & 0.13 & 0.20 \\
\hline & & $\begin{array}{l}\text { Number of sympatric species at } \\
\text { family level }\end{array}$ & 0.03 & 0.02 & 0.26 \\
\hline & & Group size & 0.09 & 0.05 & 0.10 \\
\hline \multirow[t]{4}{*}{ PGLS } & Eyes & Intercept & 1.42 & 0.09 & $<0.001$ \\
\hline & & Climate & 0.0006 & 0.003 & 0.84 \\
\hline & & $\begin{array}{l}\text { Number of sympatric species at } \\
\text { family level }\end{array}$ & -0.004 & 0.007 & 0.57 \\
\hline & & Group size & -0.01 & 0.02 & 0.62 \\
\hline \multirow[t]{4}{*}{ PGLS } & Face margins & Intercept & 1.44 & 0.13 & $<0.001$ \\
\hline & & Climate & -0.0008 & 0.004 & 0.85 \\
\hline & & $\begin{array}{l}\text { Number of sympatric species at } \\
\text { family level }\end{array}$ & -0.0002 & 0.01 & 0.99 \\
\hline & & Group size & 0.08 & 0.04 & 0.04 \\
\hline \multirow[t]{4}{*}{ PGLS } & Ears & Intercept & 0.91 & 0.20 & $<0.001$ \\
\hline & & Climate & -0.06 & 0.02 & 0.002 \\
\hline & & $\begin{array}{l}\text { Number of sympatric species at } \\
\text { family level }\end{array}$ & 0.03 & 0.04 & 0.39 \\
\hline & & Group size & 0.2 & 0.08 & 0.02 \\
\hline
\end{tabular}

length in the facial regions. 


\section{Discussion}

This study investigated the influence of social and ecological variables on the diversity of facial color pattern in lemurs. Facial color pattern complexity in lemurs could not be explained by social variables. Neither the number of sympatric species nor group size influenced facial color pattern complexity. Furthermore, species occurring in colder areas of the island have darker color in the region around the eyes, darker hair in the face margins but also longer hair on the ears. In addition, we found a moderate to high phylogenetic signal suggesting an important impact of phylogeny on the evolution of facial color patterns in lemurs.

\section{Facial pattern complexity and sociality}

Since heterospecific mating is costly, species recognition may serve as a premating isolation mechanism to avoid costly interbreeding (Coyne 1992, Gray \& Cade 2000, Fujita 1987, Fujita et al. 1997). Accordingly, it has been proposed that the diversity in facial color patterns in New World and Old World primates has evolved in the context of species recognition, with species occurring with more sympatric heterospecifics evolving more complex facial patterns (Santana et al. 2012, 2013). In lemurs in contrast, only some Eulemur ssp. and Microcebus ssp. occur in sympatry with only one sympatric congener each, and the number of sympatric species at the family level did not influence facial color complexity. Since the risk of heterospecific mating is likely higher among congeners, and most lemurs occur in allopatry with their congeners, there might be only a weak selective pressure on facial color complexity as cues for reliable species recognition in this radiation of primates. However, lemurs can use variation in facial color patterns to discriminate between species, with brown lemurs (E. fulvus) and black lemurs ( $E$. macaco) discriminating between pictures of their own species and heterospecifics (familiar and unfamiliar con- and heterospecifics; Marechal et al. 2010). Thus, although facial color patterns in lemurs might not have evolved in the context of species recognition, this does not necessarily mean that cues of facial color patterns cannot be used secondarily for species recognition. 
Facial color patterns have also been linked to group size, with New World monkeys living in smaller groups exhibiting more complex facial color pattern, whereas Old World monkeys exhibit the opposite effect (Santana et al. 2012, 2013). In lemurs, group size did not influence facial color pattern complexity. Therefore, from a comparative perspective, it is questionable whether group size has a systematic functional effect on primate facial color complexity at all. Higher complexity in facial color patterns might be rather related to facial mobility in primates and the ability for facial expression (Santana et al. 2014) than to group size. Indeed, larger primates have more expressive faces (Dobson 2009, Santana et al. 2014), and primates with lower facial mobility or less expressive faces were shown to have higher facial complexity (Santana et al. 2014).

It has been argued that complex facial color patterns potentially allow greater intraspecific and interspecific variation, facilitating recognition at the level of individuals or species (Santana et al. 2013, 2014). Because lemurs have reduced facial mobility and ability for facial expressions among the species investigated so far (e.g. in geladas (Mancini et al. 2013), rhesus monkeys (Ghazanfar \& Logothetis 2003), chimpanzees (Parr et al. 2008), ring-tailed lemurs (Palagi et al. 2014)), they should show the greatest facial color complexity according to this notion. Moreover, smaller species should be more complex in facial pattern than larger ones. A direct comparison between facial complexity among published studies is difficult as the number of facial areas and color categories varied across studies, but a comparison of mean facial color complexity of catarrhine and strepsirrhine families indicated indeed higher facial color complexity in lemurs (Cheirogaleidae $=4,91$, Daubentoniidae $=5,30$, Indriidae $=3,20$, Lemuridae $=$ 4,16, Lepilemuridae $=3,33$; Catarrhines (from Santana et al. 2013): Cercopithecinae $=$ $3,54$, Colobinae $=2,60$, Hominidae $=1,50$, Hylobatidae $=2,21)$. Thus, the fact that we found no influence of group size on facial color complexity in lemurs might be related to their reduced ability to communicate with facial expressions. Additionally, among lemurs, there is no indication for smaller species, such as the Cheirogaleidae, being more complex in facial color pattern than larger species such as Propithecus, Indri or Eulemur. Future studies should therefore look at intraspecific variation to identify the influence of individual recognition for the evolution of primate facial color complexity (cf. Tibbets \& Dale 2007). 
Compared to other primates, lemurs differ in modal social organization and group size from other primates. Most lemur species live in much smaller groups (Kappeler \& Heymann 1996, Kappeler 1997, 1999, Kappeler 2012) than colobines (Sterck 2012), cercopithecines (Cords 2012) and apes (Watts 2012). Only the Lemuridae exhibit group sizes of up to 15 individuals (Kappeler \& Heymann 1996, Kappeler \& Fichtel 2015). In New World monkeys, small group size was associated with an increase in facial color complexity, however (Santana et al. 2012). Thus, the much larger proportion of species that do not live in groups may explain why group size did not have an effect on lemur facial color complexity. In addition, the evolution of facial pattern might also be driven by other factors not investigated in this study, such as pathogen resistance or mate choice (Cooper \& Hosey 2003, Setchell 2005, Waitt et al. 2003). Finally, we found moderate to high values of Pagel's lambda in all models, indicating a strong effect of phylogeny on the diversification of lemur facial patterns. Hence, for the time being, genetic processes such as drift might best explain the evolution of facial color complexity in lemurs.

\section{Facial pigmentation, hair length and ecology}

It has been suggested that environmental factors such as habitat type or climate can affect fur coloration and hair length in mammals (West \& Packer 2002, Stoner et al. 2003b, Caro 2005). Coat color in primates, for example, has evolved under Gloger's rule (Gloger 1833), where darker pelage colors are found more often in species occurring in forested habitats (Kamilar \& Bradley 2011). Hair length varies according to the "hair rule" (Rensch 1938), with species living in colder areas having longer and thicker hair (Santana et al. 2012, 2013). Our results partly support both rules. Although we found no correlation between climate and hair color or length on the crown and on the forehead, climatic factors were associated with increased pigmentation in the area around the eyes and in the face margins. Additionally, species from colder areas of Madagascar tend to have longer hair on the ears. Madagascar's climate is highly diverse (Jury 2003, Kamilar \& Muldoon 2010), and it has been suggested that warmer regions on the island are characteristic of more open and dry forests, and at lower altitudes (Goodman \& Ganzhorn 2004, Muldoon \& Simons 2007, Goodman et al. 2009, Goodman \& Muldoon 2010, Kamilar \& Muldoon 2010). Thus, lemur species occurring in eastern, colder and more 
forested habitats developed darker hair in the face margins and darker color around the eyes in support of Gloger's rule, and longer hair in the ears following the hair rule (Rensch 1938). However, pigmentation and hair length of the other facial areas might have evolved in response to genetic drift or other selective pressures not investigated in this study. For example, selective pressures related to predator avoidance, such as crypsis, countershading, disruptive coloration or background matching may have played a role in the evolution of pelage coloration of the body (Caro 2005, Bradley \& Mundy 2008, Kamilar \& Bradley 2010), and they might be at work here as well.

\section{Conclusions}

This is the first study investigating the evolution of facial pattern complexity in the independent adaptive radiation of lemurs, the endemic primates of Madagascar. We found that lemur facial variation was not influenced by social variables and only marginally by climatic or ecological factors. Comparative analyses indicated a strong influence of phylogeny and genetic drift acting on the evolution of lemur facial patterns, perhaps reflecting the relatively recent and rapid divergence of lemurs. Moreover, and in contrast with previous studies of New and Old World monkeys, group size was unrelated to facial color complexity in primates. Thus, the evolution of facial color and hair patterns in primates is characterized by little convergence.

\section{Acknowledgements}

We thank Matthias Markolf for his great help with the phylogenetic tree. We thank Anna Gamero, Anna Schnoell, Daniel Austin, David Haring, Elke Zimmermann, Erik Patel, Shinichiro Ichino, Iris Dröscher, Kira Delmore, Klara Kittler, Mamisolo Hilgartner, Marine Joly, Matthias Markolf, Melanie Dammhahn, Melanie Seiler, Nick Garbutt, Noel Rowe, Oliver Schuelke, Patricia Wright, Rindrahatsarana Ramanankirahina, Thomas Marent, Tiana Ratolojanahary and Vola Razakarivony for providing lemur photographs. We are grateful to Stephen Nash for permission to use the illustrations of lemur faces. We also thank the German Academic Exchange Service (DAAD) for supporting and funding this study. 


\section{GENERAL DISCUSSION}

\section{Summary of results}

The aim of this thesis was to investigate the role of acoustic and visual signals for species recognition in eulemurs, as well as to determine the potential evolutionary selective pressures that might have played a role for the diversification of acoustic and visual signals in eulemurs and for the evolution of facial color pattern complexity in lemurs. The present research provides new insights into the evolution and function of acoustic and visual signals among lemurs and specifically among the true lemurs (genus Eulemur). In the next paragraphs I will first summarize the results of my studies. I will then discuss the importance of different signals for species recognition in eulemurs and evaluate the potential selective factors that might have influenced the evolution of these signals among lemurs in comparison to other primates. Finally, I will also discuss the implications of my experimental studies for taxonomy.

\section{Are redfronted lemurs (Eulemur rufifrons) able to recognize their own species from different Eulemur species using acoustic signals? \\ (Chapter 1)}

The results of my playback experiments revealed that in the west of Madagascar (Kirindy Forest), Eulemur rufifrons did not discriminate loud calls of closely related heterospecifics (E. albifrons, E. fulvus and E. rufus). However, Eulemur rufifrons was able to differentiate their own loud calls from those of E. rubriventer as they spent less time looking towards the speaker after the presentation of loud calls of E. rubriventer. The response of the animals correlated with genetic distance of E. rufifrons to the species stimuli. Individuals reacted longer to loud calls of closely related heterospecifics than to those of genetically distant ones. In the East (Ranomafana National Park) my results indicated that $E$. rufifrons did not differentiate between their own loud calls and those of closely related E. albifrons and genetically distant E. rubriventer. Moreover, genetic 
distance between the species did not influence their response. Populations of E. rufifrons in RNP and KF reacted differently. Eulemur rufifrons in RNP looked longer towards the speaker after the presentation of loud calls of E. rubriventer than did E. rufifrons in KF. There was no sex difference in responses to playbacks in both populations.

\section{Can redfronted lemurs (Eulemur rufifrons) visually recognize conspecifics from heterospecifics? (Chapter 2)}

Results from the experiments using facial photographs of eulemurs revealed that Eulemur rufifrons showed a clear preference for pictures of conspecifics compared to pictures of heterospecifics. Eulemur rufifrons looked longer towards pictures of their own species than towards pictures of heterospecifics. Additionally, the response negatively correlated with genetic distance, as animals spent more time looking at pictures of closely related species and less time at pictures of distantly related ones. More interestingly, although there was no overall significant sex difference in the responses, females and males showed different responses to some stimuli during the experiments. Males looked significantly longer at pictures of E. albifrons, E. fulvus, and E. rubriventer than females. The results of these experiments additionally revealed that E. rufifrons showed increased sniffing behavior towards pictures of conspecifics compared to pictures of heterospecifics. The intensity of sniffing behavior again correlated with the genetic distance between $E$. rufifrons and the heterospecific stimuli. Eulemur rufifrons spent significantly more time sniffing pictures of conspecifics and closely related heterospecifics. Sniffing behavior was shorter towards genetically distant congeners such as E. rubriventer.

\section{Which evolutionary selective pressures have driven the evolution of facial color patterns in lemurs? (Chapter 3)}

Results from the phylogenetic comparative analyses (PGLS) showed that facial color patterns in lemurs cannot be explained by social factors. The number of sympatric species and group size did not influence facial color pattern complexity, which is contrary to previous studies on the evolution of facial color complexity conducted in New and Old 
World monkeys. Moreover, climate factors only marginally influenced the evolution of some facial regions. Lemur species occurring in colder areas in Madagascar developed darker colors in the region around the eyes, darker hair in the face margins and longer hair in the ears, whereas there was no influence of ecological factors in the crown and the forehead. Phylogenetic signals were found to be moderate to high in all models. Hence, the results indicate a strong influence of phylogeny on the evolution of facial color pattern complexity in lemurs.

\section{The importance of species-specific signals for species recognition in eulemurs}

One of the key aims of this thesis was to look at the importance of different species-specific signals for species recognition and if eulemurs are able to discriminate between con- and heterospecifics based on different signals. Chapter $\mathbf{1}$ of this dissertation shows that eulemurs were not able to discriminate between conspecifics and heterospecifics using loud calls. This suggests that loud calls seem to play a less important role for species recognition in eulemurs and are probably not used to avoid costly interbreeding. Nevertheless, acoustic signals such as loud calls can have many other functions apart from species recognition and other types of Eulemur vocalizations could potentially play a role for species recognition. Eulemur species have other different vocalizations such as grunts, hoos and woofs that are frequently used for social interactions (Pereira \& Kappeler 1997, Pflüger \& Fichtel 2012), but which were not investigated in this study to test the ability of E. rufifrons to discriminate between vocalizations of con- and heterospecifics. Loud calls (croaks) used in this study are indeed calls that are used by eulemurs for intergroup interactions (Pereira \& Kappeler 1997) and it might be that the use of these calls is limited to this intraspecific function and are therefore not used for species recognition. Perhaps other types of vocalizations might be more important for eulemurs to distinguish acoustically between conspecifics and heterospecifics. For example, Gamba and Giacoma (2008) found that long grunts of closely related E. macaco and E. flavifrons are species-specific to their respective species. It remains unclear whether long grunts can be discriminated by eulemurs and if they could potentially function in species recognition. Specific mating calls known from other 
non-human primates (see Maestripieri \& Roney 2005, Konrad \& Geissman 2006, Thinh et al. 2011, Meyer et al. 2012) are likely to be more important in the context of species recognition than loud calls used in our study. However, eulemurs are not known to produce vocalizations used specifically in the context of mating.

Visual signals such as facial color variation were shown in this research to play a relevant role for species recognition in Eulemur taxa as demonstrated in Chapter 2. The role of visual signals for species recognition has been rarely conducted in non-human primates, but visual signals have been suggested to play important roles for several taxa (e.g. in macaques: Fujita 1987, Fujita et al. 1997, Pascalis \& Bachevalier 1998; capuchin monkeys: Dufour et al. 2006). Experiments conducted in Eulemur rufifrons therefore confirm previous findings and the suggestion of other studies that visual signals, for instance in form of facial color variation can play a relevant role for species recognition in non-human primates. Additionally, my results provide new and essential information that visual species recognition can occur in eulemurs within their natural habitats.

It has been suggested that visual signals can be used as premating isolation barrier, since they function for species recognition and therefore may play an essential role in the reproduction context (Fujita 1987, Fujita et al. 1997). As females of Eulemur rufifrons were also shown to pay less attention to the pictures of visually different heterospecific stimuli than males during the experiments, visual signals might play a relevant role so that species recognition can function as reproductive isolation mechanism to avoid costly interbreeding in eulemurs. However, further investigations are needed in order to confirm this finding, since there was no overall significant difference between the sexes. The responses might potentially be linked to mate preferences and female responses might have been influenced by their color vision ability as well. Additionally, it has already been demonstrated that females of some true lemurs (E. mayottensis, E. albifrons, E. rufus, E. collaris, E. sanfordi and E. cinereiceps) showed a preference for colorful pictures of males (Cooper \& Hosey 2003). If the ability to discriminate between conspecifics and heterospecifics is reflected by mate choice, visual signals such as facial color variation in eulemurs might also play a relevant role in the context of reproduction. 
Until now it has still remained unclear which facial components do play a role in eulemurs as well as in other primates during visual recognition of faces. Facial coloration or patterns or combination of both might be used by these species to discriminate between their own and other species. Species that have the ability for color vision and can perceive differences in coloration, for instance, might rely more on facial coloration for the process of recognition, whereas others might rely more on contrasting patterns - but this requires future investigations.

Like in all Strepsirrhines, scents are frequently used for communication in lemurs (Norscia \& Palagi 2016). Several studies have demonstrated that eulemurs are able to recognize conspecifics and heterospecifics using olfactory signals and that olfactory signals are important for species recognition in Eulemur taxa (Harrington 1979, Kappeler 1998, delBarco-Trillo et al. 2012). Our experiments using pictures also demonstrated increased sniffing behavior of eulemurs while looking at the picture stimuli of conspecifics. Hence, a combination of two different sensory modalities, a so called "multi-modal" species recognition, might be relevant for Eulemur taxa to recognize members of their own species. Studies have already shown that animal species are able to combine different sensory modalities for species recognition (e.g. domestic horses (Equus caballus: visual-auditory matching (Proops \& McComb 2012); blackcaps (Sylvia atricapilla: visual-auditory matching (Matyjasiak 2004)). Non-human primates have also been shown to match signals of different sensory modalities to discriminate between conand heterospecifics. For instance, tufted capuchin monkeys (Cebus apella) were shown to match auditory-visual sensory modalities for species recognition (Evans et al. 2005), whereas Japanese macaques (Macaca fucata) and rhesus macaques (Macaca mulatta) used visual and acoustic sensory modalities (voice-face matching) to distinguish familiar conspecifics and humans (Adachi et al. 2006, Sliwa et al. 2011). A study investigating multi-modal species recognition in lemurs has not been conducted so far, but the use of olfactory-auditory sensory modalities for multi-modal recognition has already been shown to be used for individual recognition in ring-tailed lemurs (Lemur catta, Kulahci et al. 2014). Whether eulemurs use both modalities (olfactory-visual matching) was not subject of my studies and requires further experimental investigations. 
Eulemur species are known to form natural hybrids in several areas in Madagascar (Djlelati et al. 1997, Wyner et al. 2002, Johnson 2007, Pastorini et al. 2009). The reason why eulemurs frequently hybridize in nature still remains unclear, although they have the possibility to discriminate between their own species and heterospecifics based on facial or olfactory cues and therefore might be able to avoid costly heterospecific mating. Additionally, the potential ability to use multi-modal species recognition might also be another possibility for these species to avoid interbreeding. Future studies should conduct experiments on species recognition based on visual or olfactory cues or a combination of both in hybrid zones in order to determine whether eulemurs actively try to avoid heterospecific mating. However, the fact that these species produce hybrids might also be facilitated by other factors unrelated to reproduction such as habitat destruction. Due to habitat destruction these species might be constrained to mate with heterospecifics more than under normal conditions. Future studies might also investigate whether habitat destruction might be related to hybridization in eulemurs.

One can conclude that, aside from olfactory signals, visual signals such as facial color variation play an essential role for species recognition in true lemurs, and might also function to avoid costly interbreeding. In contrast, acoustic signals such as the loud calls tested in my studies seem to be less important species-specific signals in the context of species recognition for eulemurs. 


\section{The evolution of acoustic and visual signals in eulemurs and lemurs}

Different evolutionary selective pressures have been proposed in this dissertation to have influenced the evolution of acoustic and visual signals in true lemurs. The next paragraphs will therefore discuss the influence of natural or sexual selection and random genetic processes on the evolution of acoustic and visual signals in lemurs and eulemurs.

\section{Evolution of acoustic signals}

It is known that natural selection can influence the evolution of acoustic signals in numerous animal species (Brown \& Waser 1988, Naguib 2003, Padgham 2004). Several studies have already shown the influence of natural selection through habitat adaptation on acoustic signals (Mitani \& Stuht 1998, Feng et al. 2006, Slabbekoorn \& Smith 2002, Brown et al. 1995 Brumm et al. 2004, Ey et al. 2009). In comparison to other non-human primate species that have evolved their acoustic signals in adaptation to their natural habitats (e.g. common marmosets (Callithrix jacchus): Brumm et al. 2004, baboons Papio hamadryas anubis: Ey et al. 2009), loud calls of Eulemur species do not seem to have evolved in response to adaptation to natural habitats. The structure of loud calls shows only very small differences among allopatric closely related species and the biggest difference is found among sympatric and genetically different species sharing the same habitat (Markolf et al. 2013). Additionally, loud calls do not differ within species, although populations of the same species of eulemurs occur in different habitats (e.g. $E$. rufifrons, humid and dense forests in the east and dry deciduous forests in the west; Muldoon \& Goodman 2010, Mittermeier et al. 2010) in Madagascar. Thus, natural selection and habitat differences are unlikely to explain differences between acoustic signals such as loud calls in eulemurs.

The use of loud calls does not seem to be of big importance in a reproductive context for eulemurs and sexual selection might not have influenced the evolution of theses calls. It is therefore unlikely that eulemurs use these acoustic signals to avoid heterospecific mating. I found no sex difference in responses among focal individuals (Chapter 1). It has already been shown that loud calls can be used in mating context in 
other primate species such as gibbons (Thinh et al. 2011) and langurs (Meyer et al. 2012) and for these species the evolution of acoustic signals might have been driven by sexual selection. However, loud calls in eulemurs seem not to be different enough to function for interbreeding avoidance. Moreover, eulemurs do not have mating calls and it still remains a question whether other calls not investigated in this study might be used in the context of reproduction in these species.

Random genetic drift was suggested in this research (Chapter 1) to be one of the potential evolutionary selective forces that has influenced the evolution of loud calls in eulemurs. Several other non-human primate species have also been suggested to have evolved their acoustic signals in response to genetic drift, as their structures were related to phylogeny (e.g. songs of crested gibbons (Thinh et al. 2011, loud calls of langurs (Meyer et al. 2012)). Responses of Eulemur rufifrons to loud calls of conspecifics and heterospecifics during playback experiments negatively correlated with genetic distance between the species used as stimuli. Accordingly, the more genetically distant the species and the more different their acoustic structure the better E. rufifrons is able to distinguish them. Therefore, it seems more likely that genetic drift has played a role in the evolution of acoustic signals such as loud calls in eulemurs. Allopatric Eulemur species are known to have diverged only recently within the last one million years and it seems likely that random genetic drift has not produced strong acoustic differences among species (Markolf et al. 2013).

Therefore, neither natural nor sexual selection has influenced the evolution of acoustic signals such as loud calls in eulemurs. Random genetic drift best explains the differences between loud calls and these small differences might also explain why loud calls play a less important role for species recognition in these species.

\section{Evolution of visual signals}

High diversity of facial color patterns in lemurs seems to have marginally evolved under selective pressure through habitat adaptation. Similarly to their loud calls, Eulemur species occurring in sympatry show very different facial color patterns (Mittermeier et al. 2010). More interestingly, different populations of the same species occur in very different habitats in Madagascar and do not show any facial color difference. This is, for 
example, the case of populations of E. fulvus and E. rufifrons that occur in the East and in the West of Madagascar (Mittermeier et al. 2010). Therefore, selective pressure through adaptation to natural habitats might have very little influence on the evolution of visual signals such as facial color patterns in eulemurs as well as in all lemur species.

Although there was no overall significant sex difference between the responses of females and males of E. rufifrons during the experiments using pictures, females were shown to better distinguish pictures of con- and heterospecifics (Chapter 2). Thus, facial color patterns might have partly evolved under sexual selection at least in the genus Eulemur. This is supported by the fact that, among lemurs, eulemurs are the only taxa exhibiting sexual dichromatism with males having specifically colorful faces (Mittermeier et al. 2010).

The strong effect of phylogeny on the evolution of facial diversity in lemurs as well as the ability of E. rufifrons to visually discriminate closely related species from genetically distant ones indicated an influence of genetic drift in the evolution of these visual signals in lemurs. Therefore, random genetic drift might have been the main driver in the evolution of visual signals in eulemurs as well as in lemurs.

Facial color patterns in lemurs seem to have evolved differently from other primate groups. Results in Chapter 3, for instance, showed that the evolution of facial color patterns in lemurs were not influenced by social variables. Compared to New World and Old World primates, lemurs have a special and complex social organization varying from solitary, pair to group living and differing from one species/family to another (Kappeler 1997, Kappeler \& van Schaik 2002, Kappeler 2012, Kappeler \& Fichtel 2015). Group size is therefore highly variable and most species are solitary or pair living (see Appendix 7). Moreover, lemur species do not often occur in sympatry with congeners and when they do so only with a maximum of one sympatric congener (Appendix 8). The number of sympatric species on family level is much higher, but still lower compared to those of New World and Old World primates (Santana et al. 2012, 2013). Thus, lemurs seem to be "less social" than Old World and New World primates. Since they do not often occur in sympatry with numerous other closely related species, they also do not meet them in their natural habitats and social pressure for species recognition should be low. Therefore, the 
number of sympatric species and group size might have had less influence on the evolution of facial color patterns in lemurs compared to other groups of primates.

Ecological variables such as climate factors in Madagascar compared to those of New World and Old World primates differ in many aspects. Habitat structure in Madagascar is composed by few different ecoregions. Forests are mostly either dry or humid (Muldoon \& Goodman 2010), whereas for the other groups of primates, ecological variables are highly diverse and in order to adapt them these primates seem to have evolved different facial color patterns (in hair/skin color as well as in hair length) (Santana et al. 2012, 2013). Furthermore, areas of distributions are much smaller for the lemurs of Madagascar in comparison to other non-human primate species and climate variation in Madagascar is not very high either (Jury 2003). Therefore, climate variation in Madagascar might only marginally have influenced the evolution of facial color patterns in lemurs, whereas in other groups of primates climate factors might have driven the diversity of their facial color patterns.

Finally, considering another group of primates, humans have evolved facial hair and skin coloration in different ways. In contrast to non-human primates, human skin and hair coloration has evolved mainly under genetic control (Rees 2003). However, skin and hair also evolved in response to natural selective pressures and varies in relation to ultraviolet (UV) radiation and geographic distribution (Jablonski \& Chaplin 2000). Future studies might also investigate if the evolution of skin and hair color in lemurs and other non-human primates is influenced by such other factors.

Therefore, different primate radiations seem to have evolved facial color patterns in many different ways, under different evolutionary pressures and with little convergence. 


\section{Implications for taxonomy}

Signals play important roles in the evolution and diversification of species (Ryan \& Rand 1993, Grant \& Grant 2006, Robillard et al. 2006) and are frequently used by scientists for the delineation of species, which are the units of fundamental interest in biology (de Queiroz 2005, Sites \& Marshall 2003, Wiens \& Penkrot 2002, Wiens \& Servedio 2000). Species recognition played an important role for the formulation of different species concepts. For example, according to the biological species concept, a species is characterized by a unique fertilization system which implies that individuals only mate with members of the same species (Ryan \& Rand 1993, Mayr 2000). The same applies to the species recognition concept, which focuses on specific mate recognition systems (Paterson 1985). In this context, if species recognition functions as a premating isolation mechanism to avoid costly interbreeding, species-specific signals might ensure that heterospecific mating does not occur between different species (Nevo et al. 1987).

It is therefore questionable, if differences that can be measured between signals of different populations, but which are meaningless for the animals in terms of a potentially reproductive barrier, should actually be used for the delimitation of species. My study therefore suggests that loud calls might represent little importance for species delimitation in the Eulemur fulvus group. However, the greater acoustic difference between members of the E. fulvus group and other genetically distant Eulemur species (Markolf et al. 2013) as well as the stronger response of E. rufifrons towards loud calls of E. rubriventer during playback experiments, shows that differences in acoustic structure and the potential to differentiate between calls largely depends on the degree of divergence between taxa and not necessarily on the signal itself.

In contrast, visual signals in form of facial color variation were shown to be important to discriminate conspecifics from heterospecifics in true lemurs. As experiments showed that they can differentiate among species stimuli and that they might even use visual differences to avoid heterospecific mating, facial color variation might represent a relevant trait to delimit Eulemur species. I suggest that taxonomic studies should incorporate behavioral responses of the animals whenever possible in order to verify the meaning of divergent signals for the animals and the taxa in question. 


\section{CONCLUSIONS}

The results of my thesis provide insights into the role of acoustic and visual signals in species recognition in lemurs along with potential evolutionary selective pressures that might have driven their evolution. Therefore, I conclude that based on results of my study:

a. Eulemur rufifrons is not able to distinguish conspecifics from heterospecifics using loud calls. Therefore, acoustic signals such as loud calls might play a less important role for species recognition in eulemurs. Additionally, the evolution of these signals might have been driven by random genetic drift.

b. Eulemur rufifrons has the ability to visually differentiate their own species from different ones. Visual signals such as facial color variation seem to play an essential role in true lemurs for species recognition, and Eulemur species also might potentially use them to avoid costly interbreeding. Sexual selection and genetic drift are both likely to have influenced facial color variation in eulemurs.

c. Phylogenetic comparative analyses found that the evolution of facial color patterns in lemur species might have been driven by random genetic drift. Ecological variables might have slightly influenced the evolution of some facial areas and might, however, have an effect in pelage coloration and hair length in the overall body. In contrast to New and Old World monkeys social variables were found to have no influence on the evolution of facial color complexity and the evolution of facial color complexity in primates seems to show little convergence.

d. Phylogenetic comparative analyses and specific tests such as playback experiments and experiments using photographs represent useful tools to study potential evolutionary selective pressures that might have influenced the evolution of speciesspecific signals as well as the role of species-specific signals for species recognition. 


\section{Outlook}

This thesis investigated the influence of different selective pressures on the evolution of acoustic and visual signals in lemurs as well as the ability of animals of the genus Eulemur to use acoustic or visual signals in the process of species recognition. There are some aspects that could not be investigated and new questions arose during this dissertation as well. These aspects, which could be of interest for future studies, are outlined in the following.

First, phylogenetic comparative analyses conducted in lemur species permit to open new doors to a largely unexplored topic in the evolution of their facial color patterns. Although this study found that random genetic drift might have played a bigger role in the evolution of facial color patterns in this radiation of primates, other selective pressures might have contributed to the evolution of facial color patterns as well, but were not included in this study. For instance, one could specifically look at individual variations in facial color patterns (e.g. hair length, hair color) within species and investigate whether social variables might have influenced intraspecific facial variability in order to facilitate individual recognition.

Second, visual experiments were only conducted in Kirindy forest in the West of Madagascar. It would be interesting to also conduct the same experiments in Ranomafana National Park in the East in order determine the reaction of Eulemur rufifrons to E. rubriventer within the eastern population which occurs naturally in sympatry with them. Moreover, it remains unclear which components of the face are used by eulemurs for species recognition. Experiments using artificially altered pictures (e.g. manipulation of color and shape of facial areas) could find out the significant facial components or areas of the animals that are significant in terms of species or individual recognition. As some females of Eulemur rufifrons, for instance, show genetic polymorphic trichromacy in color vision, differences in responses can also be correlated with color vision. Future studies on color vision could also be conducted, for instance, on individuals of $E$. rufifrons that participated in the experiments in order to investigate whether responses in experiments using pictures are related to color vision of focal individuals. 
Third, olfactory and visual signals seem to represent a relevant tool for species recognition in eulemurs. As they showed their ability for olfactory recognition while processing visual recognition during the experiments, one could conduct specific tests on the use of olfactory and visual sensory modalities for multi-modal species recognition in these taxa.

Finally, it is well known that eulemurs often hybridize in captivity or in their natural habitats and that they can form viable and sometimes fertile hybrids (Djlelati et al. 1997, Wyner et al. 2002, Johnson 2007, Pastorini et al. 2009). Thus, species-specific signals should be relevant for them to avoid costly interbreeding. Therefore, it would be interesting to conduct similar experiments within a known hybridization zone of eulemurs to elaborate if and which signals can actively contribute to reproductive isolation in wild populations. 


\section{REFERENCES}

Adachi I, Kuwahata H, Fujita K, Tomonaga M, Matsuzawa T. Japanese macaques form a cross-modal representation of their own species in their first year of life. Primates. 2006, 47(4):350-354.

Agapow PM, Bininda- Emonds OR, Crandall KA, Gittleman JL, Mace GM, Marshall JC, Purvis A. The impact of species concept on biodiversity studies. The quarterly review of biology. 2004, 79(2):161-179.

Alatalo RV, Gustafsson L, Lundberg A. Male coloration and species recognition in sympatric flycatchers. Proceedings of the Royal Society of London B: Biological Sciences. 1994, 256(1346):113-118.

Alexander RD. The evolution of social behavior. Annual review of ecology and systematics. 1974, 325-383.

Allen WL, Higham JP. Assessing the potential information content of multicomponent visual signals: a machine learning approach. Proceedings of the Royal Society of London B: Biological Sciences. 2015, 282(1802).

Anderson MJ. Penile morphology and classification of bush babies (subfamily Galagoninae). International Journal of Primatology. 2000;21(5):815-836.

Arnold ML, Meyer A. Natural hybridization in primates: one evolutionary mechanism. Zoology. 2006, 109(4):261-276.

Backwell PR, Jennions MD. Mate choice in the neotropical frog, Hyla ebraccata: sexual selection, mate recognition and signal selection. Animal Behaviour. 1993, 45(6):1248-1250.

Balakrishnan R. Species concepts, species boundaries and species identification: a view from the tropics. Systematic Biology. 2005, 54(4):689-693. 
Baugh AT, Akre KL, Ryan MJ. Categorical perception of a natural, multivariate signal: mating call recognition in túngara frogs. Proceedings of the National Academy of Sciences. 2008, 105(26):8985-8988.

Belk MC, Smith MH. Pelage coloration in oldfield mice (Peromyscus polionotus): antipredator adaptation?. Journal of Mammalogy. 1996, 77(3):882-890.

Benedict L, Bowie RC. Macrogeographical variation in the song of a widely distributed African warbler. Biology Letters. 2009, 5(4):484-487.

Boake CR, DeAngelis MP, Andreadis DK. Is sexual selection and species recognition a continuum? Mating behavior of the stalk-eyed fly Drosophila heteroneura. Proceedings of the National Academy of Sciences. 1997, 94(23):12442-12445.

Boul KE, Funk WC, Darst CR, Cannatella DC, Ryan MJ. Sexual selection drives speciation in an Amazonian frog. Proceedings of the Royal Society of London B. 2007, 274:399-406.

Bradbury JW, Vehrencamp SL. Principles of animal communication. Sunderland: Sinauer Associates. 1998.

Bradley BJ, Mundy NI. The primate palette: the evolution of primate coloration. Evolutionary Anthropology: Issues, News, and Reviews. 2008, 17(2):97-111.

Bradley CE, McClung MR. Vocal divergence and discrimination of long calls in tamarins: A comparison of allopatric populations of Saguinus fuscicollis nigrifrons and S. f. lagonotus. American Journal of Primatology. 2015, 77:679-687.

Braune P, Schmidt S, Zimmermann E. Acoustic divergence in the communication of cryptic of nocturnal primates (Microcebus spp.). BMC Biology. 2008, 6:19.

Brenowitz EA. The contribution of temporal song cues to species recognition in the redwinged blackbird. Animal behaviour. 1983, 31(4):1116-1127.

Brown $\mathrm{CH}$, Gomez R, Waser PM. Old World monkey vocalizations: adaptation to the local habitat? Animal Behaviour. 1995, 50:945-961. 
Brown $\mathrm{CH}$, Waser PM. Environmental influences on the structure of primate vocalizations. In: Primate vocal communication. Springer Berlin Heidelberg. 1988. p. 51-66.

Bruce C. Face recognition by monkeys: absence of an inversion effect. Neuropsychologia. 1982, 20(5):515-521.

Brumm H, Voss K, Köllmer I, Todt D. Acoustic communication in noise: regulation of call characteristics in a New World monkey. Journal of Experimental Biology. 2004, 207(3):443-448.

Bultin RK. Reinforcement: an idea evolving. Trends in Ecology and Evolution. 1995, 10:432- 434.

Burrows AM. The facial expression musculature in primates and its evolutionary significance. BioEssays. 2008, 30(3):212-225.

Burt DM, Perrett DI. Perception of age in adult Caucasian male faces: Computer graphic manipulation of shape and colour information. Proceedings of the Royal Society of London B: Biological Sciences. 1995, 259(1355):137-143.

Burtt Jr EH, Ichida JM. Gloger's rule, feather- degrading bacteria, and colour variation among song sparrows. Condor. 2004, 106:681-686.

Byers JA, Waits L. Good genes sexual selection in nature. Proceedings of the National Academy of Sciences. 2006, 103(44):16343-16345.

Campbell P, Pasch B, Pino JL, Crino OL, Phillips M, Phelps SM. Geographical variation in the songs of neotropical singing mice: testing the relative importance of drift and local adaptation. Evolution. 2010, 64:1955-1972.

Cardoso GC, Hu Y, Mota PG. Birdsong, sexual selection, and the flawed taxonomy of canaries, goldfinches and allies. Animal Behaviour. 2012, 84(1):111-119.

Caro T. Contrasting coloration in terrestrial mammals. Philosophical Transactions of the Royal Society of London B: Biological Sciences. 2009, 364(1516):537-548. 
Caro T. The adaptive significance of coloration in mammals. Bioscience. 2005, 55:125136.

Caro T, Stankowich T, Mesnick SL, Costa DP, Beeman K. Pelage coloration in pinnipeds: functional considerations. Behavioral Ecology. 2012, 23(4):765-774.

Caspers BA, Schroeder FC, Franke S, Streich WJ, Voigt CC. Odour-based species recognition in two sympatric species of sac-winged bats (Saccopteryx bilineata, $S$. leptura): combining chemical analyses, behavioural observations and odour preference tests. Behavioral ecology and sociobiology. 2009, 63(5):741-749.

Charpentier MJ, Boulet M, Drea CM. Smelling right: the scent of male lemurs advertises genetic quality and relatedness. Molecular Ecology. 2008, 17(14):3225-3233.

Charpentier MJ, Crawford JC, Boulet M, Drea CM. Message 'scent': lemurs detect the genetic relatedness and quality of conspecifics via olfactory cues. Animal Behaviour. 2010, 80(1):101-108.

Chatterjee H, Ho S, Barnes I, Groves C. Estimating the phylogeny and divergence times of pri- mates using a supermatrix approach. BMC Evolutionary Biology. 2009, 9:259.

Clark AB. Interspecific differences and discrimination of auditory and olfactory signals of Galago crassicaudatus and Galago garnettii. International Journal of Primatology. 1988, 9:557- 571.

Clough D, Heistermann M, Kappeler PM. Individual facial coloration in male Eulemur fulvus rufus: a condition-dependent ornament? International Journal of Primatology. 2009, 30(6):859-875.

Clutton-Brock TH, Parker GA. Potential reproductive rates and the operation of sexual selection. Quarterly Review of Biology. 1992, 67:437-456.

Cooper VJ, Hosey GR. Sexual dichromatism and female preference in Eulemur fulvus subspecies. International Journal of Primatology. 2003, 24(6):1177-1188. 
Cords M. The behavior, ecology and social evolution of Cercopithecine monkeys. In: The evolution of primate societies (eds J. C. Mitani, J. Call, P. M. Kappeler, R. Palombit, J. B. Silk), University of Chicago Press. 2012. p.91-112.

Coyne JA, Orr HA. Speciation. Sunderland, MA: Sinauer Associates. 2004.

Coyne JA. Genetics and speciation. Nature. 1992, 355(6360): 511-515.

Curé C, Mathevon N, Mundry R, Aubin T. Acoustic cues used for species recognition can differ between sexes and sibling species: evidence in shearwaters. Animal Behaviour. 2012, 84:239-250.

De Queiroz K. Different species problems and their resolution. BioEssays. 2005, 27(12):1263-1269.

delBarco-Trillo J, Sacha CR, Dubay GR, Drea CM. Eulemur, me lemur: the evolution of scent-signal complexity in a primate clade. Philosophical Transactions of the Royal Society of London B: Biological Sciences. 2012, 367:1909-1922.

Delmore KE, Louis EE, Johnson SE: Morphological characterization of a brown lemur hybrid zone (Eulemur rufifrons $\times$ E. cinereiceps). American Journal of Physical Anthropology. 2011, 145:55-66.

Dittrich W. How monkeys see others: discrimination and recognition of monkeys' shape. Behavioural Processes. 1994, 33:139-154.

Djelati R, Brun B, Rumpler Y. Meiotic study of hybrids in the genus Eulemur and taxonomic considerations. American Journal of Primatology. 1997, 42(3):235-245.

Dobson SD. Allometry of facial mobility in anthropoid primates: implications for the evolution of facial expression. American Journal of Physical Anthropology. 2009, 138(1), 70-81.

Dufour V, Pascalis O, Petit O. Face processing limitation to own species in primates: a comparative study in brown capuchins, Tonkean macaques and humans. Behavioural Processes. 2006, 73(1):107-113. 
Endler JA. Some general comments on the evolution and design of animal communication systems. Philosophical Transactions of the Royal Society of London B: Biological Sciences. 1993, 340(1292):215-225.

Endler JA. A predator's view of animal color patterns. In: Hecht MK, Steere WC, Wallace B, editors. Evolutionary biology, evolutionary biology. US: Springer. 1978. p. $319-364$.

Endler JA. On the measurement and classification of colour in studies of animal colour patterns. Biological Journal of the Linnean Society. 1990, 41:315-352.

Ettlinger G, Wilson WA. Cross-modal performance: behavioural processes, phylogenetic considerations and neural mechanisms. Behavioural Brain Research. 1990, 40(3):169-192.

Evans CS, Evans L, Marler P. On the meaning of alarm calls: functional reference in an avian vocal system. Animal Behaviour. 1993, 46(1):23-38.

Evans TA, Howell S, Westergaard GC. Auditory-visual cross-modal perception of communicative stimuli in tufted capuchin monkeys (Cebus apella). Journal of experimental psychology. Animal behavior processes. 2005, 31(4):399-406.

Ey E, Rahn C, Hammerschmidt K, Fischer J. Wild female olive baboons adapt their grunt vocalizations to environmental conditions. Ethology. 2009, 115(5):493-503.

Feng AS, Narins PM, Xu C-H, Lin W-Y, Yu Z-L, Qiu Q, et al. Ultrasonic communication in frogs. Nature. 2006, 440:333-336.

Fichtel C, Kappeler PM. Anti-predator behavior of group-living Malagasy primates: mixed evidence for a referential alarm call system. Behavioral Ecology and Sociobiology. 2002, 51:262-275.

Fichtel C. Acoustic differences in loud calls of Decken's and crowned Sifakas (Propithecus deckenii and P. coronatus at two sites in Madagascar. Primate Conservation. 2014. p.1-7. 
Fichtel C. Reciprocal recognition of sifaka (Propithecus verreauxi verreauxi) and redfronted lemur (Eulemur fulvus rufus) alarm calls. Animal Cognition. 2004, 7:4552.

Forrest TG. From sender to receiver: propagation and environmental effects on acoustic signals. American Zoologist. 1994, 34(6):644-654.

Francis CD, Ortega CP, Cruz A. Different behavioural responses to anthropogenic noise by two closely related passerine birds. Biology Letters. 2011, 7(6):850.

Fujita K, Watanabe K, Widarto TH, Suryobroto B. Discrimination of macaques by macaques: the case of Sulawesi species. Primates. 1997, 38(3):233-245.

Fujita K. Species recognition by five macaque monkeys. Primates. 1987;28(3):353-366.

Funk WC, Caminer M, Ron SR. High levels of cryptic species diversity uncovered in Amazonian frogs. Proceedings of the Royal Society of London B. 2011. doi: rspb20111653.

Furtman M. Ruffed grouse: woodland drummer. Stackpole Books. 2004.

Gamba M, Giacoma C. Subspecific Divergence in the black lemur's low-pitched vocalizations. Open Acoustics Journal. 2008, 1:49-53.

Gauthier I, Logothetis NK. Is face recognition not so unique after all?. Cognitive Neuropsychology. 2000, 17(1-3):125-142.

Gerald MS. 2001. Primate colour predicts social status and aggressive outcome. Animal Behaviour, 61(3):559-566.

Ghazanfar AA, Logothetis NK. Neuroperception: Facial expressions linked to monkey calls. Nature. 2003, 423(6943):937-938.

Gloger CL. Das Abändern der Vögel durch Einfluss des Klimas, Breslau. Pland: Schulz. 1833.

Goodman SM, Ganzhorn JU. Biogeography of lemurs in the humid forests of Madagascar: the role of elevational distribution and rivers. Journal of Biogeography. 
2004, 31(1):47-55.

Grant PR, Grant BR. Species before speciation is complete. Annals of the Missouri Botanical Garden. 2006, 93:94-102.

Grant PR, Grant BR. The secondary contact phase of allopatric speciation in Darwin's finches. Proceedings of the National Academy of Sciences USA. 2009, 106:2014120148.

Gray D, Cade WH. Sexual selection and speciation in field crickets. Proceedings of the National Academy of Sciences, USA. 2000, 97:14449-14454.

Hamilton AE, Buettner, Janusch J. Chromosomes of Lemuriformes III. The Genus Lemur: Karyotypes of Species, Subspecies, and Hybrids. Annals of the New York Academy of Sciences. 1977, 293(1):125-159.

Harrington JE. Responses of Lemur fulvus to scents of different subspecies of L. fulvus and to scents of different species of Lemuriformes. Zeitschrift für Tierpsychologie. 1979, 49:1-9.

Hauser MD. The evolution of communication. MIT press. 1996.

Herrera JP, Dávalos LM. Phylogeny and divergence times of lemurs inferred with recent and ancient fossils in the tree. Systematic biology. 2016.

Higham JP. Primate coloration: an introduction to the special issue. International journal of Primatology. 2009, 30(6):749-751.

Höbel G, Gerhardt HC. Reproductive character displacement in the acoustic communication system of green tree frogs (Hyla cinerea). Evolution. 2003, 57:894904.

Hoekstra HE, Krenz JG, Nachman, MW. Local adaptation in the rock pocket mouse (Chaetodipus intermedius): natural selection and phylogenetic history of populations. Heredity. 2005, 94:217-228.

Irwin DE, Thimgan MP, Irwin JH. Call divergence is correlated with geographic and genetic distance in greenish warblers (Phylloscopus trochiloides): a strong role for 
stochasticity in signal evolution? Journal of Evolutionary Biology. 2008, 21:435448.

Jablonski NG, Chaplin G. The evolution of human skin coloration. Journal of Human Evolution. 2000, 39(1):57-106.

Jacobs GH, Deegan JF. Photopigments underlying color vision in ringtail lemurs (Lemur catta) and brown lemurs (Eulemur fulvus). American Journal of Primatology. 1993, 30(3):243-256.

Jacobs GH. Primate color vision: a comparative perspective. Visual neuroscience. 2008, 25(5-6):619-633.

Jacobs GH. Variations in primate color vision: mechanisms and utility. Evolutionary Anthropology: Issues, News, and Reviews. 1994, 3(6):196-205.

Janson $\mathrm{CH}$, Goldsmith ML. Predicting group size in primates: foraging costs and predation risks. Behavioral Ecology. 1995, 6(3):326-336.

Jennions MD, Petrie M. Variation in mate choice and mating preferences: a review of causes and consequences. Biological Reviews. 1997, 72(2):283-327.

Johnson SE. Evolutionary divergence in the brown lemur species complex. In: Gould L, Sauther ML, editors. Lemurs: Ecology and adaptation. New York: Springer. 2007. p. $187-210$.

Johnson SE. Ecology and speciation in brown lemurs: White-collared lemurs (Eulemur albocollaris) and hybrids (Eulemur albocollaris $\square \square$ Eulemur fulvus rufus) in southeastern Madagascar. Ph.D. dissertation, University of Texas at Austin, Austin, TX. 2002.

Jury M. The climate of Madagascar. Goodman S, Benstead J, editors. The Natural History of Madagascar. Chicago: The University of Chicago Press. 2003. p. 75-85.

Kamilar JM, Bradley BJ. Countershading is related to positional behavior in primates. Journal of Zoology. 2010, 283(4):227-233. 
Kamilar JM, Bradley BJ. Interspecific variation in primate coat colour supports Gloger's rule. Journal of Biogeography. 2011, 38(12):2270-2277.

Kamilar JM, Muldoon KM. The climatic niche diversity of Malagasy primates: a phylogenetic perspective. PLoS One. 2010, 5(6):e11073.

Kappeler PM, Fichtel C. A 15-year perspective on the social organization and life history of sifaka in Kirindy Forest. In: Kappeler PM, Watts DP, editors. Long- term field studies of primates. Berlin Heidelberg: Springer; 2012a. p. 101-121.

Kappeler PM, Fichtel C. Female reproductive competition in Eulemur rufifrons: eviction and reproductive restraint in a plurally breeding Malagasy primates. Molecular Ecology. 2012b, 23:685-698.

Kappeler PM, Fichtel C. The evolution of Eulemur social organization. International Journal of Primatology. 2015, 37(1):10-28.

Kappeler PM, van Schaik CP. Evolution of primate social systems. International Journal of Primatology. 2002, 23(4):707-40.

Kappeler PM. Mate choice. In: The evolution of primate societies. 2012a. p. 343-366.

Kappeler PM. The transmission and function of chemical signals in Lemur catta. Behavioral Ecology and Sociobiology. 1998, 42:411-421.

Kappeler PM, Heymann EW. Nonconvergence in the evolution of primate life history and socio- ecology. Biological Journal of the Linnean Society. 1996, 59(3):297-326.

Kappeler PM. Determinants of primate social organization: comparative evidence and new insights from Malagasy lemurs. Biological Reviews. 1997, 72(1):111-151.

Kappeler PM. Convergence and divergence in primate social systems. In Fleagle JG, Janson C, Reed KE, editors. Primate communities. Cambridge University Press, Cambridge. 1999. p.158-170.

Kappeler PM. The behavioral ecology of strepsirrhines and tarsiers. In Mitani JC, Call J, Kappeler PM, Palombit R, Silk JB, editors. The evolution of primate societies. University of Chicago Press. 2012b, p.17-42. 
Keller LF, Waller DM. Inbreeding effects in wild populations. Trends in Ecology \& Evolution. 2002, 17(5):230-241.

Kondo N, Izawa E, Watanabe S. Crows cross-modally recognize group members but not non-group members. Proceedings of the Royal Society B: Biological Sciences. 2012, 279(1735):1937-42.

Konrad R, Geissmann T. Vocal diversity and taxonomy of Nomascus in Cambodia. International Journal of Primatology. 2006, 27:713-745.

Kraaijeveld K, Kraaijeveld-Smit FJL, Maan ME. Sexual selection and speciation: the comparative evidence revisited. Biological Reviews. 2011, 86:367-377.

Krebs EA, Hunte W, Green DJ. Plume variation, breeding performance and extra-pair copulations in the cattle egret. Behaviour. 2004, 141(4):479-499.

Kulahci IG, Drea CM, Rubenstein DI, Ghazanfar AA. Individual recognition through olfactory-auditory matching in lemurs. Proceedings of the Royal Society B: Biological Sciences. 2014, 281(1784).

Kuznetsova A, Brockhoff PB, Christensen RHB. LmerTest: tests for random and fixed effects for linear mixed effect models. R package Version 2.0-3. 2013, http://CRAN.R-project.org/packageplmerTest.

Laidre ME, Johnstone RA. Animal signals. Current Biology. 2013, 23(18):829-33.

Lukhtanov VA, Kandul NP, Plotkin JB, Dantchenko AV, Haig D, Pierce NE. Reinforcement of pre-zygotic isolation and karyotype evolution in Agrodiaetus butterflies. Nature. 2005, 436(7049):385-9.

Maan ME, Seehausen O, Söderberg L, Johnson L, Ripmeester EA, Mrosso HD, Taylor MI, Van Dooren TJ, Van Alphen JJ. Intraspecific sexual selection on a speciation trait, male coloration, in the Lake Victoria cichlid Pundamilia nyererei. Proceedings of the Royal Society of London B: Biological Sciences. 2004, 271(1556):2445-52. 
Macedonia JM, Stanger KF. Phylogeny of the Lemuridae revisited: evidence from communication signals. Folia Primatologica. 1994, 63:1-43.

Maestripieri D, Roney JR. Primate copulation calls and postcopulatory female choice. Behavioral Ecology. 2005, 16(1):106-13.

Mallet J. Hybrid speciation. Nature. 2007, 446(7133):279-83.

Mancini G, Ferrari PF, Palagi E. Rapid facial mimicry in geladas. Scientific reports. 2013, 3:1527.

Manser MB, Seyfarth RM, Cheney DL. Suricate alarm calls signal predator class and urgency. Trends in cognitive sciences. 2002, 6(2):55-7.

Marechal L, Genty E, Roeder JJ. Recognition of faces of known individuals in two lemur species (Eulemur fulvus and E. macaco). Animal Behaviour. 2010, 79(5):1157-63.

Markolf M, Kappeler PM. Phylogeographic analysis of the true lemurs (genus Eulemur) underlines the role of river catchments for the evolution of micro-endemism in Madagascar. Frontiers in zoology. 2013, 10(1):1.

Markolf M, Rakotonirina H, Fichtel C, Grumbkow P, Brameier M, Kappeler PM. True lemurs... true species - Species delimitation using multiple data sources in the brown lemur complex. BMC Evolutionary Biology. 2013, 13:233.

Martin OY, Hosken DJ. Costs and benefits of evolving under experimentally enforced polyandry or monogamy. Evolution. 2003, 57(12):2765-72.

Marty JS, Higham JP, Gadsby EL, Ross C. Dominance, coloration, and social and sexual behavior in male drills Mandrillus leucophaeus. International Journal of Primatology. 2009, 30(6):807-23.

Matauschek C, Roos C, Heymann EW. Mitochondrial phylogeny of tamarins (Saguinus, Hoffmannsegg 1807) with taxonomic and biogeographic implications for the $S$. nigricollis species group. American Journal of Physical Anthropology. 2011, 144:564-574.

Matyjasiak P. Birds associate species-specific acoustic and visual cues: recognition of 
heterospecific rivals by male blackcaps. Behavioral Ecology. 2004, 16(2):467-71.

Mayr E. The biological species concept. Species concepts and phylogenetic theory: a debate. Columbia University Press, New York. 2000. p.17-29.

Mayr E. What is a species, and what is not? Philosophy of Science. 1996, 63:262- 277.

McLennan DA, Ryan MJ. Responses to conspecific and heterospecific olfactory cues in the swordtail Xiphophorus cortezi. Animal Behaviour. 1997, 54:1077-1088.

Meyer D, Hodges JK, Rinaldi D, Wijaya A, Roos C, Hammerschmidt K. Acoustic structure of male loud-calls support molecular phylogeny of Sumatran and Javanese leaf monkeys (genus Presbytis). BMC evolutionary biology. 2012, 12(1):1.

Mitani JC, Stuht J. The evolution of nonhuman primate loud calls: acoustic adaptation for long-distance transmission. Primates. 1998, 39(2):171-182.

Mitani JC. Sexual selection and adult male orangutan long calls. Animal Behaviour. $1985,33: 272-283$.

Mitani JC. Species discrimination of male song in gibbons. American Journal of Primatology. 1987, 13:413-423.

Mittermeier RA, Louis Jr EE, Richardson M, Schwitzer C, Langrand O, Rylands AB, Hawkins F, Rajaobelina S, Ratsimbazafy J, Rasoloarison RM, Roos C. Lemurs of Madagascar, 3rd ed. Tropical Field Guide Series. Arlington, VA: Conservation International; 2010.

Moller AP, Pomiankowski A. Why have birds got multiple sexual ornaments?. Behavioral Ecology and Sociobiology. 1993 32(3):167-76.

Morton ES. Ecological sources of selection on avian sounds. American Naturalist. 1975, 17-34.

Muldoon KM, Goodman SM. Ecological biogeography of Malagasy non-volant mammals: community structure is correlated with habitat. Journal of Biogeography. 2010, 37:1144-1159. 
Muldoon KM, Simons EL. Ecogeographic size variation in small-bodied subfossil primates from Ankilitelo, Southwestern Madagascar. American journal of physical anthropology. 2007, 134(2):152-161.

Muroyama Y, Thierry B. Species differences of male loud calls and their perception in Sulawesi macaques. Primates. 1998, 39:115-126.

Myers N, Mittermeier RA, Mittermeier CG, Da Fonseca GA, Kent J. Biodiversity hotspots for conservation priorities. Nature. 2000, 403(6772):853-8.

Naguib M. Reverberation of rapid and slow trills: implications for signal adaptations to long-range communication. The Journal of the Acoustical Society of America. 2003, 113(3):1749-56.

Nahm FK, Perret A, Amaral DG, Albright TD. How do monkeys look at faces?. Journal of Cognitive Neuroscience. 1997, 9(5):611-23.

Nevo E, Heth G, Beiles A, Frankenberg E. Geographic dialects in blind mole rats: Role of vocal communication in active speciation. Proceedings of the National Academy of Sciences, USA. 1987, 84:3312-3315.

Nietsch A, Kopp M-L. Role of vocalization in species differentiation of Sulawesi tarsiers. Folia Primatologica. 1998, 69:371-378.

Norscia I, Palagi E. The Missing Lemur Link: An Ancestral Step in the Evolution of Human Behaviour. Cambridge University Press. 2016.

Oda R, Masataka N. Interspecific responses of ringtailed lemurs to playback of antipredator alarm calls given by Verreaux's sifakas. Ethology. 1996, 102:441-453.

Ord TJ, Blumstein DT, Evans CS. Ecology and signal evolution in lizards. Biological Journal of the Linnean Society. 2002, 77(1):127-48.

Ord TJ, Peters RA, Clucas B, Stamps JA. Lizards speed up visual displays in noisy motion habitats. Proceedings of the Royal Society of London B: Biological Sciences. 2007, 274(1613):1057-62. 
Ortolani, A. 1999. Spots, stripes, tail tips and dark eyes: predicting the function of carnivore colour patterns using the comparative method. Biological Journal of the Linnean Society. 67(4):433-476.

Overdorff DJ, Tecot SR. Social pair-bonding and resource defense in wild red-bellied lemurs (Eulemur rubriventer). In: Gould L, Sauther ML, editors. Lemurs: Ecology and adaptation. New York: Springer. 2007. p. 235-254.

Overdorff DJ. Similarities, differences, and seasonal patterns in the diets of Eulemur rubriventer and Eulemur fulvus rufus in the Ranomafana National Park, Madagascar. International Journal of Primatology. 1993, 14:721-753.

Padgham M. Reverberation and frequency attenuation in forests-implications for acoustic communication in animals. The Journal of the Acoustical Society of America. 2004, 115(1):402-10.

Palagi E, Norscia I, Spada G. Relaxed open mouth as a playful signal in wild ring-tailed lemurs. American journal of primatology. 2014, 76(11):1074-1083.

Parr LA, de Waal FB. Visual kin recognition in chimpanzees. Nature. 1999, 399(6737):647-648.

Parr LA, Dove T, Hopkins WD. Why faces may be special: evidence of the inversion effect in chimpanzees. Journal of Cognitive Neuroscience. 1998, 10(5):615-22.

Parr LA, Heintz M, Lonsdorf E, Wroblewski E. Visual Kin Recognition in Nonhuman Primates: (Pan troglodytes and Macaca mulatta): Inbreeding Avoidance or Male Distinctiveness? Journal of Comparative Psychology. 2010, 124(4):343-50.

Parr LA, Winslow JT, Hopkins WD, de Waal FB. Recognizing Facial Cues: Individual Discrimination by Chimpanzees (Pan troglodytes) and Rhesus Monkeys (Macaca mulatta). Journal of Comparative Psychology. 2000, 114(1):47-60.

Parr LA, Taubert J. The importance of surface-based cues for face discrimination in nonhuman primates. Proceedings of the Royal Society of London B: Biological Sciences. 2011, 278:1964-1972. 
Parr LA, Waller BM, Heintz M. Facial expression categorization by chimpanzees using standardized stimuli. Emotion. 2008, 8(2):216-231.

Pascalis O, Bachevalier J. Face recognition in primates: a cross-species study. Behavioural processes. 1998, 43(1):87-96.

Pastorini J, Zaramody A, Curtis DJ, Martin RD, Forstner MRJ. Sympatric hybridisation between Eulemur fulvus and E. mongoz. Folia Primatologica. 2001, 72:176.

Pastorini J, Zaramody A, Curtis DJ, Nievergelt CM, Mundy NI. Genetic analysis of hybridization and introgression between wild mongoose and brown lemurs. BMC Evolutionary Biology. 2009, 9:1-13.

Paterson HEH. The recognition concept of species. Species and speciation 1985. p 21-29.

Pereira ME, Kappeler PM. Divergent systems of agonistic behaviour in lemurid primates. Behaviour. 1997, 134(3):225-74.

Peres CA. Consequences of joint-territoriality in a mixed-species group of tamarin monkeys. Behaviour. 1992; 123:220-246.

Pfennig KS. Facultative mate choice drives adaptive hybridization. Science. 2007, 318(5852):965-7.

Pflüger FJ, Fichtel C. On the function of redfronted lemur's close calls. Animal cognition. 2012, 15(5):823-31.

Plenderleith M, Van Oosterhout C, Robinson RL, Turner GF. Female preference for conspecific males based on olfactory cues in a Lake Malawi cichlid fish. Biology Letters. 2005, 1(4):411-4.

Potvin DA, Parris KM, Mulder RA. Geographically pervasive effects of urban noise on frequency and syllable rate of songs and calls in silvereyes (Zosterops lateralis). Proceedings of the Royal Society of London B: Biological Sciences. 2011, 278(1717):2464-2469.

Proops L, McComb K. Cross-modal individual recognition in domestic horses (Equus caballus) extends to familiar humans. Proceedings of the Royal Society of London 
B: Biological Sciences. 2012, 279(1741):3131-3138.

Prum RO, Torres RH. Structural colouration of mammalian skin: convergent evolution of coherently scattering dermal collagen arrays. Journal of Experimental Biology. 2004, 207(12):2157-2172.

Raemaekers JJ, Raemaekers PM. Field playback of loud calls to gibbons (Hylobates lar): territorial, sex-specific and species-specific responses. Animal Behaviour. 1985, 33:481-491.

Rafferty NE, Boughman JW. Olfactory mate recognition in a sympatric species pair of three-spined sticklebacks. Behavioral Ecology. 2006, 17(6):965-970.

Rakotonirina H, Kappeler PM, Fichtel C. The role of acoustic signals for species recognition in redfronted lemurs (Eulemur rufifrons). BMC Evolutionary Biology. 2016, 16(1):1-11.

Ramakrishnan U, Coss RG. Recognition of heterospecific alarm vocalization by Bonnet macaques (Macaca radiata). Journal of Comparative Psychology. 2000, 114: 3.

Ratcliffe LM, Grant PR. Species recognition in Darwin's finches (Geospiza, Gould) I. Discrimination by morphological cues. Animal Behaviour. 1983, 31(4):1139-1153.

Rees JL. Genetics of hair and skin color. Annual review of genetics. 2003, 37(1):67-90.

Rendall D, Owren MJ, Ryan MJ. What do animal signals mean?. Animal Behaviour. 2009, 78(2):233-240.

Rensch B. Some problems of geographical variation and species-formation. Proceedings of the Linnean Society of London. 1938, 150(4):275-285.

Reynolds JD, Gross MR. Costs and benefits of female mate choice: is there a lek paradox?. American Naturalist. 1990, 230-243.

Robert T. Parental investment and sexual selection. Sexual Selection \& the Descent of Man, Aldine de Gruyter, New York. 1972. p. 136-79. 
Robillard T, Höbel G, Gerhardt HC. Evolution of advertisement signals in North American hylid frogs: vocalizations as end-products of calling behavior. Cladistics 2006, 22:533-545.

Rumpler Y. The significance of chromosomal studies in the systematics of the Malagasy lemurs. In: Tattersall I Sussman RW, editors. Lemur Biology. New York, Plenum Press. 1975. p. 25-40.

Ryan MJ, Rand AS. Species recognition and sexual selection as a unitary problem in animal communication. Evolution. 1993, 47:647-57.

Salazar C, Baxter SW, Pardo-Diaz C, Wu G, Surridge A, Linares M, Bermingham E, Jiggins CD. Genetic Evidence for Hybrid Trait Speciation in Heliconius Butterflies. PLoS Genetics. 2010, 6(4).

Santana SE, Alfaro JL, Alfaro ME. Adaptive evolution of facial colour patterns in neotropical primates. Proceedings of the Royal Society B: Biological Sciences. 2012, 279:2204-11.

Santana SE, Alfaro JL, Noonan A, Alfaro ME. Adaptive response to sociality and ecology drives the diversification of facial colour patterns in catarrhines. Nature communications. 2013, 4:1-7.

Santana, S. E., Dobson, S. D. \& Diogo, R. Plain faces are more expressive: comparative study of facial colour, mobility and musculature in primates. Biology Letters. 2014, 10: 20140275.

Santini L, Rojas D, Donati G. Evolving through day and night: origin and diversification of activity pattern in modern primates. Behavioral Ecology. 2015, 26:789-796.

Seehausen O, Terai Y, Magalhaes IS, Carleton KL, Mrosso HDJ, Miyagi R, et al. Speciation through sensory drive in cichlid fish. Behavioral Ecology and Sociobiology. 2008, 42:1-8. 
Setchell JM, Wickings EJ, Knapp LA. Signal content of red facial coloration in female mandrills (Mandrillus sphinx). Proceedings of the Royal Society of London B: Biological Sciences. 2006, 273(1599):2395-2400.

Setchell JM. Do female mandrills prefer brightly colored males?. International Journal of Primatology. 2005, 26(4):715-735.

Seyfarth RM, Cheney DL, Marler P. Vervet monkey alarm calls: semantic communication in a free-ranging primate. Animal Behaviour. 1980, 28(4):1070-94.

Sherman PW. Nepotism and the evolution of alarm calls. Science. 1977, 197(4310):124653.

Sites JW, Marshall JC. Delimiting species: a Renaissance issue in systematic biology. Trends in Ecology \& Evolution. 2003, 18(9):462-70.

Slabbekoorn H, Smith TB. Habitat-dependent song divergence in the little greenbul: an analysis of environmental selection pressures on acoustic signals. Evolution. 2002, $56: 1849-58$.

Sliwa J, Duhamel JR, Pascalis O, Wirth S. Spontaneous voice-face identity matching by rhesus monkeys for familiar conspecifics and humans. Proceedings of the National Academy of Sciences. 2011, 108(4):1735-40.

Snowdon CT, Hodun A, Rosenberger AL, Coimbra-Filho AF. Long-call structure and its relation to taxonomy in lion tamarins. American Journal of Primatology. 1986, $11: 253-261$.

Snowdon CT. Sexual selection and communication. Sexual selection in primates: New and comparative perspectives. 2004. p.57.

Sterck EH. The behavioral ecology of colobine monkeys. In Mitani JC, Call J, Kappeler PM, Palombit R, Silk JB, editors. The evolution of primate societies. University of Chicago Press. 2012. p.65-90. 
Stevens M, Merilaita S. Animal camouflage: current issues and new persspectives. Philosophical Transactions of the Royal Society B: Biological Sciences. 2009, 364 (1516):423-427.

Stevens M. Predator perception and the interrelation between different forms of protective coloration. Proceedings of the Royal Society of London B: Biological Sciences. 2007, 274(1617):1457-1464.

Stoddard MC, Prum RO. How colorful are birds? Evolution of the avian plumage color gamut. Behavioral Ecology. 2011, 22 (5):1042-1052.

Stoner CJ, Bininda-Emonds OR, Caro T. The adaptive significance of coloration in lagomorphs. Biological Journal of the Linnean Society. 2003a, 79(2), 309-328.

Stoner CJ, Caro TM, Graham CM. Ecological and behavioral correlates of coloration in artiodactyls: systematic analyses of conventional hypotheses. Behavioral Ecology. 2003b, 14(6):823-840.

Stuart-Fox D, Moussalli A. Camouflage, communication and thermoregulation: lessons from colour changing organisms. Philosophical Transactions of the Royal Society of London B: Biological Sciences. 2009, 364(1516), 463-470.

Stuart-Fox D, Moussalli A, Whiting MJ. Predator-specific camouflage in chameleons. Biology Letters. 2008, 4(4):326-329.

Sumner P, Mollon JD. Colors of primate pelage and skin: objective assessment of conspicuousness. American Journal of Primatology. 2003, 59(2):67-91.

Surridge AK, Osorio D, Mundy NI. Evolution and selection of trichromatic vision in primates. Trends in Ecology \& Evolution. 2003, 18(4):198-205.

Tan Y, Li WH. Trichromatic vision in prosimians. Nature: International weekly journal of science. $1999,402(6757): 36$.

Tanaka M. Development of the visual preference of chimpanzees (Pan troglodytes) for photographs of primates: effect of social experience. Primates. 2007, 48(4):303-9. 
Tattersall I. Madagascar's lemurs: cryptic diversity or taxonomic inflation?. Evolutionary Anthropology: Issues, News, and Reviews. 2007, 16(1):12-23.

Thayer AH. The law which underlies protective coloration. The Auk 1896, 13(2):124-129.

Thinh VN, Hallam C, Roos C, Hammerschmidt K. Concordance between vocal and genetic diversity in crested gibbons. BMC Evolutionary Biology. 2011, 11:36.

Tibbetts EA, Dale J. Individual recognition: it is good to be different. Trends in Ecology \& Evolution. 2007, 22(10):529-537.

Torrentera L, Belk D. New penis characters to distinguish between two American Artemia species. Hydrobiologia. 2002, 470(1-3):149-56.

Trivers RL. Parental investment and sexual selection. In: Sexual Selection \& the Descent of Man, Aldine de Gruyter, New York. 1972. p.136-179.

Ueno Y. Olfactory discrimination of urine odors from five species by tufted capuchin (Cebus apella). Primates. 1994, 35(3):311-23.

Veilleux CC, Louis EE, Bolnick DA. Nocturnal light environments influence color vision and signatures of selection on the OPN1SW opsin gene in nocturnal lemurs. Molecular Biology and Evolution. 2013, 30(6):1420-1437.

Waitt C, Little AC, Wolfensohn S, Honess P, Brown AP, Buchanan-Smith HM, Perrett DI. Evidence from rhesus macaques suggests that male coloration plays a role in female primate mate choice. Proceedings of the Royal Society of London B: Biological Sciences. 2003, 270:144-146.

Watanabe K, Matsumura S. The borderlands and possible hybrids between three species of macaques, $M$. nigra, $M$. nigrescens, and $M$. hecki, in the northern peninsula of Sulawesi. Primates. 1991, 32(3):365-70.

Watts DP. The apes: taxonomy, biogeography, life histories, and behavioral ecology. In Mitani JC, Call J, Kappeler PM, Palombit R, Silk JB. The evolution of primate societies. University of Chicago Press. 2012. p.113-141. 
West PM, Packer C. Sexual Selection, Temperature, and the Lion's Mane. Science. 2002, 297:1339-1343.

Wich SA, Krützen M, Lameira AR, Nater A, Arora N, Bastian ML, Meulman E, Morrogh-Bernard HC, Atmoko S, Pamungkas J, Perwitasari-Farajallah D. Call Cultures in Orang-Utans?. PLoS ONE. 2012, 7(5).

Wiens JJ, Penkrot TA. Delimiting species using DNA and morphological variation and discordant species limits in spiny lizards (Sceloporus). Systematic Biology. 2002, 51(1):69-91.

Wiens JJ, Servedio MR. Species delimitation in systematics: inferring diagnostic differences between species. Proceedings of the Royal Society of London B: Biological Sciences. 2000, 267(1444):631-636.

Wiernasz DC, Kingsolver JG. Wing melanin pattern mediates species recognition in Pieris occidentalis. Animal Behaviour. 1992, 43(1):89-94.

Wiley RH, Richards DG. Physical constraints on acoustic communication in the atmosphere: implications for the evolution of animal vocalizations. Behavioral Ecology and Sociobiology. 1978, 3(1):69-94.

Williams GC. Natural selection, the costs of reproduction, and a refinement of Lack's principle. The American Naturalist. 1966, 100(916):687-90.

Wyner YM, Johnson SE, Stumpf RM, Desalle R. Genetic assessment of a white- collared $\times$ red- fronted lemur hybrid zone at Andringitra, Madagascar. American Journal of Primatology. 2002, 57(2):51-66.

Yoder AD, Cartmill M, Ruvolo M, Smith K, Vilgalys R. Ancient single origin for Malagasy primates. Proceedings of the National Academy of Sciences of the United States of America. 1996, 93:5122-5126.

Yovel G, Freiwald WA. Face recognition systems in monkey and human: are they the same thing?. F1000Prime Reports. 2013, 5:10. 
Zinner D, Groeneveld LF, Keller C, Roos C. Mitochondrial phylogeography of baboons (Papio spp.)-Indication for introgressive hybridization?. BMC Evolutionary Biology. 2009, 9(1):1. 


\section{APPENDICES}

\section{Appendix 1}

Table showing the average looking durations towards the speaker after each playback stimulus in the populations at Kirindy Forest and Ranomafana National Park.

\begin{tabular}{llr}
\hline Species used as playback stimuli & Location & $\begin{array}{r}\text { Looking duration towards } \\
\text { the speaker (average) }\end{array}$ \\
\hline Eulemur albifrons & Kirindy & $15.80( \pm 14.36)$ \\
& Ranomafana & $9.61( \pm 11.00)$ \\
Eulemur rubriventer & Kirindy & $4.56( \pm 6.93)$ \\
& Ranomafana & $13.89( \pm 15.49)$ \\
Eulemur rufifrons & Kirindy & $14.95( \pm 12.79)$ \\
& Ranomafana & $16.73( \pm 15.53)$ \\
\hline
\end{tabular}




\section{Appendix 2}

Photograph showing the presentation of the pictures to test the visual ability of $E$. rufifrons for species recognition.

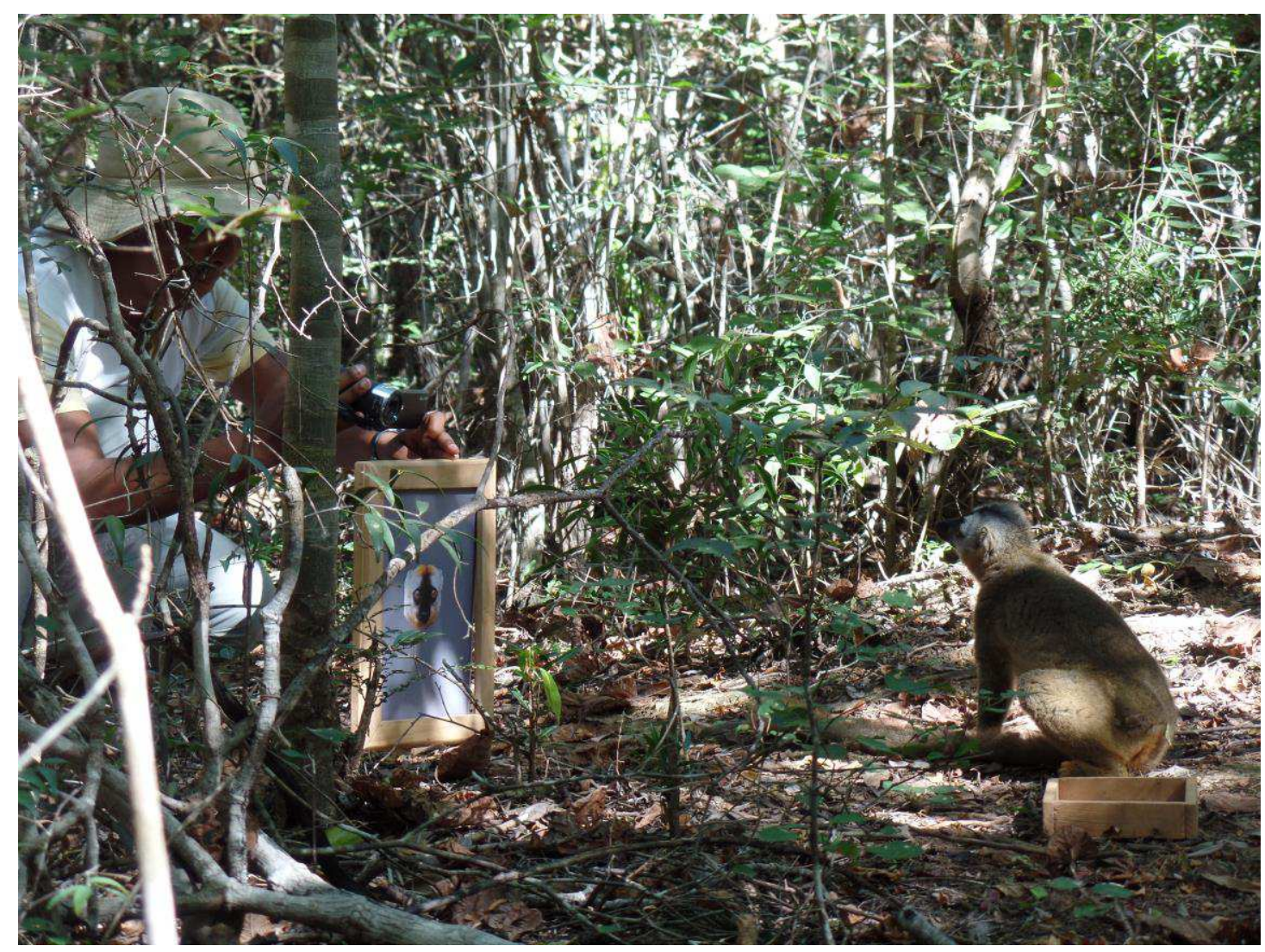

(C) Markolf Rakotonirina 


\section{Apppendix 3}

Categorization of hair length for each area in the face. $1=$ depilated, to $2=$ short hair, then $3=$ Medium hair, to $4=$ long hair.

\section{1. depilated}

\section{2. short}

\section{3. medium}

\section{4. long}
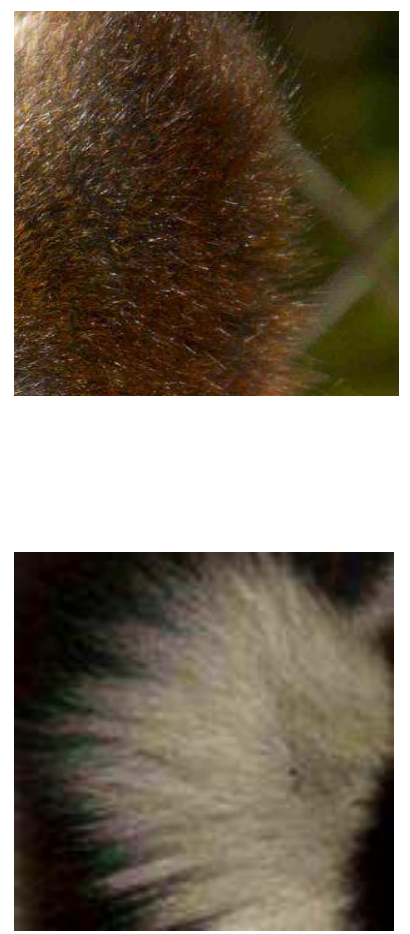


\section{Appendix 4}

Categorization of skin color in the face. $1=$ depigmented (white skin), pigmented with $2=$ pink skin, 3 = mottled, and 3,5 = gold skin (the appearance of the color is gold), hyper pigmented (dark skin) with $4=$ brown, 5 = black.

1.Depigmented (white skin)

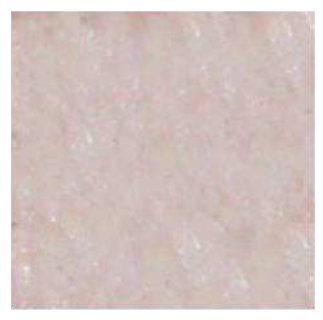

3,5. pigmented (gold skin)

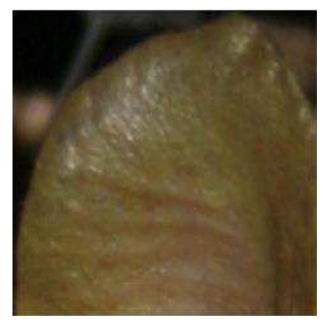

2.Pigmented (pink skin)

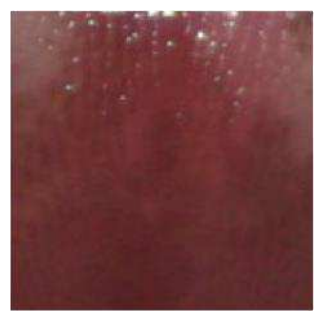

4. Hyperpigmented (dark skin, brown)

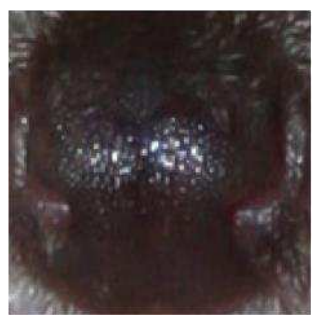

3.pigmented (mottled)

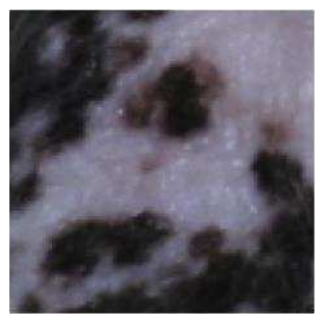

5.Hyperpigmented (dark skin, black)

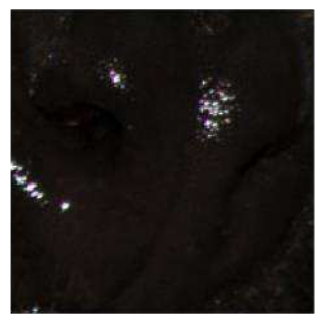




\section{Appendix 5}

Categorization of hair coloration in each area of the face. $1=$ white, $2=$ light agouti, $3=$ medium agouti, 4 = dark agouti, $5=$ Light brown, $6=$ medium brown, $7=$ dark brown, $8=$ Light grey, $9=$ medium grey, $10=$ black, $11=$ light yellow, $12=$ medium yellow and $13=$ Reddish/dark yellow.

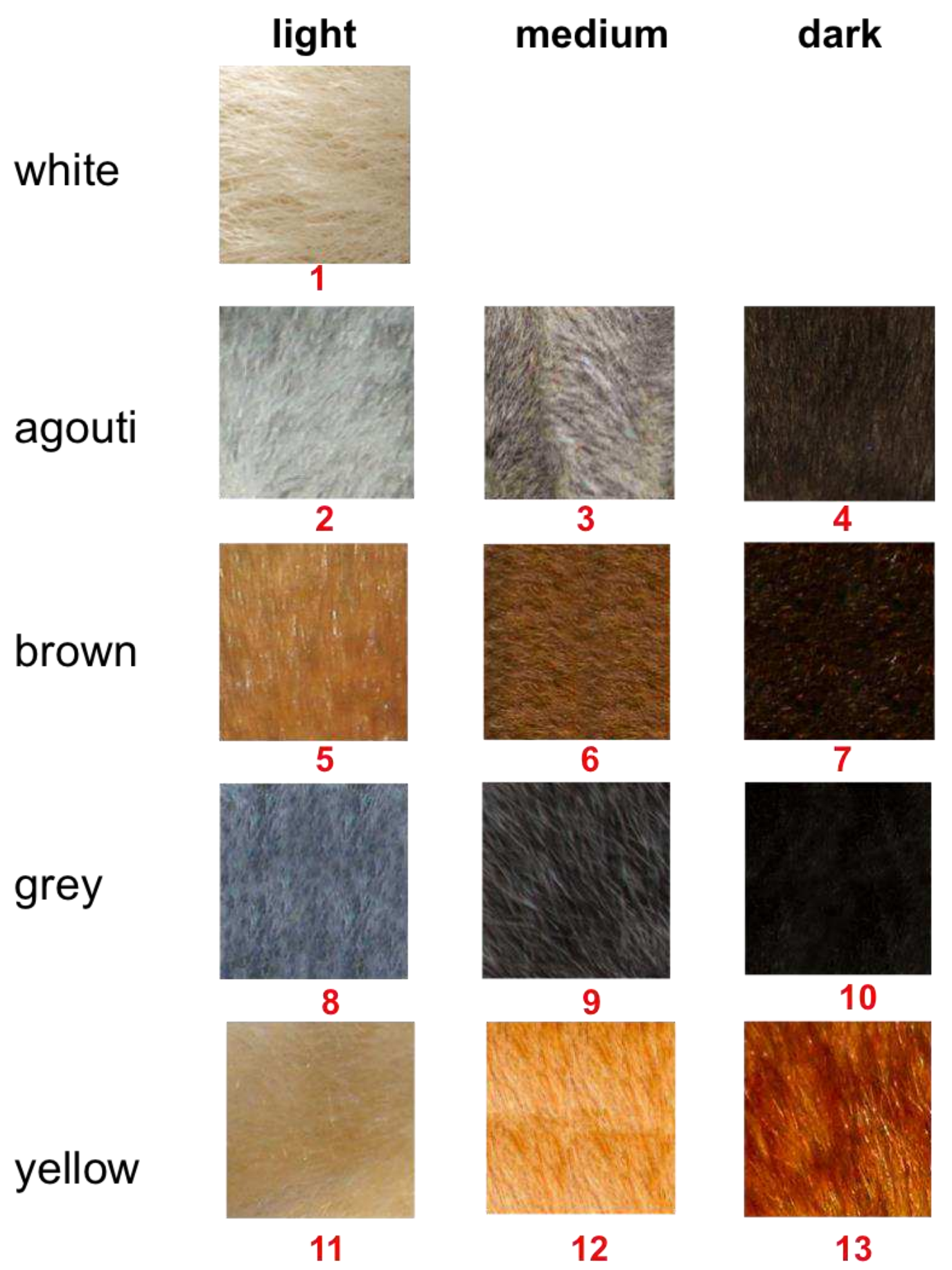




\section{Appendix 6}

List of all lemur species used for Phylogenetic comparative analyses

\begin{tabular}{ll}
\hline Family & Species \\
\hline Cheirogaleidae & Allocebus trichotis \\
Cheirogaleidae & Cheirogaleus crossleyi \\
Cheirogaleidae & Cheirogaleus major \\
Cheirogaleidae & Cheirogaleus medius \\
Cheirogaleidae & Cheirogaleus sibreei \\
Cheirogaleidae & Microcebus berthae \\
Cheirogaleidae & Microcebus griseorufus \\
Cheirogaleidae & Microcebus lehilahytsara \\
Cheirogaleidae & Microcebus murinus \\
Cheirogaleidae & Microcebus myoxinus \\
Cheirogaleidae & Microcebus ravelobensis \\
Cheirogaleidae & Microcebus rufus \\
Cheirogaleidae & Microcebus tavaratra \\
Cheirogaleidae & Mirzacoquereli \\
Cheirogaleidae & Mirzazaza \\
Cheirogaleidae & Phanerfurcifer \\
Cheirogaleidae & Phaner pallescens \\
Daubentoniidae & Daubentonia madagascariensis \\
Indriidae & Avahi cleesei \\
Indriidae & Avahi laniger \\
Indriidae & Avahi meridionalis \\
Indriidae & Avahioccidentalis \\
\hline Indriidae & Avahi unicolor \\
\hline
\end{tabular}




\begin{tabular}{ll}
\hline Indriidae & Propithecus deckenii \\
Indriidae & Propithecus diadema \\
Indriidae & Propithecus edwardsi \\
Indriidae & Propithecus perrieri \\
Indriidae & Propithecus tattersalli \\
Indriidae & Propithecus verreauxi \\
Lemuridae & Eulemur albifrons \\
Lemuridae & Eulemur cinereiceps \\
Lemuridae & Eulemur collaris \\
Lemuridae & Eulemur coronatus \\
Lemuridae & Eulemur flavifrons \\
Lemuridae & Eulemur fulvus \\
Lemuridae & Eulemur macaco \\
Lemuridae & Eulemur mongoz \\
Lemuridae & Eulemur rubriventer \\
Lemuridae & Eulemur rufifrons \\
Lemuridae & Eulemur rufus \\
Lemuridae & Eulemur sanfordi \\
Lemuridae & Hapalemur aloatrensis \\
Lemuridae & Hapalemur aureus \\
Lemuridae & Hapalemur griseus \\
Lemuridae & Hapalemur meridionalis \\
Lemuridae & Hapalemur occidentalis \\
Lemuridae & Lemur catta \\
Lemuridae & Prolemur simus \\
Lemuridae & Varecia rubra \\
Lemuridae & Varecia variegata \\
\hline
\end{tabular}




\begin{tabular}{ll}
\hline Lepilemuridae & Lepilemur mustelinus \\
Lepilemuridae & Lepilemur randrianasoloi \\
Lepilemuridae & Lepilemur ruficaudatus \\
Lepilemuridae & Lepilemur sahamalazensis \\
Lepilemuridae & Lepilemur septentrionalis \\
\hline
\end{tabular}




\section{Appendix 7}

Group size and activity pattern of Lemur species included in this study source: All the World's Primates.

\begin{tabular}{|c|c|c|}
\hline Species & $\begin{array}{l}\text { Activity } \\
\text { pattern }\end{array}$ & $\begin{array}{c}\text { Group } \\
\text { size }\end{array}$ \\
\hline Allocebus trichotis & $\mathrm{N}$ & 1,59 \\
\hline Cheirogaleus crossleyi & $\mathrm{N}$ & 2 \\
\hline Cheirogaleus major & $\mathrm{N}$ & 2 \\
\hline Cheirogaleus medius & $\mathrm{N}$ & 2 \\
\hline Cheirogaleus sibreei & $\mathrm{N}$ & 2 \\
\hline Microcebus berthae & $\mathrm{N}$ & 1 \\
\hline Microcebus griseorufus & $\mathrm{N}$ & 1 \\
\hline Microcebus lehilahytsara & $\mathrm{N}$ & 1 \\
\hline Microcebus murinus & $\mathrm{N}$ & 1 \\
\hline Microcebus myoxinus & $\mathrm{N}$ & 1 \\
\hline Microcebus ravelobensis & $\mathrm{N}$ & 1 \\
\hline Microcebus rufus & $\mathrm{N}$ & 1 \\
\hline Microcebus tavaratra & $\mathrm{N}$ & 1 \\
\hline Mirza coquereli & $\mathrm{N}$ & 1 \\
\hline Mirza zaza & $\mathrm{N}$ & 1 \\
\hline Phaner furcifer & $\mathrm{N}$ & 2 \\
\hline Phaner pallescens & $\mathrm{N}$ & 2,14 \\
\hline Daubentonia madagascariensis & $\mathrm{N}$ & 1,3 \\
\hline Avahi cleesei & $\mathrm{N}$ & 2,95 \\
\hline Avahi laniger & $\mathrm{N}$ & 2 \\
\hline Avahi meridionalis & $\mathrm{N}$ & 2 \\
\hline Avahi occidentalis & $\mathrm{N}$ & 3,5 \\
\hline Avahi unicolor & $\mathrm{N}$ & 2 \\
\hline Indri indri & $\mathrm{D}$ & 3,6 \\
\hline Propithecus candidus & $\mathrm{D}$ & 4,33 \\
\hline
\end{tabular}




\begin{tabular}{|c|c|c|}
\hline Propithecus coquereli & $\mathrm{D}$ & 4,5 \\
\hline Propithecus coronatus & $\mathrm{D}$ & 3,58 \\
\hline Propithecus deckenii & $\mathrm{D}$ & 4,07 \\
\hline Propithecus diadema & $\mathrm{D}$ & 4,6 \\
\hline Propithecus edwardsi & $\mathrm{D}$ & 5,36 \\
\hline Propithecus perrieri & $\mathrm{D}$ & 3,67 \\
\hline Propithecus tattersalli & $\mathrm{D}$ & 4,01 \\
\hline Propithecus verreauxi & $\mathrm{D}$ & 5,54 \\
\hline Eulemur albifrons & $\mathrm{C}$ & 8,05 \\
\hline Eulemur cinereiceps & $\mathrm{C}$ & 6,69 \\
\hline Eulemur collaris & $\mathrm{C}$ & 7,03 \\
\hline Eulemur coronatus & $\mathrm{C}$ & 6,07 \\
\hline Eulemur flavifrons & $\mathrm{C}$ & 7,35 \\
\hline Eulemur fulvus & $\mathrm{C}$ & 8,46 \\
\hline Eulemur macaco & $\mathrm{C}$ & 9,56 \\
\hline Eulemur mongoz & $\mathrm{C}$ & 2,81 \\
\hline Eulemur rubriventer & $\mathrm{C}$ & 2,81 \\
\hline Eulemur rufifrons & $\mathrm{C}$ & 5,43 \\
\hline Eulemur rufus & $\mathrm{C}$ & 6,37 \\
\hline Eulemur sanfordi & $\mathrm{C}$ & 6,88 \\
\hline Hapalemur aloatrensis & $\mathrm{C}$ & 2,68 \\
\hline Hapalemur aureus & $\mathrm{C}$ & 3,14 \\
\hline Hapalemur griseus & $\mathrm{C}$ & 4,28 \\
\hline Hapalemur meridionalis & $\mathrm{C}$ & 5,08 \\
\hline Hapalemur occidentalis & $\mathrm{C}$ & 3,63 \\
\hline Lemur catta & $\mathrm{D}$ & 11,06 \\
\hline Prolemur simus & $\mathrm{C}$ & 9,72 \\
\hline Varecia rubra & $\mathrm{C}$ & 4,8 \\
\hline Varecia variegata & $\mathrm{C}$ & 6,03 \\
\hline Lepilemur ankaranensis & $\mathrm{N}$ & 2 \\
\hline Lepilemur dorsalis & $\mathrm{N}$ & 2 \\
\hline Lepilemur edwardsi & $\mathrm{N}$ & 2 \\
\hline Lepilemur hubbardorum & $\mathrm{N}$ & 2 \\
\hline
\end{tabular}




\begin{tabular}{llll}
\hline Lepilemur leucopus & $\mathrm{N}$ & 2 & \\
Lepilemur microdon & $\mathrm{N}$ & 2 & N: Nocturnal, C: Cathemeral, D: \\
Lepilemur mustelinus & $\mathrm{N}$ & 2 & Diurnal \\
Lepilemur randrianasoloi & $\mathrm{N}$ & 2 & \\
Lepilemur ruficaudatus & $\mathrm{N}$ & 2 & \\
Lepilemur sahamalazensis & $\mathrm{N}$ & 2 & \\
Lepilemur septentrionalis & $\mathrm{N}$ & 2 & \\
\hline
\end{tabular}




\section{Appendix 8}

Number of sympatric species on the family and genus level of all lemur species included in this study

\begin{tabular}{|c|c|c|c|}
\hline Species & Family level & Genus level & Climate PC1 \\
\hline Allocebus trichotis & 7 & 0 & $-1,49418108$ \\
\hline Cheirogaleus crossleyi & 16 & 2 & $-0,38142958$ \\
\hline Cheirogaleus major & 3 & 0 & $-1,49418108$ \\
\hline Cheirogaleus medius & 9 & 1 & 1,31603635 \\
\hline Cheirogaleus sibreei & 2 & 1 & $-1,88861293$ \\
\hline Microcebus berthae & 4 & 1 & 2,05385985 \\
\hline Microcebus griseorufus & 3 & 1 & 3,25353701 \\
\hline Microcebus lehilahytsara & 2 & 0 & $-1,88861293$ \\
\hline Microcebus murinus & 10 & 5 & 1,31603635 \\
\hline Microcebus myoxinus & 5 & 1 & 1,84536148 \\
\hline Microcebus ravelobensis & 3 & 1 & 1,84536148 \\
\hline Microcebus rufus & 7 & 0 & $-0,38142958$ \\
\hline Microcebus tavaratra & 3 & 1 & 1,84536148 \\
\hline Mirza coquereli & 5 & 0 & 1,94961067 \\
\hline Mirza zaza & 2 & 0 & $-0,02162573$ \\
\hline Phaner furcifer & 5 & 0 & $-1,09974922$ \\
\hline Phaner pallescens & 9 & 0 & 1,31603635 \\
\hline Daubentonia madagascariensis & 0 & 0 & $-0,38142958$ \\
\hline Avahi cleesei & 1 & 0 & 1,84536148 \\
\hline Avahi laniger & 5 & 1 & $-1,49418108$ \\
\hline Avahi meridionalis & 1 & 0 & $-1,49418108$ \\
\hline Avahi occidentalis & 2 & 0 & 1,84536148 \\
\hline Avahi unicolor & 0 & 0 & $-1,88861293$ \\
\hline Indri indri & 3 & 0 & $-1,49418108$ \\
\hline Propithecus candidus & 2 & 0 & $-1,88861293$ \\
\hline
\end{tabular}




\begin{tabular}{|c|c|c|c|}
\hline Propithecus coquereli & 1 & 0 & 1,84536148 \\
\hline Propithecus coronatus & 0 & 0 & 1,84536148 \\
\hline Propithecus deckenii & 1 & 0 & $-0,02162573$ \\
\hline Propithecus diadema & 2 & 0 & $-1,49418108$ \\
\hline Propithecus edwardsi & 2 & 0 & $-1,49418108$ \\
\hline Propithecus perrieri & 1 & 0 & 1,84536148 \\
\hline Propithecus tattersalli & 0 & 0 & 1,84536148 \\
\hline Propithecus verreauxi & 1 & 0 & 1,31603635 \\
\hline Eulemur albifrons & 4 & 1 & $-1,49418108$ \\
\hline Eulemur cinereiceps & 6 & 2 & $-1,49418108$ \\
\hline Eulemur collaris & 1 & 0 & $-1,49418108$ \\
\hline Eulemur coronatus & 2 & 1 & $-0,02162573$ \\
\hline Eulemur flavifrons & 1 & 0 & $-1,0679711$ \\
\hline Eulemur fulvus & 6 & 3 & $-0,38142958$ \\
\hline Eulemur macaco & 3 & 1 & $-1,88861293$ \\
\hline Eulemur mongoz & 3 & 2 & 1,84536148 \\
\hline Eulemur rubriventer & 8 & 4 & $-1,49418108$ \\
\hline Eulemur rufifrons & 7 & 2 & 0,08262346 \\
\hline Eulemur rufus & 4 & 1 & 1,31603635 \\
\hline Eulemur sanfordi & 2 & 1 & $-0,02162573$ \\
\hline Hapalemur aloatrensis & 0 & 0 & $-1,88861293$ \\
\hline Hapalemur aureus & 6 & 1 & $-1,88861293$ \\
\hline Hapalemur griseus & 12 & 1 & $-1,49418108$ \\
\hline Hapalemur meridionalis & 1 & 0 & $-1,49418108$ \\
\hline Hapalemur occidentalis & 6 & 0 & $-0,02162573$ \\
\hline Lemur catta & 2 & 0 & 1,31603635 \\
\hline Prolemur simus & 6 & 0 & $-1,88861293$ \\
\hline Varecia rubra & 2 & 0 & $-1,09974922$ \\
\hline Varecia variegata & 8 & 0 & $-1,49418108$ \\
\hline Lepilemur ankaranensis & 0 & 0 & 1,84536148 \\
\hline Lepilemur dorsalis & 0 & 0 & $-1,88861293$ \\
\hline Lepilemur edwardsi & 0 & 0 & 1,84536148 \\
\hline Lepilemur hubbardorum & 0 & 0 & 2,05385985 \\
\hline
\end{tabular}


Appendices

\begin{tabular}{llll}
\hline Lepilemur leucopus & 0 & 0 & 3,25353701 \\
Lepilemur microdon & 0 & 0 & $-1,49418108$ \\
Lepilemur mustelinus & 0 & 0 & $-1,49418108$ \\
Lepilemur randrianasoloi & 0 & 0 & 1,84536148 \\
Lepilemur ruficaudatus & 0 & 0 & 1,31603635 \\
Lepilemur sahamalazensis & 0 & 0 & 1,84536148 \\
Lepilemur septentrionalis & 0 & 0 & $-1,88861293$ \\
\hline
\end{tabular}




\section{Appendix 9}

Boxplot showing the correlation of activity pattern with the first principle component of the climate. The black bars represent medians.

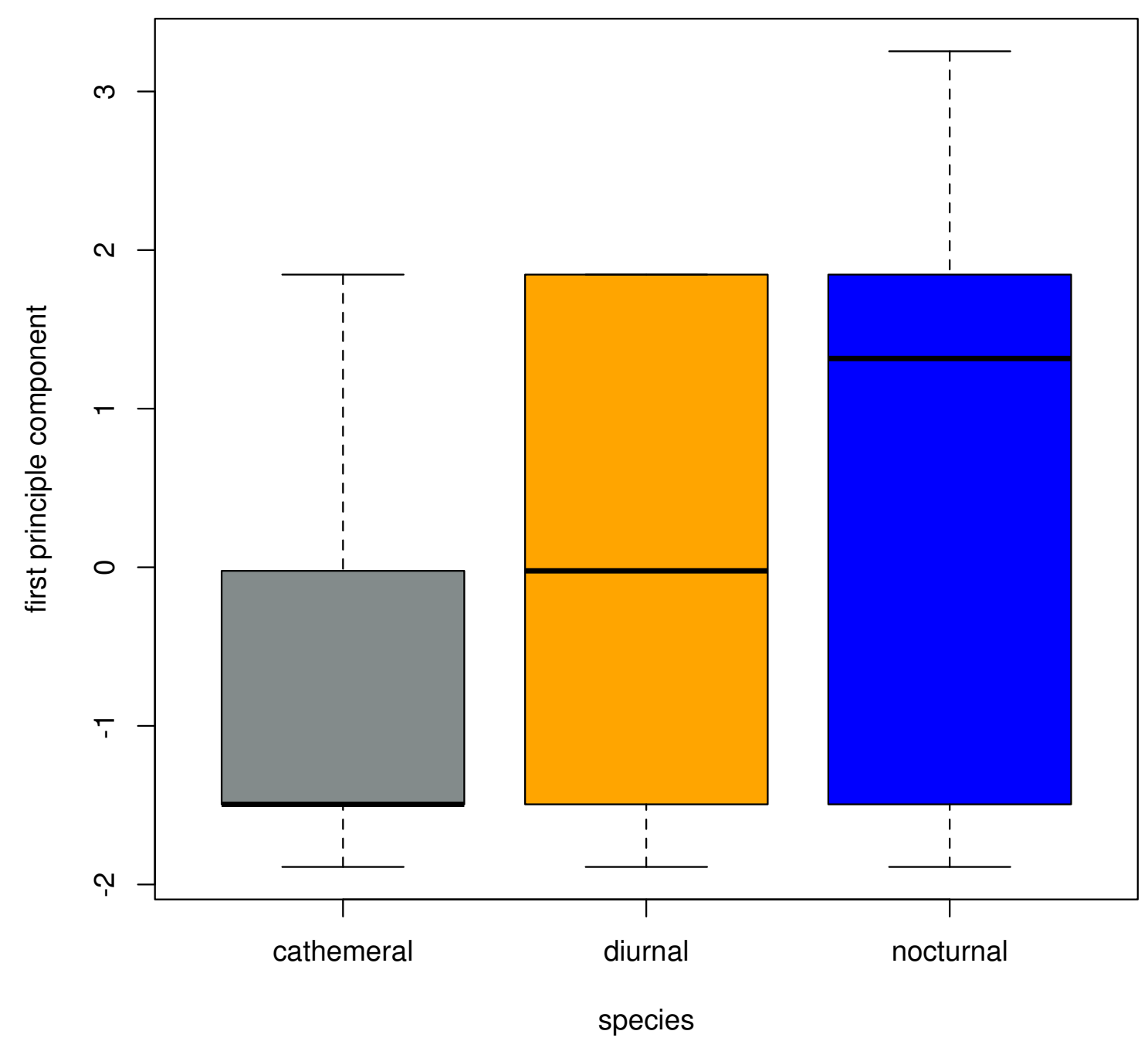




\section{ACKNOWLEDGEMENTS}

Above all, I praise God, the almighty for providing me this opportunity and granting me the capability to proceed successfully. This thesis would not have been in its current form without the assistance and guidance of many people.

I would like to express my special appreciation and thanks to my advisor Professor Dr. Peter Kappeler, who has been a tremendous mentor for me, encouraging my research and allowing me to grow as a research scientist. I would also like to express my sincere gratitude to Dr. Claudia Fichtel for the continuous support of my research, for her contributions of time, offering valuable advice and thoughtful guidance.

I am grateful to Prof. Dr. Eckhard W. Heymann for being member of my committee and evaluating this thesis. I would also like to thank my committee members Prof. Dr. Erwin Bergmeier, PD. Dr. Matthias Waltert and PD. Dr. Oliver Schuelke for agreeing to take part of my examination committee board.

A special thanks the "Equipe Kirindy" as well as the "Equipe Ranomafana" in Madagascar, for the very warming welcome that they gave me everytime I was in the field, good food, moral support and especially jokes that brought me lots of smiles even during my hardest time. My cordial thanks to Victor Rasendrasoa, Jean-Pierre Tolojanahary, Tianasoa Andrianjanahary, Mamy Solohery Razafindrasamba, Rodin Rasoloarison and Léonard Razafimanantsoa who contributed immensely to this project. I would especially like to thank Daniela Fuchs for helping me analyzing part of my videos.

I would also like to thank the Malagasy Ministère de l'Environnement et des Eaux et Forêts, the Département de Biologie, Ecologie et Conservation Animale de 1'Université d'Antananarivo, the Centre National de Formation, d'Etudes et de Recherche en Environnement et Foresterie de Morondava, Madagascar National Parks and the Centre ValBio Ranomafana for allowing and supporting research in Kirindy Forest and Ranomafana National Park. 
I am also truly grateful to the German Primate Center (DPZ) as well as the German Academic Exchanges (DAAD), this project would not have been possible without their financial supports.

I am truly grateful to all my family and friends near and far. All of you have been there to support me with all your love. I also had the chance to meet so many amazing people during my whole $\mathrm{PhD}$ project, with whom I shared wonderful and unforgettable moments. Thank you all very much.

I would like express appreciation to my lovely husband, Matthias Markolf, who is always my support. Misaotra be dia be Malala for your love, your encouragements and patience.

Last but not the least, words cannot express how grateful I am to my parents and my brother for supporting me spiritually throughout writing this thesis and my life in general and for all the sacrifices that they made on my behalf. Ho an'i Dada sy Neny, Mankasitraka feno anareo mivady aho noho ny fanohananareo ahy tamin'ny fianarako ka nahatongavako amin'izao tanjona izao. Tsy ho haiko raha any hamaly ny soa vitanareo tamiko sy ny fihafiana niharetanareo noho ny fianaranay, ary indrindra ny fitondranareo tsy tapaka ambavaka ity zanakareo. Mankasitraka anao ihany koa aho ry zandry malalako amin'ny fanohananao ahy amin'ny fitondrana am-bavaka sy ny fanamboniana ny moraly ataon'ialahy an'i zoky. Andriamanitra manankarem-pahasoavana anie hanonitra zato avo heny ny soa be zay natolotrareo tamim-pitiavana ahy. 


\section{DECLARATION}

I hereby declare that I have written this thesis entitled "The role of acoustic and visual signals in species recognition in true lemurs (Eulemur: Primates)" independently and with no other aids or sources than quoted.

Miadana Hanitriniaina Markolf Rakotonirina

Göttingen, 08. 11. 2016 